EDSON ALVES DE LIMA JUNIOR

Doxorrubicina causa intolerância à glicose mediada pela inibição da sinalização da AMPk no músculo esquelético

Dissertação apresentada ao programa de Pós-Graduação em Biologia Celular e Tecidual do Instituto de Ciências Biomédicas da Universidade de São Paulo, para a obtenção do grau de mestre em Ciências. 
Edson Alves de Lima Junior

\section{Doxorrubicina causa intolerância à glicose mediada pela inibição da sinalização da AMPk no músculo esquelético}

Dissertação apresentada ao programa de Pós-Graduação em Biologia Celular e Tecidual do Instituto de Ciências Biomédicas da Universidade de São Paulo, para a obtenção do grau de mestre em Ciências.

Área de concentração: Biologia Celular e Tecidual

Orientador: Prof. Dr. José Cesar Rosa Neto

Versão corrigida. A versão original eletrônica encontra-se disponível tanto na Biblioteca do ICB quanto na Biblioteca Digital de Teses e Dissertações da USP (BDTD). 
DADOS DE CATALOGAÇĀO NA PUBLICAÇĀO (CIP)

Serviço de Biblioteca e Informação Biomédica do

Instituto de Ciências Biomédicas da Universidade de São Paulo

reprodução não autorizada pelo autor

Lima Junior, Edson Alves de.

Doxorubicina causa intolerância à glicose mediada pela inibição da sinalização do AMPK no músculo esquelético / Edson Alves de Lima Junior. -- São Paulo, 2015.

Orientador: Prof. Dr. José Cesar Rosa Neto.

Dissertação (Mestrado) - Universidade de São Paulo. Instituto de Ciências Biomédicas. Departamento de Biologia Celular e do Desenvolvimento. Área de concentração: Biologia Celular e Tecidual. Linha de pesquisa: Imumetabolismo.

Versão do título para o inglês: Doxorubicin cause glucose intolerance mediated by inhibition of AMPK signaling in skeletal muscle.

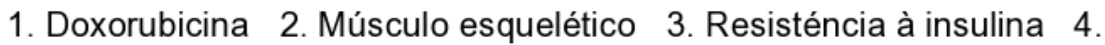
Intolerância à glicose 5 . AMPK 6 . Quimioterapia I. Rosa Neto, Prof. Dr. José Cesar II. Universidade de São Paulo. Instituto de Ciências Biomédicas. Programa de Pós-Graduação em Biologia Celular e Tecidual III. Título. 
Candidato(a):

Título da Dissertação:

Orientador(a):
Edson Alves de Lima Junior.

Doxorubicina causa intolerância à glicose mediada pela inibição da sinalização do AMPK no músculo esquelético.

A Comissão Julgadora dos trabalhos de Defesa da Dissertação de Mestrado, em sessão pública realizada a .l. considerou
( ) Aprovado(a)
( ) Reprovado(a)

Examinador(a): Assinatura:

Nome:

Instituição:

Examinador(a): Assinatura:

Nome:

Instituição:

Presidente: Assinatura:

Nome:

Instituição: 


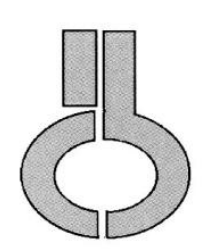

UNIVERSIDADE DE SÃO PAULO INSTITUTO DE CIÊNCIAS BIOMÉDICAS

Cidade Universitária "Armando de Salles Oliveira"

Av. Prof. Lineu Prestes, 2415 - CEP. 05508-000 São Paulo, SP Brasil

Telefone :(55) (011) 3091.7733 - e-mail: cep@icb.usp.br

\section{Certificado}

Certificamos que o protocolo registrado sob $n^{\circ} \mathbf{0 5 4}$ nas fls. 06 do livro 03 para uso de animais em experimentação, sob a responsabilidade do Prof(a) Dr(a)) José Cesar Rosa Neto Coordenador (a) da Linha de pesquisa "Efeito da doxorrubicina sobre a sensibilidade à insulina" do qual participam o(s) aluno(s) Edson Alves de Lima Junior, Camila Oliveira de Souza, Alexandre Abilio de Souza Teixeira, Fábio Santos de Lira, está de acordo com os Princípios Éticos de Experimentação Animal adotado pela Sociedade Brasileira de Ciência de Animais de Laboratório (SBCAL) e foi aprovado pela COMISSÃO DE ÉTICA NO USO DE ANIMAIS (CEUA) em 12.07.2013, com validade de 4 anos.

São Paulo, 31 de julho de 2013.

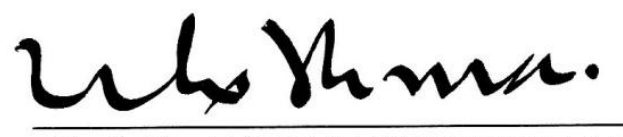

Prof. Dr. Wothan TAVARES DE Lima Coordenador-CEUA - ICB/USP

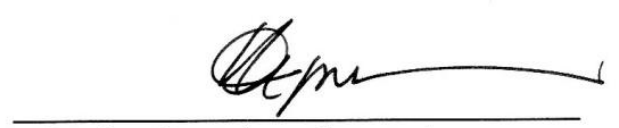

Profa. Dra. ANA PAULA LEPIQUE Secretária- CEUA - ICB/USP 
A essência do conhecimento consiste em aplicá-lo uma vez possuído.

Confúcio 
Aos meus familiares, em especial à minha mãe Sandra, ao meu pai Edson e ao meu irmão Gustavo que sempre incentivaram e apoiaram minha educação.

À minha namorada Angélica, pelo amor e compreensão durante esses anos. 


\section{Agradecimentos}

Ao professor Dr. José Cesar Rosa Neto pelo apoio, sugestões e amizade durante o processo de orientação.

Aos amigos do laboratório de Imunometabolismo, Xandy, Camila, Luana, Helena, Lucas, Adriane e Giovanna.

Aos professores Dr. Fábio Santos de Lira, Dr. William Tadeu Lara Festuccia, Dr ${ }^{\underline{a}}$ Marília Cerqueira Seelander, $\mathrm{Dr}^{\underline{a}}$ Alison Colquhoun, $\mathrm{Dr}^{\underline{a}}$ Fernanda Ortis, Dr. Ronaldo Vagner T Santos, Dr. Emilio Luiz Streck e suas respectivas equipes pela colaboração durante o projeto.

Também à Emília Ribeiro, Alex Shimura, Rodrigo das Neves, Guga e Loreana Silveira.

A todos os professores que contribuíram para minha formação. Aos funcionários do ICB pelo suporte, em especial à secretaria da pós-graduação do departamento de Biologia Celular e do Desenvolvimento e a biblioteca.

A FAPESP e CAPES pelo apoio financeiro. 


\section{RESUMO}

Lima, EAJ. Doxorrubicina causa intolerância à glicose mediada pela inibição da sinalização da AMPk no músculo esquelético. [Dissertação (Mestrado em Biologia Celular e Tecidual)]. São Paulo: Instituto de Ciências Biomédicas, Universidade de São Paulo; 2015.

Atualmente o câncer é considerado a segunda causa de mortes por doenças no mundo. Para o tratamento dessa morbidade, frequentemente são utilizadas estratégias farmacológicas baseadas na intervenção quimioterápica, no qual a doxorubicina é um dos agentes quimioterápicos mais utilizados. Entretanto, sua utilização é limitada pelo desencadeamento de uma série de efeitos colaterais como cardiotoxicidade e sarcopenia. Visto que, o músculo esquelético possui um relevante papel na captação de glicose, o objetivo do presente trabalho foi investigar o efeito da administração da doxorubicina na intolerância à glicose e avaliar o envolvimento desse tecido nesse processo. Para isso foram utilizados ratos Wistar, os quais receberam uma dose única de doxorrubicina (grupo DOX) ou salina (grupo CT) intraperitonealmente na dose de $15 \mathrm{mg} / \mathrm{kg}$ de peso corporal. Após 48 horas, parte desses animais foram submetidos ao teste de tolerância à insulina (iTT). Após 72 horas, o restante dos animais foram eutanasiados e para avaliamos a expressão de proteínas envolvidas na sensibilidade à insulina e captação de glicose. Os ensaios captação de 2-deoxi-[14C]-D-glicose foram realizados em cultura de miócitos L6, no qual foi utilizado o agonista de AMPK (AICAR).O tratamento com doxorubicina causou resistência à insulina, hiperglicemia e hiperinsulinemia. No músculo EDL e em miócitos L6 observamos menor expressão de GLUT-4 e da atividade da AMPk. Em cultura celular a doxorubicina causou diminuição da captação de glicose, a qual foi recuperado com a utilização do AICAR. Sendo assim, concluímos que o tratamento com doxorubicina causou intolerância à glicose in vivo e in vitro. A redução da atividade da proteína AMPk é negativamente modulada com o tratamento quimioterápico, sendo assim, a utilização do agonista dessa proteína demonstrou ser um possível alvo terapêutico capaz de recuperar a intolerância à glicose.

Paravras-chave: Doxorubicina. Músculo esquelético. Resistência à insulina. Intolerância à glicose. AMPk. Quimioterapia. 


\begin{abstract}
Lima, EAJ. Doxorubicin cause glucose intolerance mediated by inhibition of AMPK signaling in skeletal muscle. [Masters thesis (Celular and Tissue Biology)]. São Paulo: Instituto de Ciências Biomédicas, Universidade de São Paulo; 2015.
\end{abstract}

Currently cancer is considered the second cause of death by disease in the world. For the treatment of this disease are frequently used chemotherapeutic strategies based on pharmacological intervention, in which doxorubicin is among the most used chemotherapeutic agents. However, the use of doxorubicin is limited due to a number of side effects, such as cardiotoxicity and sarcopenia. Since, the skeletal muscle has an important role in glucose uptake; the aim of this study was to investigate the effect of doxorubicin administration on intolerance glucose and evaluated the involvement of this tissue in this process. Thereat, Wistar rats received a single dose of doxorubicin (DOX group) or saline (group CT) intraperitoneally in the dose of $15 \mathrm{mg} / \mathrm{kg}$ body weight. After 48 hours, these animals were submitted to the insulin tolerance test (ITT). After 72 hours, the remaining animals were sacrificed and evaluated the expression of proteins involved in insulin sensitivity and glucose uptake. Assays uptake of 2-deoxy [14C] -D-glucose were performed in L6 myocytes culture, which was used the agonist of AMPK (AICAR). Treatment with doxorubicin caused insulin resistance, hyperglycemia, and hyperinsulinemia. In the EDL muscle and L6 myocyte was observed lower expression of GLUT4 and AMPK activity. In cell culture, doxorubicin caused a decrease in glucose uptake, which was recovered with the use of AICAR. In cell culture doxorubicin caused a decrease in glucose uptake, which was recovered using AICAR. Conclusions - Treatment with doxorubicin caused impaired glucose tolerance in vivo and in vitro. The reduction of AMPK protein activity is negatively modulated with treatment, in which the use of the agonist of this protein was shown to be a possible therapeutic target able of recovered glucose intolerance.

Keywords: Doxorubicin. Skeletal muscle. Insulin resistance. Glucose intolerance. AMPK. Chemotherapy. 


\section{Lista de tabelas}

Tabela 1 - Sequências dos primer's do RT-PCR ....... 


\section{Lista de figuras}

Figura 1 - Farmacodinâmica da doxorubicina em células tumorais.

Figura 2 - As vias de sinalização da insulina na regulação do transporte de glicose, na síntese de glicogênio, lipídios e proteínas e no crescimento e diferenciação celular.

Figura 3 - Translocação de GLUT-4 no músculo esquelético estimulada por insulina e pela contração muscular......................................................... 24

Figura 4 - Diferença do peso corporal inicial e final (g/ animal)................... 35

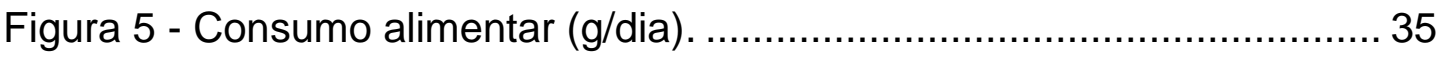

Figura 6 - Peso do tecido adiposo Epididimal (g)...................................... 36

Figura 7 - Peso do tecido adiposo retroperitoneal (g)............................... 36

Figura 8 - Razão peso do músculo EDL (g)/ comprimento da tíbia $(\mathrm{cm})$..... 37

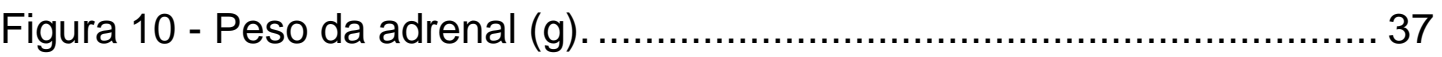

Figura 11 - A. Quantificação da área de secção transversa da fibra muscular do EDL $\left(\mu \mathrm{m}^{2}\right)$; B. Cortes histológicos do músculo EDL corados com H\&E .. 38

Figura 12 - Expressão gênica de Atrogin-1 no músculo EDL. ...................... 39

Figura 13 - Razão da concentração corticosterona/ testosterona................... 39

Figura 14 - Atividade dos complexos mitocondriais 1 e $3 \ldots \ldots \ldots \ldots \ldots \ldots \ldots \ldots \ldots . . . . . . . . . . . .40$

Figura 15 - Marcador de dano hepático AST.......................................... 41

Figura 16 - Concentração de ácido úrico no soro. .................................... 41

Figura 17 - Concentração circulante de ácidos graxos livres no soro........... 42

Figura 18 - Avaliação da glicemia (mg/dl) ............................................ 42

Figura 19 - Avaliação da insulinemia basal $(\mathrm{ng} / \mathrm{ml})$.. ................................ 43

Figura 20 - Modelo de avaliação da homeostase de resistência à insulina

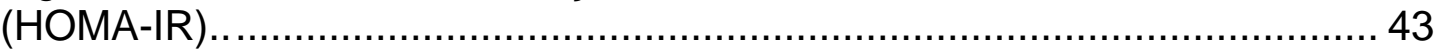

Figura 21 - Teste de tolerância à insulina (iTT). A. Curva da glicemia após injeção intraperitoneal de insulina $(0,5 \mathrm{UI})$; $\mathrm{B}$. Constante de decaimento da

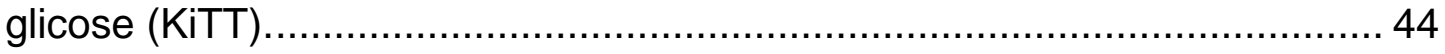

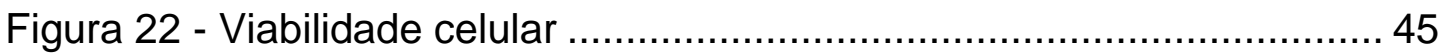

Figura 23 - Doxorubicina diminui a captação de glicose em miócitos L6...... 45

Figura 24 - Expressão de genes envolvidos no metabolismo de glicose do

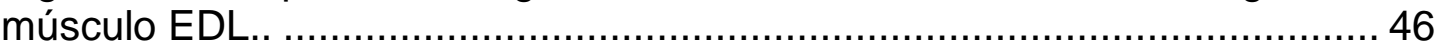

Figura 25 - Expressão de proteínas envolvidas no metabolismo de glicose no

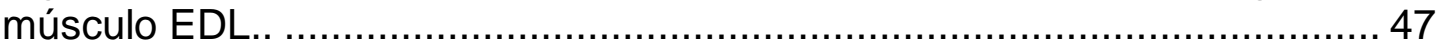

Figura 27 - Concentração de adiponectina no tecido adiposo retroperitoneal. 
Figura 28 - Expressão gênica dos receptores de adiponectina 1 e 2 no

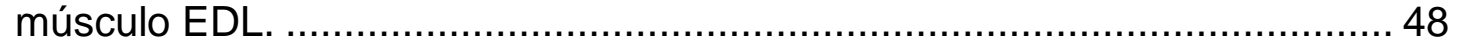

Figura 29 - Conteúdo de triacilglicerol no músculo gastrocnêmio.................. 49

Figura 30 - Expressão gênica de proteínas envolvidas no metabolismo

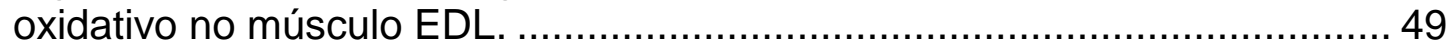

Figura 31 - Atividade da citrato sintase no músculo EDL. .......................... 50

Figura 32 - Atividade da malato desidrogenase no músculo EDL................ 50

Figura 33 - Concentração das citocinas TNF-a, IL-6 e IL-10 no músculo EDL (pg/mg proteína).

Figura 34 - Expressão gênica de proteínas envolvidas na inflamação realizadas no músculo EDL............................................................... 52

Figura 35 - Expressão proteica de GLUT-4 e AMPk em células L6............. 53

Figura 36 - Tratamento crônico com AICAR recupera a captação de 2-deoxi[14C]-D-glicose em cultura de miócitos L6. 


\section{Lista de abreviaturas}

PBS - Tampão salina fosfato

IL-10 - Interleucina 10

IL-6 - Interleucina 6

TNF- $\alpha$ - Fator de necrose tumoral $\alpha$

AMPk - Proteína quinase ativada por AMP

Akt - Proteina quinase $B$

IRS-1 - Substrato do receptor de insulina 1

GSK3- $\beta$ - Glicogênio sintase quinase $3 \beta$

IR - Receptor de insulina

GLUT-4 - Transportador de glicose 4

GLUT-1 -Transportador de glicose 1

ADIPOR1 - Receptor de adiponectina 1

ADIPOR2 - Receptor de adiponectina 2

PGC1- $\alpha$ - Coativador 1 alfa do receptor ativado por proliferador de peroxissoma

IL-1 $\beta$ - Interleucina $1 \beta$

NLRP-1 - NOD-like receptor family 1

NLRP-3 - NOD-like receptor family 3

NOD-1 - Nucleotide-binding oligomerization domain-containing protein 1

NOD-2 - Nucleotide-binding oligomerization domain-containing protein 2

TLR-4 - Toll like receptor 4

RPL-19 - Proteína ribossomal L 19

RNA - Ácido ribonucleico

cDNA - DNA complementar

RT-PCR - Reverse transcription polymerase chain reaction

ELISA - Enzyme-linked immunosorbent assay

TARP - Tecido adiposo retroperitoneal

TAEP - Tecido adiposo epididimal

EDL - Extensor digitorum longus

iTT- teste de tolerância à insulina

AICAR - 5-Aminoimidazole-4-carboxamide ribonucleotide

DMSO - Sulfóxido de dimetilo

AST- Aspartato aminotransferase 
HOMA-IR - Modelo de avaliação da homeostase de resistência à insulina 


\section{SUMÁRIO}

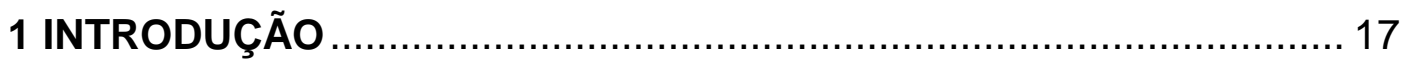

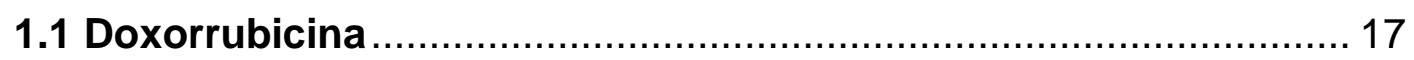

1.2 Doxorrubicina e músculo esquelético............................................. 19

1.3 Músculo esquelético e captação de glicose ….............................. 20

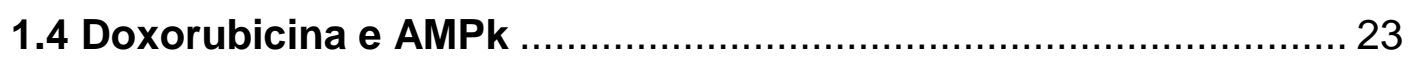

1.5 Doxorubicina e metabolismo da glicose ........................................ 25

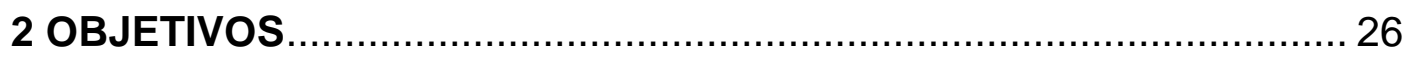

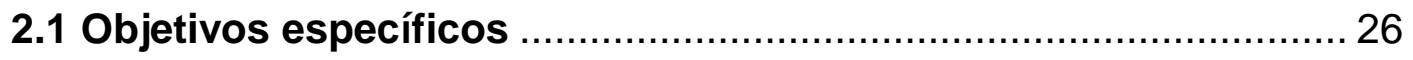

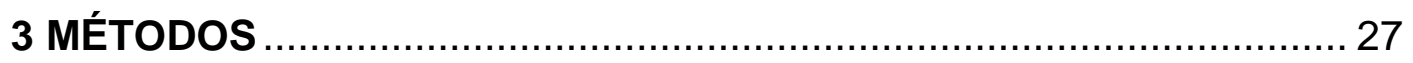

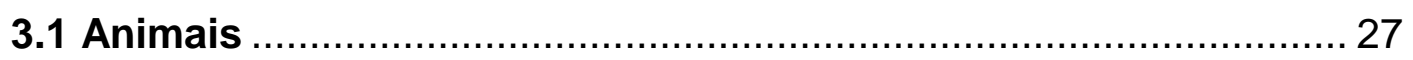

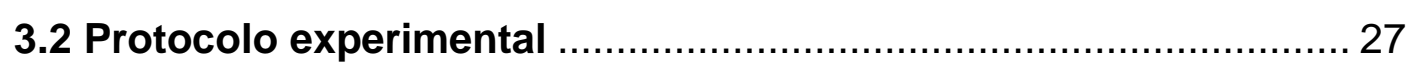

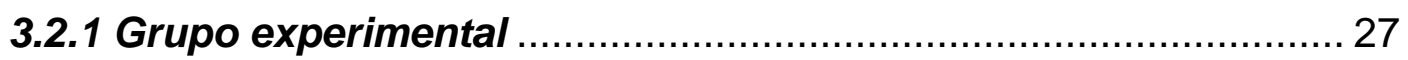

3.2.2 Composição corporal, ingestão alimentar e ganho de peso...... 27

3.2.3 Avaliações da responsividade à insulina................................... 27

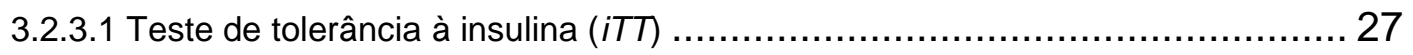

3.2.3.2 Ativação de proteínas envolvidas na via de sinalização à insulina.................... 28

3.2.4 Determinação da expressão gênica ............................................ 29

3.2.5 Avaliação dos parâmetros plasmáticos ...................................... 30

3.2.6 Histologia do músculo esquelético .......................................... 30

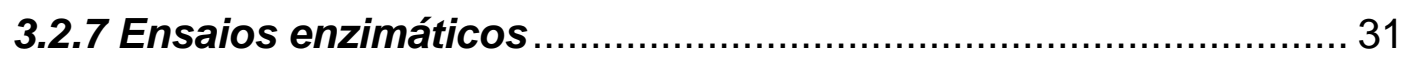

3.2.8 Determinação da concentração de TNF- $\alpha$, IL-10, IL-6 e

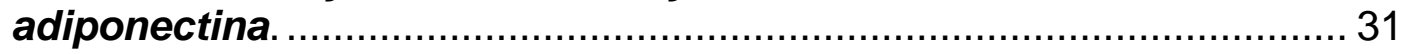

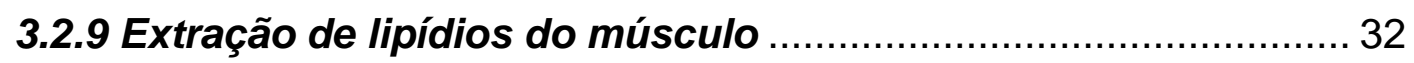

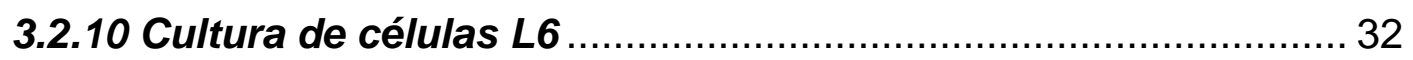

3.2.10.1 Ensaio de viabilidade Celular .................................................... 32

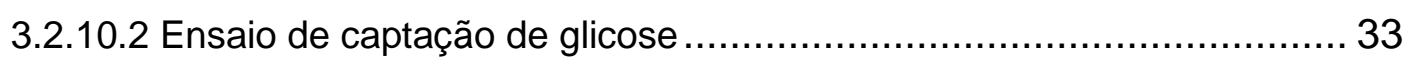

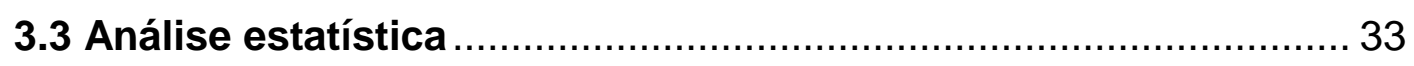

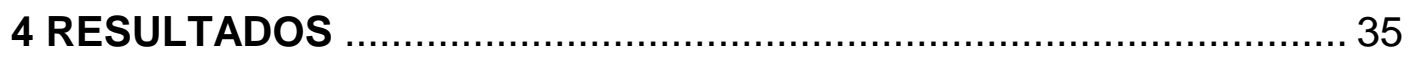

4.1 Caracterização do modelo experimental...................................... 35

4.2 Doxorubicina e resistência à insulina sistêmica ............................ 42

4.3 Doxorubicina e cultura de miócitos L6 ...................................... 44

4.4 Expressão de proteínas envolvidas na captação de glicose no

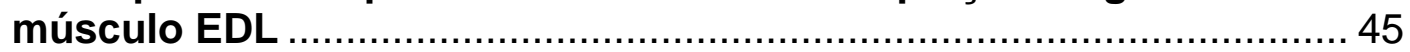

4.5 Concentração de adiponectina e de seus receptores no músculo

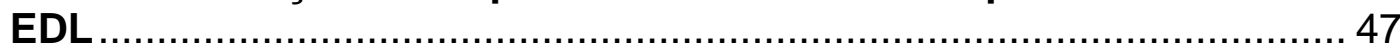

4.6 Doxorubicina e acúmulo de triacilglicerol ..................................... 48

4.7 Doxorubicina e inflamação.................................................... 50 
4.8 Expressão de GLUT-4 e AMPk em cultura de miócitos L6 52

4.9 Efeito do AICAR sobre a captação de 2-deoxi-[14C]-D-glicose .... 53

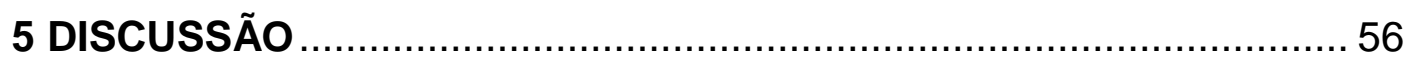

6 CONCLUSÃO

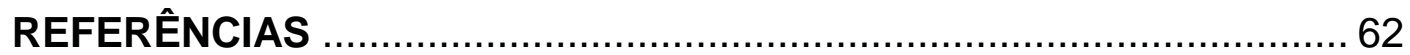




\section{INTRODUÇÃO}

\subsection{Doxorrubicina}

O câncer é atualmente considerado uma das principais causas de mortalidade e morbidade por doenças no mundo (1-2). Somente no Brasil, entre o período de 2014 e 2015, foram estimados cerca de 580 mil novos casos (3). Para o tratamento dessa enfermidade frequentemente são utilizadas estratégias farmacológicas baseadas na intervenção quimioterápica, no qual a doxorubicina é um dos agentes quimioterápicos mais utilizados.

A doxorrubicina é um quimioterápico da família das antraciclinas desenvolvido na década de 70 a partir do metabólito da bactéria Streptomyces peucetius var caesius (4). Atualmente, é um medicamento amplamente utilizado para o tratamento de leucemia, linfomas Hodgkin e non-Hodgkin e câncer de mama (5).

Após administração intravenosa, de 80 a $85 \%$ da droga se encontra associada a proteínas plasmáticas (6). Sua concentração plasmática diminui rapidamente graças à larga distribuição para os tecidos, no qual o efeito de doses repetidas leva ao acúmulo do quimioterápico a nível celular. Sua meia-vida terminal é de aproximadamente 30 horas e reflete a eliminação celular (6).

Seu influxo para dentro da célula ocorre principalmente de maneira passiva, mas há também participação da proteína SLC22A16 (7). Já a exportação celular é dependente de proteínas transportadoras como ABCB1, ABCC1, ABCC2, ABCG2, RALBP1, muitas dos quais estão envolvidas no mecanismo de resistência a esse quimioterápico (8-15).

Esta droga apresenta características lipofílicas e alta capacidade de se intercalar com o DNA. Em geral, a concentração encontrada no núcleo é cerca de cinquenta vezes mais elevada que no citosol. Sofre intensa metabolização no fígado e possui como principal via de excreção o sistema hepatobiliar, mas há participação dos rins no processo de excreção da doxorubicina (16).

Sua atividade tumoricida ocorre por vários mecanismos, acredita-se que a principal é via inibição da enzima topoisomerase II, a qual impede a replicação do DNA e deflagra alguns mecanismos de morte celular (17-18). Ao atingir saturação no 
núcleo, uma molécula de doxorubicina é capaz de se intercalar a cada 5 pares de bases do DNA (19-20).

Além disso, a doxorubicina leva ao aumento da produção de espécies reativas de oxigênio (EROS) por interação com Fe III, perturbação da regulação do oxido nítrico (NO) e via ciclo redox da droga (21-23). O estresse oxidativo gerado leva a danos no DNA e ativação de mecanismos apoptóticos, como a via de interação da proteína p53 e DNA, e a ativação da sinalização intrínseca das caspases (24-25). A figura 1 esquematiza a farmacodinâmica da doxorubicina em células tumorais.

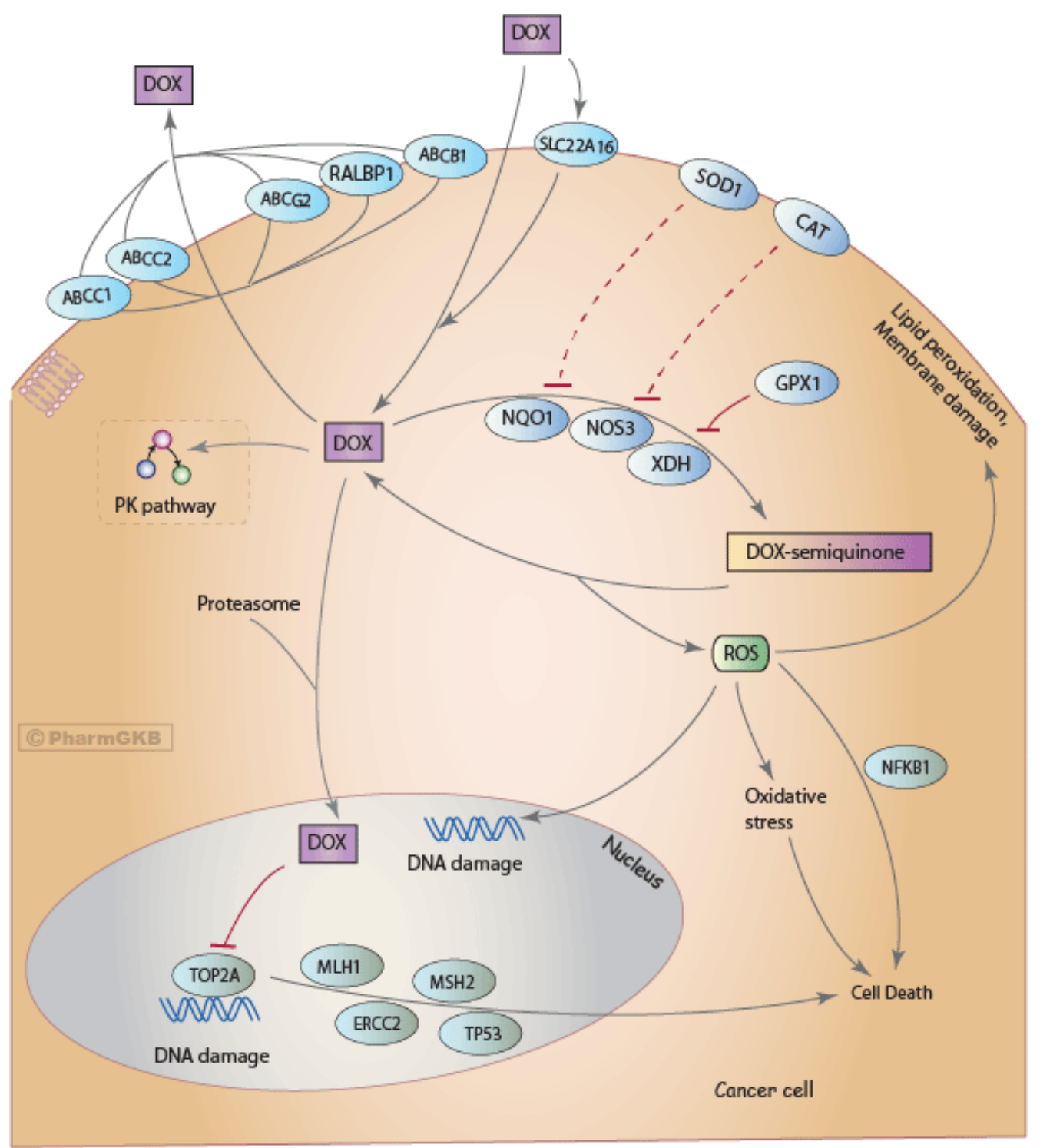


Figura 1 - Farmacodinâmica da doxorubicina em células tumorais.

Doxorubicina (DOX); topoisomerase II (TOP2A); NAD(P)H desidrogenase (NQO1) xantina oxidase (XDH EC) óxido nítrico sintase endotelial (NOS3) espécies reativas de oxigênio (ROS); catalase (CAT) e superóxido dismutase (SOD1) glutationa peroxidase (GPX1). Proteínas exportadoras de doxorubicina na célula (ABCB1, ABCC1, ABCC2, ABCG2, RALBP1). Proteína envolvida na importação da droga (SLC22A16) (26).

Apesar de ser um dos principais quimioterápicos utilizados na prática clínica, sua utilização é limitada devido a uma série de efeitos colaterais indesejados. Nesse contexto o principal alvo de investigação na literatura é a cardiotoxicidade, apesar de também poder causar mielossupressão, nefrotoxicidade, alterações gastrointestinais, miotoxicidade, dentre outras (27-30).

\subsection{Doxorrubicina e músculo esquelético}

A importância do estudo dos efeitos colaterais de quimioterápicos é de grande relevância, já que o câncer atualmente é considerado uma das principais causas de mortes por doenças no mundo (1-2). Nesse sentido, no tratamento com doxorubicina ,assim como se observa no músculo cardíaco, encontra-se uma grande toxicidade no tecido muscular estriado esquelético (30). Nesse último, os principais alvos de investigação referem-se ao estudo dos mecanismos que envolvem fadiga, astenia, proteólise e o estresse oxidativo.

Na pratica clínica, com frequência o tratamento leva à fadiga debilitante e queda do desempenho físico (31-34), fato esse que tem sido associado à piora da qualidade de vida dos pacientes (35). Alterações no metabolismo de cálcio sarcoplasmático causadas pela doxorubicina estão associadas à piora nos parâmetros de força máxima, relaxamento máximo e fadiga (36-37). Esses prejuízos contráteis são observados tanto no fenótipo de fibras musculares lentas quanto de fibras rápidas (38-39).

A sarcopenia faz parte do processo fisiológico de senescência, mas também é presente em diversas morbidades, inclusive no próprio tratamento com quimioterápicos, afetando negativamente a qualidade e expectativa de vida dos indivíduos (40-41).

Alguns dos mecanismos pelo qual a doxorubicina contribui para a atrofia já foram identificados, entre os quais, o papel das proteases intracelulares, mediadas principalmente por calpaínas e caspases, associado à elevada expressão de 
proteínas autofágicas (42). Em 2012, Gilliam e colaboradores (43) observaram aumento da atividade da E3 ubiquitina ligase atrogin-1/muscle atrophy F-box (MAFbx) e da caspase-3, via estresse oxidativo, como um importante fator envolvido na diminuição da massa magra por esse quimioterápico.

Por sua vez, o exercício físico contribui para a atenuação dos efeitos adversos da doxorubicina sobre esse tecido. No músculo esquelético atenua a expressão de proteínas envolvidas na proteólise como FoxO1, MuRF-1, BNIP3 e miostatina (44), aumenta a concentração de enzimas antioxidantes e diminui a ativação das calpaínas e da caspase-3 (42).

\subsection{Músculo esquelético e captação de glicose}

Em humanos, o músculo esquelético representa aproximadamente 50-60\% do peso corporal e possui importante papel na regulação do metabolismo da glicose. A captação de glicose por esse tecido ocorre por difusão facilitada no qual há participação de proteínas de membrana denominadas transportadoras de glicose (GLUT). Catorze isoformas dessa proteína já foram identificadas no tecido de mamíferos (45-46), das quais as mais investigadas no músculo esquelético são o GLUT-1 e GLUT-4.

Nesse tecido, na condição basal, a captação de glicose ocorre por meio da atividade do GLUT-1, em um processo que é independente da sinalização da insulina (47). Essa isoforma de proteína é encontrada constitutivamente no sarcolema, diferente do que ocorre com o GLUT-4, o qual necessita de mecanismos que ativem sua translocação, por meio de vesículas intracelulares, sua ancoragem e fusão no sarcolema (48).

O músculo esquelético é responsável pela captação de aproximadamente 75\% glicose circulante em condições insulino-dependentes (49-50). Esse hormônio é um dos reguladores chave no processo de captação de glicose nesse tecido, no qual alterações em sua cascata de sinalização levam a prejuízos de seus efeitos metabólicos.

A insulina é um hormônio peptídico produzido pelas células $\beta$ pancreáticas responsáveis pela secreção dessa proteína em resposta a fatores hormonais, neurais e nutricionais, em especial, pelo aumento da glicemia (51). Esse hormônio 
age aumentando a captação de glicose no músculo esquelético e tecido adiposo, inibindo a gliconeogênese hepática, estimulando a síntese de glicogênio, de proteínas e lipídios. Possui também importante função sobre o crescimento e diferenciação celular (52).

A sinalização celular desse hormônio se dá através de mecanismos que envolvem fosforilação e interação proteína-proteína. O receptor de insulina é uma proteína transmembrânica, heterotetramérica, constituída por duas subunidades a e duas subunidades $\beta$, que faz parte da família de receptores com atividade tirosina quinase (53). As subunidades a têm por função inibir alostericamente a atividade de tirosina quinase das subunidades $\beta$. Porém quando há ligação da insulina junto à subunidade $\alpha$, ocorre alteração conformacional e transfosforilação da subunidade $\beta$ que leva ao aumento da atividade tirosina quinase por essa última (53). Essa ativação permite a fosforilação de diversas proteínas em tirosina, dentre as quais a família dos substratos do receptor de insulina (IRS). Em particular a fosforilação de IRS-1 e IRS-2 estão envolvidas no mecanismo de captação de glicose (54-56).

A Fosfatidilinositol-3-quinase (PI3K) é um dímero composto pela subunidade catalítica (p110) e pela subunidade regulatória (p85) que interage com o IRS (57). Essa interação ativa o domínio catalítico responsável pela fosforilação dos fosfoinositídeos na posição 3 do anel de inositol, resultando em produção de fosfatidilinositol-3-fosfato, fosfatidilinositol-3,4-difosfato e fosfatidilinositol-3, 4,5trifosfato (58). A estimulação dessa via resulta em ativação da proteína quinase B (Akt) e da proteína quinase C atípica levando a translocação do GLUT-4 (59-60). A AS160 é uma enzima downstream da Akt, que age através de seu domínio Rab GAP (proteína de ativação da GTPase) na translocação do GLUT-4 do sarcoplasma para o sarcolema (61).

Adicionalmente a captação de glicose mediada por insulina pode ocorrer pela ativação do complexo CAP/Cbl (62-63). Essa via ocorre independente da ativação de PI3K. Esse complexo estimula a translocação de GLUT-4 por um processo que envolve a ativação de C3G e troca de GDP por GTP no lipid-raft associado à proteina TC10 (64). Essa última interage com moléculas efetoras (como CIP4, Exo70, e Par6/Par3/PKC $\lambda$ ) que estão relacionadas ao translocamento de GLUT-4 (65). Na figura 2 se encontra a representação das vias de sinalização da insulina. 


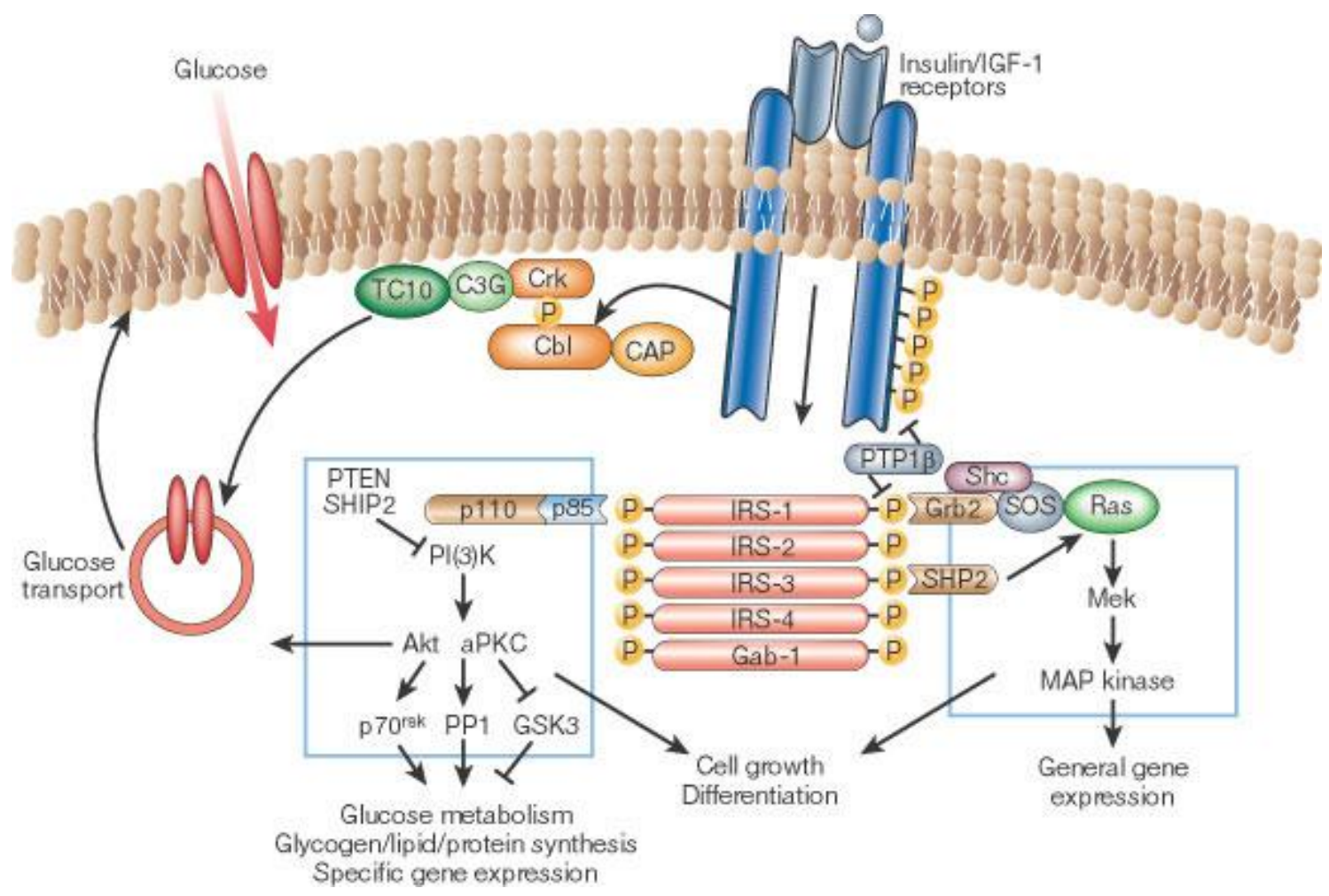

Figura 2 - As vias de sinalização da insulina na regulação do transporte de glicose, na síntese de glicogênio, lipídios e proteínas e no crescimento e diferenciação celular (52).

Distúrbios nessas sinalizações geram um quadro acentuado de resistência à insulina (66). Sedentarismo, hábitos alimentares inadequados, obesidade, inflamação, terapias farmacológicas entre outras condições estão envolvidas na alteração da sinalização de insulina contribuindo para a resistência a esse hormônio.

Como já discutido anteriormente, a proteína transportadora de glicose 4 (GLUT-4) é expressa e seqüestrada em vesículas intracelulares que somente após estímulos migra para a membrana plasmática. Esse efeito é obtido mediante a estimulação da exocitose de vesículas contendo GLUT-4 e diminuição de sua taxa endocítica. Além do estímulo da insulina, a translocação de GLUT-4 pode ocorrer em conseqüência da contração muscular. Sinais intracelulares como a AMPK, $\mathrm{Ca}^{2+} \mathrm{e}$ ativação das proteínas quinases dependentes de cálcio-Calmodulina (CaMKs) e de 
óxido nítrico sintase (NOS) são alterados na contração muscular e levam ao aumento da captação de glicose (67).

O ancoramento e fusão do GLUT-4 são controlados pelas proteínas SNAREs (soluble $\mathrm{N}$-ethylmaleimide-sensitive factor-attachment protein receptors) e proteínas regulatórias de SNARE. As v-SNARES interagem com as t-SNARES complementares sobre a membrana alvo, ancorando a vesícula contendo GLUT-4 em local de destino (68).

\subsection{Doxorubicina e AMPk}

A AMPk (proteína quinase ativada por AMP) é uma proteína heterotrímera, composta por uma subunidade a catalítica e uma subunidade $\beta$ e y regulatória (69), que age como um dos principais sensores do nível energético celular. É estimulada principalmente em função de uma alta razão AMP/ATP e ADP/ATP (70), sendo a contração muscular um importante fator para sua ativação (71-72). Além disso, pode ser ativada pelas proteínas LKB1 (liver kinase B1) e CaMKK $\beta\left(\mathrm{Ca}^{++} /\right.$calmodulindependente protein kinase $\beta$ ), que a ativam via fosforilação no resíduo $\operatorname{Thr}^{172}(70)$. Hormônios e fármacos envolvidos com a melhora da sensibilidade à insulina como a metformina, a adiponectina e as tiazolidinedionas possuem parte de seus efeitos em decorrência da ativação da AMPk.

Em miócitos a estimulação da AMPk eleva a captação de glicose promovendo uma melhora da sensibilidade à insulina $(69,73)$. O aumento da translocação do GLUT-4 para o sarcolema mediado por AMPk ocorre através da fosforilação e inibição da RAB-GTPase TBC1D1 (TBC1 domain Family member 1) e AS160, permitindo o aumento da ligação de 14-3-3 com essa proteína, levando a um aumento da atividade da RAB-GTP, os quais se fundem nas vesículas contendo GLUT-4 e viabilizam seu tráfego para a membrana (74-76), como demonstrado na figura 3. 


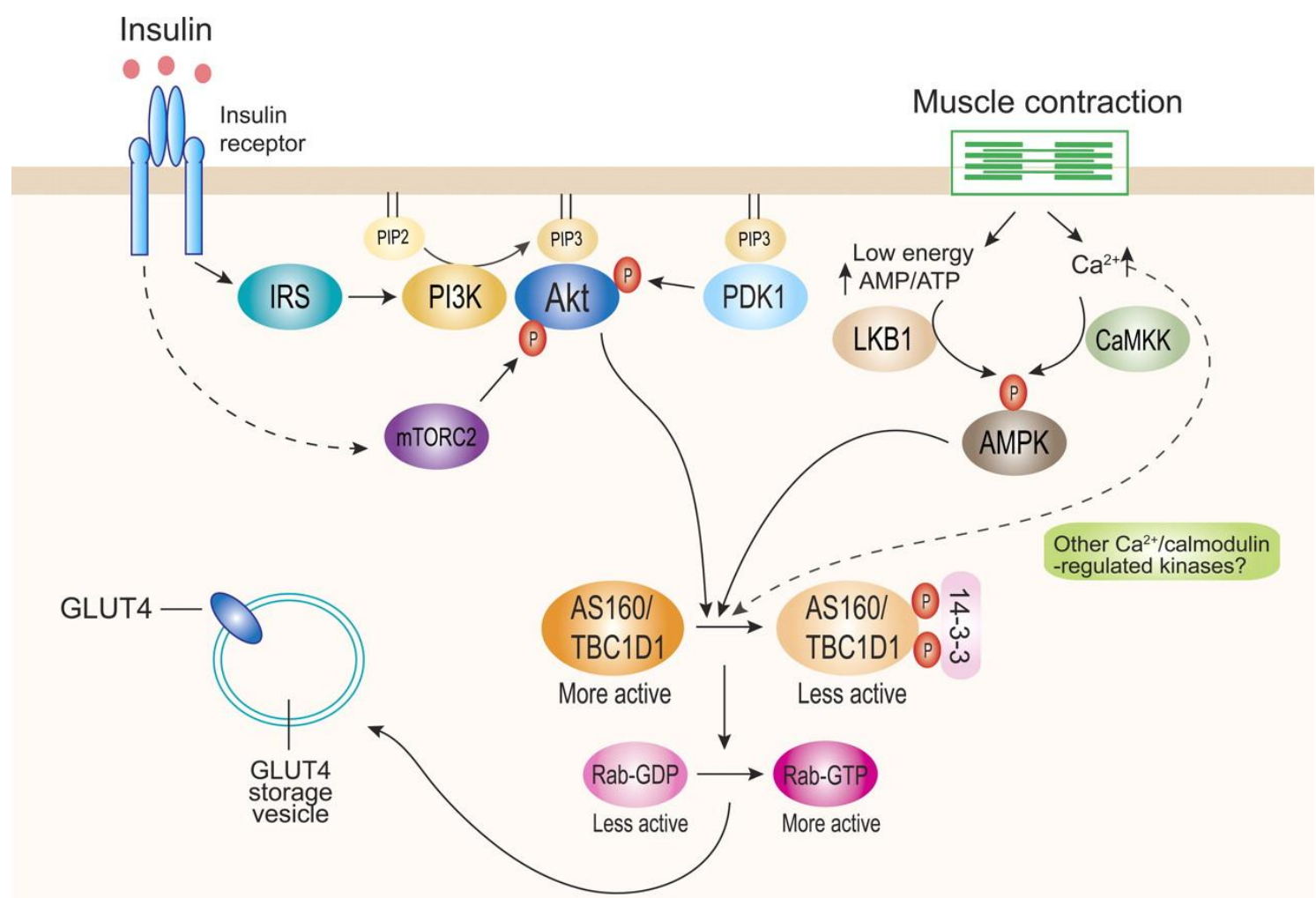

Figura 3 - Translocação de GLUT-4 no músculo esquelético estimulada por insulina e pela contração muscular (73).

Além disso, a AMPk regula a expressão gênica do transportador de glicose 4 através da ativação e translocação de fatores de transcrição para o núcleo que se ligam a região promotora do gene do GLUT-4, como o MEF2A (myocytes enhancer factor) e o GEF (GLUT-4 enhancer factor) (77-78). Ademais, a ativação de AMPk aumenta a capacidade de oxidação de ácidos graxos, uma vez que fosforila e inibe a atividade de acetil-CoA carboxilase com concomitante aumento da expressão de genes relacionados ao metabolismo e biogênese mitocondrial (79-82).

Até agora não se sabe qual o papel desse quimioterápico sobre a atividade da AMPk no músculo esquelético. Nós hipotetizamos que o tratamento com doxorrubicina leva a uma inibição de sua atividade no músculo esquelético, já que, ao menos em cardiomiócitos e fibroblastos embrionários, isso já foi observado (8387), embora em carcinomas a atividade dessa enzima se eleve (88) contribuindo no processo de apoptose, autofagia e quimiossensibilização. 


\subsection{Doxorubicina e metabolismo da glicose}

Distúrbios na homeostase da glicose são comuns em pacientes com câncer, no qual com frequência se observa diminuição da sensibilidade à insulina em tecidos periféricos (89-90). Não somente a enfermidade, mas o tratamento em si, com determinados quimioterápicos pode contribuir para esse efeito, como o 5-fluorouracil $(91-92)$.

Comparada com células não tumorais, células cancerosas apresentam diversas alterações metabólicas como as envolvidas na regulação da glutamina, na síntese de lipídios e em especial na produção de energia, que é altamente dependente da glicólise aeróbia (denominado efeito Warburg) (93). Essa última característica, associada a uma maior resistência periférica à insulina possibilitam maior disponibilidade de substratos energéticos para o tumor. Associado a isso, a alta disponibilidade de glicose e insulina, condições semelhantes a de pacientes com resistência à insulina, apresentam pior eficiência ao tratamento com quimioterápicos, inclusive os indivíduos tratados com a doxorubicina (94-96).

Animais diabéticos apresentam maior área sobre a curva do quimioterápico no plasma, levando a maior acúmulo no músculo cardíaco e menor clearance renal, causando um efeito tóxico mais acentuado. Apesar desses efeitos sobre a atividade e toxicidade do quimioterápico, pouco se conhece sobre os efeitos da doxorubicina como causa do distúrbio da homeostase de glicose. No músculo esquelético, por prejudicar a sinalização da insulina uma série de terapias farmacológicas geram diminuição da sensibilidade à insulina (97-99). Entretanto pouco se conhece sobre os efeitos da doxorubicina sobre a sensibilidade à insulina e seu efeito sobre o metabolismo de glicose no músculo esquelético. 


\section{OBJETIVOS}

O objetivo geral desse projeto foi investigar se o tratamento com doxorubicina leva ao desenvolvimento de resistência à insulina e intolerância à glicose no músculo esquelético e o possível mecanismo celular envolvido.

\subsection{Objetivos específicos}

1- Verificar a resposta sistêmica da administração de doxorrubicina sobre a sensibilidade à insulina.

2- Investigar se ocorrem alterações moleculares na via de sinalização da insulina e na captação de glicose com o tratamento com doxorubicina no músculo esquelético.

3- Avaliar se ocorre a modulação da enzima AMPk com o tratamento.

4- Determinar se a ativação da AMPk em cultura de miócitos L6 leva a restauração da captação de glicose após o tratamento com a doxorrubicina. 


\section{MÉTODOS}

\subsection{Animais}

Foram utilizados ratos Wistar com idade aproximada de 14 semanas. Os animais foram mantidos em sala com ciclo claro-escuro de 12-12 h e temperatura de $23 \pm 2{ }^{\circ} \mathrm{C}$, com dieta normal (ração Nuvital da Nuvilab, Colombo, PR) e água ad libitum durante o tratamento. Todos os procedimentos desse estudo seguiram os princípios éticos de experimentação animal e foram aprovados pelo Comitê de Ética em Experimentação Animal da Universidade de São Paulo (n0.054, fls.06,I.3).

\subsection{Protocolo experimental}

\subsubsection{Grupo experimental}

Os animais foram dividos em dois grupos. O grupo experimental recebeu uma dose única (15 mg/kg de peso) de cloridrato de doxorrubicina (Eurofarma, São Paulo, SP, Brasil. Lot 350552 A ) que foi injetada intraperitonealmente (grupo DOX). O grupo controle $(\mathrm{CT})$ recebeu o mesmo volume na forma de salina $(0,09 \%)$. Após 72 horas os animais foram eutanasiados por decapitação.

\subsubsection{Composição corporal, ingestão alimentar e ganho de peso}

O peso e a ingestão alimentar foram acompanhados ao longo do tratamento. Ao final, os seguintes parâmetros foram mensurados: peso seco e úmido do músculo EDL (extensor digitorum longus), e peso dos coxins adiposos retroperitonial e epididimal.

\subsubsection{Avaliações da responsividade à insulina}

\subsubsection{Teste de tolerância à insulina (iTT)}

Após 48 horas do início do tratamento, em restrição alimentar de 6 horas, parte dos animais realizou o teste de tolerância à insulina, conforme descrito 
previamente por Bonora e colaboradores (100). A glicemia capilar caudal foi então mensurada e monitorada a cada 5 min através do glicosímetro (Accu-Chek Active, Roche) após injeção intraperitoneal de insulina (0,5 UI/kg de peso corpóreo), durante 30 min. A taxa de decaimento de glicose após a administração de insulina foi calculada segundo Bonora e colaboradores (100).

\subsubsection{Ativação de proteínas envolvidas na via de sinalização à insulina}

A ativação de proteínas envolvidas na sinalização à insulina foi avaliada por western blotting. $\mathrm{O}$ músculo EDL foi rapidamente isolado e homogeneizado em tampão de extração com inibidores de protease e fosfatase. As amostras foram então centrifugadas a $14.000 \mathrm{~g}$, a $4^{\circ} \mathrm{C}$, por 30 min e os sobrenadantes submetidos à quantificação protéica pelo método de Bradford (101), usando curva de albumina como padrão.

A análise por western blotting foi realizada segundo Towbin e colaboradores (102). Alíquotas de cada amostra, com a mesma concentração de proteínas totais $(75 \mu \mathrm{g})$ foram tratadas de acordo com o método descrito por Laemmli (103) e submetidasà eletroforese em SDS-gel de poliacrilamida (SDS-PAGE) (104). Em seguida, as proteínas do gel foram transferidas para uma membrana de nitrocelulose, por $80 \mathrm{~min}$, a $120 \mathrm{~V}$. Estas foram incubadas, após o bloqueio com anticorpos para IR; Akt total e Akt ${ }^{\text {pSer473; }}$ AMPka e AMPka ${ }^{\text {pThr172 }}$ (Cell Signaling Technology® Danvers, MA, USA) ou GLUT-4 ,GAPDH e b-Tubulina (Santa Cruz Biotechnology, Santa Cruz, CA, USA) em solução basal acrescida de $1 \%$ BSA overnight à $4 \stackrel{\circ}{ } \mathrm{C}$. As membranas foram lavadas novamente e submetidas à incubação com o segundo anticorpo anti-lgG conjugado com peroxidase, por 1 hora, em solução basal contendo leite a $3 \%$, à temperatura ambiente. Após nova sessão de lavagens ( $3 \times 10 \mathrm{~min}$ ), as membranas foram incubadas com o substrato para peroxidase (kit ECL) por 1 min e imediatamente expostas a filmes de raio- $X$ por períodos variáveis de tempo, de 1 a $30 \mathrm{~min}$. Os filmes foram revelados de forma convencional. As intensidades das bandas das autorradiografias foram quantificadas por densitometria óptica, pelo programa Scion Image (Frederick, Maryland, EUA).

Miócitos L6, após tratamento crônico com doxorubicina (100 nMol - 48 h) e AICAR (2 mMol agudo - 1 h; crônico - 48 h), foram lisados em tampão contendo 
inibidores de protease e fosfatase, centrifugados a $14000 \times g$ por 10 min a $4{ }^{\circ} \mathrm{C}$. Os sobrenadantes foram avaliados utilizando o kit BCA protein assay (Thermo Scientific, Rockford, IL, USA, Ref. 23225 ) para mensurar a concentração de proteína. O sobrenadante foi submetido ao mesmo protocolo acima para determinação da expressão proteica de GLUT-4, AMPka e AMPk a ${ }^{\text {pThr172. }}$.

\subsubsection{Determinação da expressão gênica}

Os tecidos foram homogeneizados em reagente TRIZOL para extração do RNA total (105). O RNA foi quantificado por leitura em espectrofotômetro a $260 \mathrm{~nm}$ (A260 nm = 1 corresponde a $44 \mu \mathrm{g} / \mathrm{mL}$ ) e o grau de pureza determinado pelo razão 260/280 nm (razão igual a dois indica alto grau de pureza). O cDNA foi sintetizado a partir de $2 \mu \mathrm{g}$ do RNA total extraído utilizando a transcriptase reversa. A expressão gênica foi quantificada por PCR em tempo real (106), utilizando o aparelho ROTOR GENE 3000 da Corbett Research (Mortlake, NSW, Austrália) e SYBER Green como marcador fluorescente. A quantificação da expressão dos genes foi realizada usando o método da $\mathrm{Ct}$ comparativa $(\mathrm{Ct}$ = threshold cycle; número de ciclo no qual o produto do PCR atinge um limiar dedetecção), tendo a expressão da RPL-19 como padrão interno (107). Foram avaliados seguintes genes:substrato do receptor de insulina-1 (IRS-1), proteina quinase B (AKT), glicogênio sintase quinase $3 \beta$ (GSK3- $\beta$ ), GLUT-4 (Slc2a4), proteína quinase ativada por AMP (AMPk), coativador 1 alfa do receptor ativado por proliferador de peroxissoma (PGC1- $\alpha)$, receptor de adiponectina 1 (ADIPOR1), receptor de adiponectina 2 (ADIPOR2), Atrogin 1, Interleucina $1 \beta$ (IL1$\beta$ ), Caspase 1, NLRP-1, NLRP-3, NOD-1, NOD-2 e TLR-4 no músculo EDL dos animais. As sequências de primer's utilizados estão demonstradas na tabela 1.

Tabela 1 - Sequências dos primer's do RT-PCR

\begin{tabular}{cccc} 
Gene & Primer Left & Primer Right & GenBank \\
\hline Irs1 & 5' GCG TTG GGT GGA GAG AGT 3' & 5' CTC AGT TCC ACA TTC CAA GAG A 3' & NM_012969.1 \\
Akt1 & 5' ATC ATT GCA AAG GAT GAA GTC G 3’ & 5' CAT GGG TCT GGA AGG CAT ACT 3' & NM_033230.2 \\
Gsk3b & 5' CCA CCA TCC TTA TCC CTC CT 3' & 5’ TTA GTA TCT GAG GCT GCT GTG G 3' & NM_032080.1 \\
Slc2a4 & 5' TCA GGC ATC AAT GCT GTT TTC 3' & 5' CGA GAC CAA CGT GAA GAC G 3' & NM_012751.1 \\
AMPka2 & 5' TTG AAT GGA AGG TAG TGA ATG C 3' & 5' GAT AGC TCC GAT TGT CAA CCA 3' & NM_023991.1
\end{tabular}




\begin{tabular}{|c|c|c|c|}
\hline Fbxo32 & 5'GATGTTGCAGCCAAGAAGAG 3' & 5'TCCATGGCGCTCCTTAGT 3' & 521.1 \\
\hline Cpt1a & 5'GAGCAATAGGTCCCCACTCA 3' & 5'ATCTGTTTGAGGGCTTCGTG 3' & NM_031559.2 \\
\hline Acaca & 5'GTAGTTGGCAGAGCCAGGTT 3' & 5'ATCCAGGTTTGCAGGATCAG 3' & NM_022193.1 \\
\hline Ppargc1a & 5'GAGTCACCAAATGACCCCAAG & 5'GGCTTTATGAGGAGGAGTCGT 3' & NM_031347.1 \\
\hline Adipor1 & 5'CCAGATGGGCTGGTTCTT & 5'TGAGACTGGAACCATATGTCAA 3' & NM_207587.1 \\
\hline Adipor2 & 5'GGCCTCCTATGCCTTCTTTC & 5'CACAACCTAGGAGATGTGTCCA & NM_001037979.1 \\
\hline $111 \mathrm{~b}$ & 5' GCA GCT TTC GAC AGT GAG G 3' & $5^{\prime}$ TCA AGG GCT TGG AAG CAA 3' & NM_031512.2 \\
\hline Casp1 & 5' AGC TTC AGT CAG GTC CAT CA 3' & 5' CGC CAC CTT CTT TGT TCA G 3' & NM_012762.2 \\
\hline Nlrp1a & $5^{\prime}$ GCT TCA GCC CCC AAA GAT 3' & $5^{\prime}$ TTG TCC AAG AGA GGG TCC AC $3^{\prime}$ & NM_001145755.2 \\
\hline Nlrp3 & 5' GCT GAA CTT GAG CAA CAA CG 3' & 5' CAC CCA ACT GTA GGC TCT GC 3' & NM_001191642.1 \\
\hline Nod1 & $5^{\prime}$ TGC ATT CAA TGG CAT CTC C $3^{\prime}$ & 5' TGG TCA GCC AGA TTA TTG TCA 3' & NM_001109236.1 \\
\hline Nod2 & 5' CAT CCC AGA GGG CAA GAA GA 3' & 5' GCC TCG TAA GGC AGA GAC AGT 3' & NM_001106172.1 \\
\hline Trr4 & $5^{\prime}$ TCT AAA TGC CAA CTG GAA CAG A $3^{\prime}$ & $5^{\prime}$ ATG GGA TGG ATC CAG AAA CA 3’ & NM_019178.1 \\
\hline Rpl19 & 5 'GAG GGA CGC TTC ATT TCT TG 3' & $5^{\prime}$ CAT GGA GCA CAT CCA CAA AC $3^{\prime}$ & NM_031103.1 \\
\hline
\end{tabular}

\subsubsection{Avaliação dos parâmetros plasmáticos}

A glicemia, o ácido úrico e a aspartato transaminase (AST) foram avaliadas no soro através do kit Labtest (Lagoa Santa, MG, Brasil, Ref. 133-2/500, 140-1/250, 109-2/100, respectivamente). Já a insulina, adiponectina, testosterona e corticosterona foram quantificadas pela técnica de imunoensaio (enzyme-linked immunosorbent assay). O kit de insulina foi obtido da Millipore Corp. (Bedford, MA, (EZRMI-13K) EUA) e o kit de adiponectina foi obtido da $R$ \& $D$ Systems (Minneapolis, MN, EUA (RRP300)). Os kits de corticosterona e testosterona foram obtidos da Assay Designs, Inc.( Ann Arbor, MI, EUA. Ref. ADI-900-097 e ADI-900065, respectivamente). O ácido graxo livre no soro foi analisado utilizando o NEFAkit-U (Wako Chemical GmbH, Neuss, Alemanha, Ref. 999-34691, 995-34791, 99134891, 993-35191 e 276-76491). Todos esses ensaios colorimétricos foram lidos em espectofotômetro EON (BioTek Instruments, Inc., Winooski, VT, USA) respeitando a densidade ótica ideal estabelecida no manual de fabricação de cada um dos kits.

HOMA-IR (modelo de avaliação homeostático de resistência à insulina) foi utilizado para avaliar a resistência à insulina. $O$ índice foi determinado por meio do cálculo: insulina $(\mathrm{mU} / \mathrm{ml}) \times$ glicose no plasma $\left(\mathrm{mmol} \mathrm{L}^{-1}\right) / 22.5$.

\subsubsection{Histologia do músculo esquelético}


O corte histológico do músculo EDL foi realizado em criostato (10 $\mu \mathrm{m}$ de espessura) à $-25^{\circ} \mathrm{C}$ de temperatura. As lâminas foram incubadas com hematoxilina e eosina (HE) para a análise da área da secção transversal da fibra (AST). A análise morfométrica foi realizada através de um microscópio (Nikon Eclipse E600, Fukuoka, Japão) equipado com uma câmera de vídeo digital acoplado a um software para analisar as imagens (Metamorph, Universal Corporation, Downingtown, EUA). As imagens digitalizadas foram analisadas utilizando Image-Pro Plus (Media Cybernetics, Silver Spring, MD) software. Para a análise de área de secção transversal da fibra, cerca de 1.000 fibras musculares foram analisadas em cada grupo. Foram analisados 4-5 campos por animal do músculo EDL nos grupos estudados.

\subsubsection{Ensaios enzimáticos}

O músculo EDL foi homogeneizado em SETH buffer, pH 7.4 (250 mM sacarose, $2 \mathrm{mM}$ EDTA, 10- $\mathrm{mM}$ Trizma base, $50 \mathrm{IU} / \mathrm{ml}$ heparina). A atividade enzimática da citrato sintase, malato desidrogenase e do complexo mitocondrial $1 \mathrm{e}$ 3 foram realizado conforme descrito por Souza e colaboradores (108).

\subsubsection{Determinação da concentração de TNF-a, IL-10, IL-6 e adiponectina}

Os tecidos congelados $(0,1-0,3 \mathrm{~g})$ foram homogeneizados em tampão RIPA $(0,625 \%$ de Nonidet P-40, 0,625\% de desoxicolato de sódio, fosfato de sódio 6,25mM, e $1 \mathrm{mM}$ de ácido tetra-acético de etilenodiamina a $\mathrm{pH} 7,4$ ) contendo 10 $\mu \mathrm{g} / \mathrm{ml}$ do coquetel com inibidor de protease (Roche, Mannheim, Alemanha, Ref. 04693116001). Os homogenatos foram centrifugados a $14000 \mathrm{~g}$ durante $30 \mathrm{~min}$ a $4^{\circ}$ C, o sobrenadante retirado, e a avaliação da concentração de proteína total determinada utilizando o ensaio de Bradford (Bio-Rad, Hercules, Califórnia, USA, Ref. 500-0006). A avaliação quantitativa de TNF- $\alpha$, IL-6, IL-10 e de adiponectina foi realizada por ELISA (DuoSet ELISA, R\&D Systems, Minneapolis, MN, Ref. DY510, DY506, DY522, RRP300, respectivamente). 


\subsubsection{Extração de lipídios do músculo}

Os lipídios foram extraídos do músculo gastrocnêmio pela homogeneização em clorofórmio-metanol (2:1 v/v), seguido da adição de 0,2 de seu volume em água segundo o método de Folch (109). A concentração de triacilglicerol do extrato lipídico foi determinada enzimaticamente (Labtest, Lagoa Santa, MG, Brasil, Ref. 872/100).

\subsubsection{Cultura de células $L 6$}

As células foram mantidas em meio Dulbecco's modificado de Eagle' $\mathrm{s}$ (DMEM, Cell Signaling Technology ${ }^{\circledR}$ Danvers, MA, USA, Ref. D6429) a $37{ }^{\circ} \mathrm{C}$ em atmosfera úmida contendo $5 \%$ de $\mathrm{CO}^{2}$. Foram suplementadas com $10 \%$ de soro fetal bovino e $2 \%$ de solução contendo os antibióticos streptomicina e penicilina. Para diferenciação, as placas com aproximadamente $80 \%$ de confluência de células tiveram a concentração de soro fetal bovino reduzida para $2 \%$ durante sete dias. Durante todo tratamento o meio DMEM foi trocado a cada dois dias. Para o ensaio de captação de glicose, o soro fetal bovino foi removido 6 horas antes do início do mesmo.

\subsubsection{Ensaio de viabilidade Celular}

Para a avaliação da viabilidade celular foi realizado o ensaio de MTT (3-(4,5dimethylthiazol-2-yl)-2,5-diphenyltetrazolium bromide). Foram plaquadas $2 \times 10^{4}$ células por poço em placas de 96 poços, as quais foram diferenciadas após 24 horas. As células foram tratadas com diferentes concentrações de doxorubicina $(0 \mathrm{a}$ $1 \mathrm{mMol}$ ) durante 48 horas, e, após esse período, foi realizado o ensaio de viabilidade celular. O meio de células foi substituído por meio DMEM novo (200 ul/poço, contendo $0,125 \mathrm{mg} / \mathrm{ml}$ de MTT (Cell Signaling Technology ${ }^{\circledR}$, Saint Louis, Missoure, USA, Ref. M2003) e cultivadas durante $3 \mathrm{~h}$ na incubadora de células. O sobrenadante foi removido (até atingir um volume final de $25 \mu \mathrm{l}$ ) e $100 \mu \mathrm{l}$ de isopropanol/ $/ \mathrm{HCl}(11 \mathrm{M})$ foi adicionado por poço. A absorbância de $595 \mathrm{~nm}$ foi utilizada para leitura das placas. Três poços por placas foram utilizadas como 
branco. Todos os ensaios foram repetidos duas vezes em triplicata. O efeito da doxorrubicina sobre a viabilidade celular foi relativizado pelo grupo DMSO (Cell Signaling Technology®, Saint Louis, Missoure, USA, Ref. D2650).

\subsubsection{Ensaio de captação de glicose}

A captação da glicose nas células L6 foi avaliada utilizando o 2-desoxi- [C14] D-glucose. Foram plaqueadas 5,9 × $10^{4}$ células por poço em placas com 24 poços, as quais foram diferenciadas após 24 horas, com uma confluência aproximada de aproximadamente $80 \%$. Essas células foram tratadas com $100 \mathrm{nMol}$ de doxorrubicina ou DMSO durante 48 horas.Para avaliar o efeito crônico do AICAR (agonista de AMPk), esta droga foi adicionada em conjunto ao início do tratamento com doxorubicina (2 mMol/ $48 \mathrm{~h}$ ).

Para o ensaio de captação de glicose, as células permaneceram em jejum (meio isento de soro) durante 6 horas. Após, as células serem lavadas em PBS (tampão salina fosfato), e adicionadas em meio isento de glicose (HEPES, $140 \mathrm{mMol}$ de $\mathrm{NaCl}, 20 \mathrm{mMol}$ de Na-Hepes pH 7,4, KCl $5 \mathrm{mMol}, 2,5 \mathrm{mMol} \mathrm{MgSO} 4, \mathrm{CaCl} 21$ $\mathrm{mMol}$ ) durante $30 \mathrm{~min}$, com ou sem insulina(100 nMol),com ou sem AICAR (2 mMol / 1 hora para tratamento agudo e 48 horas para o tratamento crônico com o agonista da AMPk). Após, solução contendo Hepes 2-desoxi- [C14] -D-glicose (1mCiu/ml) foi adicionado durante $30 \mathrm{~min}$. A reação foi parada através da lavagem com $\mathrm{NaCL}$ gelado $(0,9 \%)$. Posteriormente, as células foram digeridas (50 mMol de $\mathrm{NaOH}$ ), e parte da amostra foi utilizada para a quantificação de proteína total através do método de Bradford e parte transferidas para frascos contendo líquido de cintilação. A radioatividade foi mensurada por contador beta (Packard Perkin Elmer, Tri Carb 2100TR Liquid Scillination, Waltham, Massachusetts, EUA).

\subsection{Análise estatística}

A análise estatística foi realizada utilizando o software GraphPad Prism versão 5.0 para Windows (GraphPad Software, SanDiego, CA, USA). Os dados foram expressos como média e desvio padrão. Foi utilizado o Teste-t de Student para comparação estatística entre dois grupos. Para comparação dos ensaios 
realizados em cultura foi utilizado o teste ANOVA de uma via ou o teste ANOVA de duas vias, com o pós-teste de Bonferroni. O nível de significância adotado foi $p<0,05$. 


\section{RESULTADOS}

\subsection{Caracterização do modelo experimental}

O tratamento com doxorubicina causou importante diminuição do peso corporal em relação peso inicial do tratamento (figura 4 - CT 12,78 \pm 3.79 (g) vs. DOX $-30.05 \pm 4.57$ (g); p = $<0,0001$ ) e queda no consumo alimentar (figura 5 - CT $27,10 \pm 4,60$ (g) vs. DOX 4,58 $\pm 1,41$ $(g) ; p=<0.0001)$.

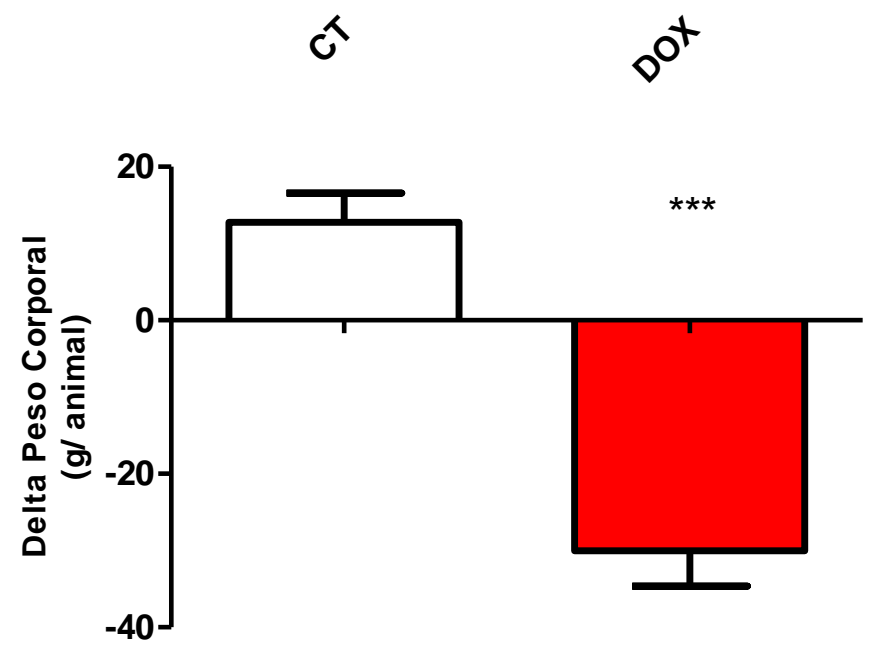

Figura 4 - Caracterização do modelo experimental. Diferença do peso corporal inicial e final ( $\mathrm{g} /$ animal). CT-grupo controle, DOX-grupo tratado com doxorubicina ( $15 \mathrm{mg} / \mathrm{kg}) . n=9-8 .{ }^{* *} \mathrm{p}<0,001$.

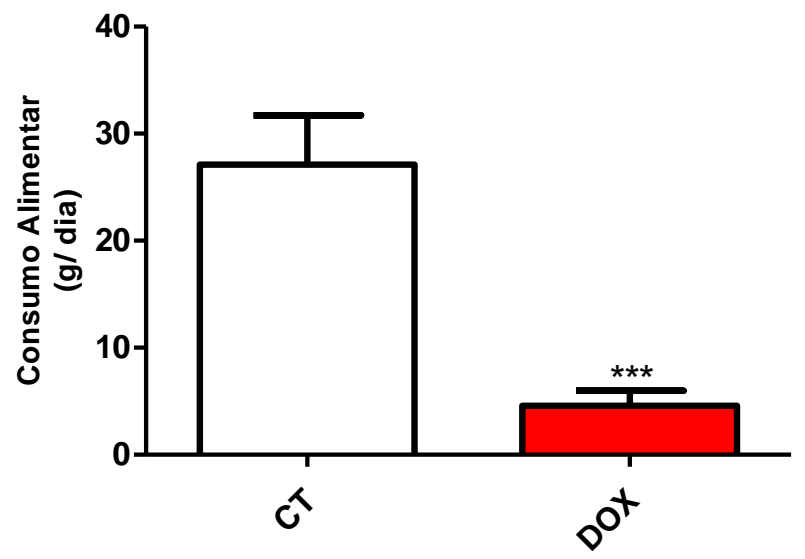

Figura 5 - Caracterização do modelo experimental. Consumo alimentar (g/dia). CT-grupo controle, DOX- grupo tratado com doxorubicina $(15 \mathrm{mg} / \mathrm{kg}) . \mathrm{n}=9-8 .{ }^{* * *} \mathrm{p}<0,001$. 
72 horas após a aplicação do quimioterápico, observamos uma diminuição do peso do coxim adiposo epididimal no grupo DOX (figura 6 - CT 5,92 $\pm 0,62$ (g) vs. DOX 4,00 $\pm 0,65(\mathrm{~g}) ; \mathrm{p}=0,0029$ ) e do músculo EDL (figura 8 - CT 3,91 $\pm 0,42(\mathrm{~g} / \mathrm{cm}$ ) vs. DOX $3,41 \pm 0,40$ $(\mathrm{g} / \mathrm{cm}) ; \mathrm{p}=0,0177)$, sem diferença estatística para 0 peso do coxim adiposo retroperitoneal (figura 7 - CT 6,23 $\pm 1,87$ (g) vs. DOX 4,17 $\pm 1,19$ (g); $p=0,0991$ ), fígado (figura 9 - CT 12,67 $\pm 0,73$ (g) vs. DOX 12,13 $\pm 0,77$ (g); $p=0,3321$ ) e adrenal (figura 10 - CT 28,00 \pm 4,24 (g) vs. DOX $33,00 \pm 12,59(\mathrm{mg}) ; \mathrm{p}=0,4767$ ).

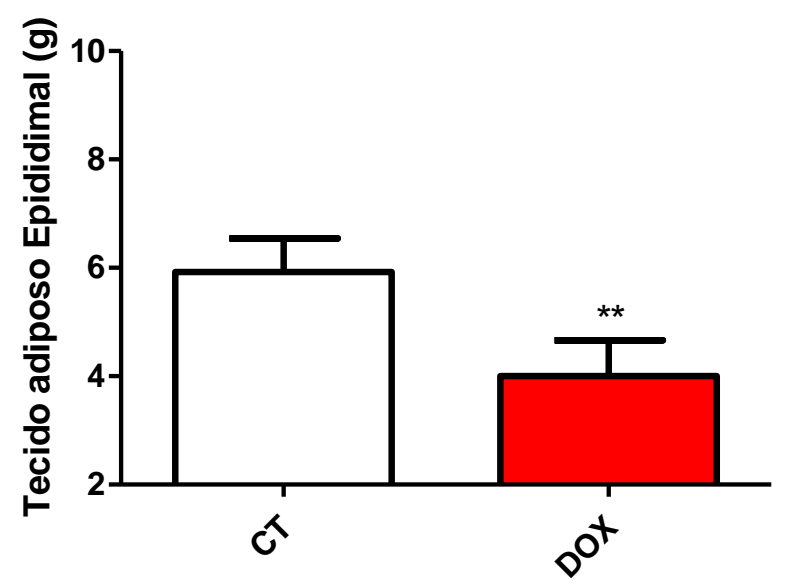

Figura 6 - Caracterização do modelo experimental. Peso do tecido adiposo Epididimal (g). CT-grupo controle, DOX- grupo tratado com doxorubicina $(15 \mathrm{mg} / \mathrm{kg}) . \mathrm{n}=4-5 .{ }^{* *} \mathrm{p}<0,01$.

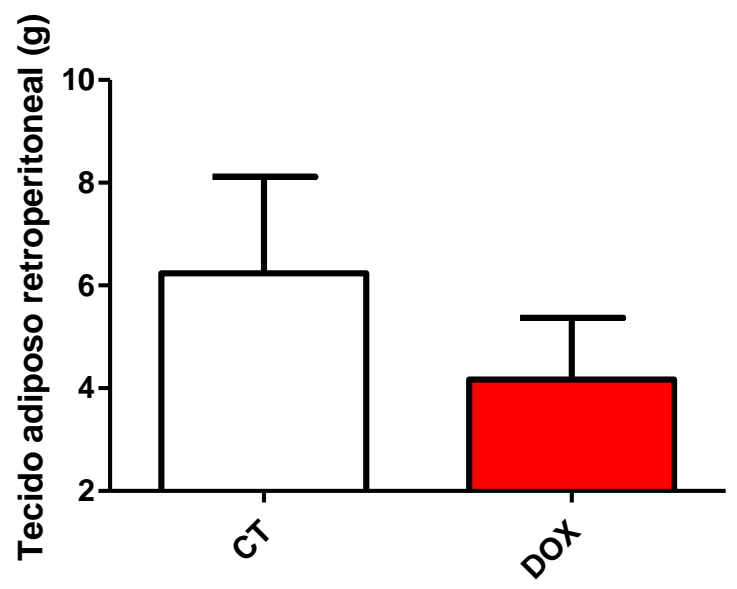

Figura 7 - Caracterização do modelo experimental. Peso do tecido adiposo retroperitoneal (g). CTgrupo controle, DOX- grupo tratado com doxorubicina (15 mg/kg). $n=4-5$. 


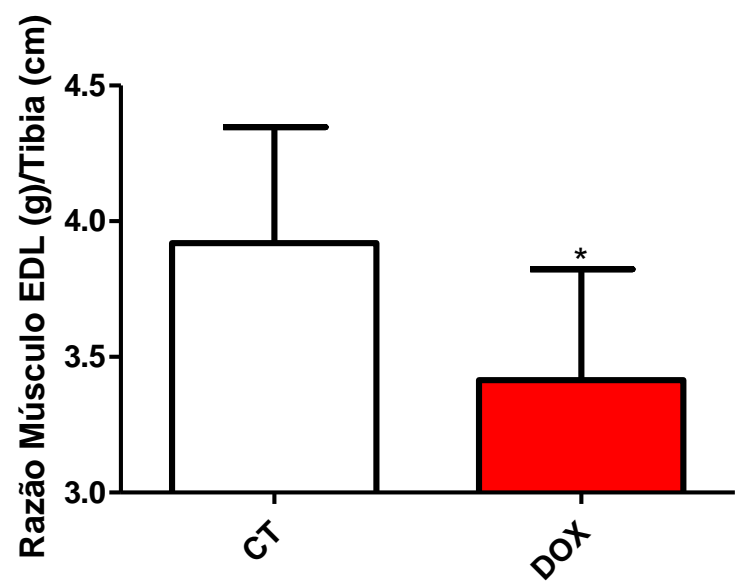

Figura 8 - Caracterização do modelo experimental. Razão peso do músculo EDL (g)/ comprimento da tíbia (cm). CT-grupo controle, DOX- grupo tratado com doxorubicina (15 mg/kg). $n=10-9 .{ }^{*} p<0,05$.

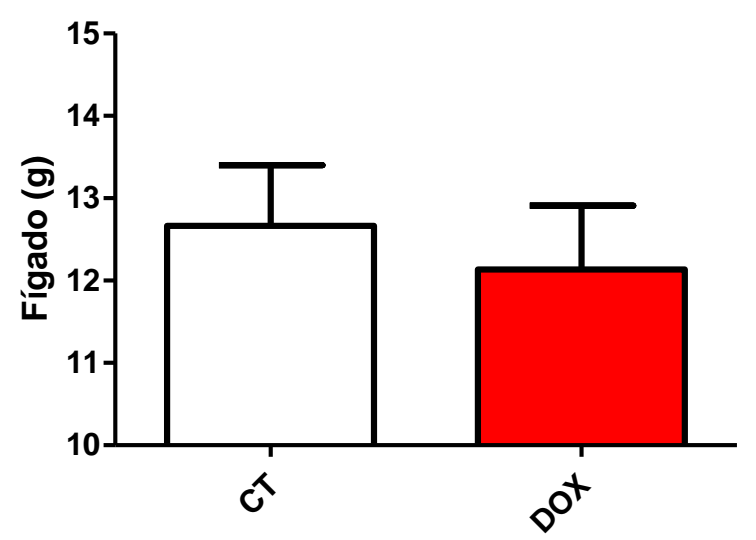

Figura 9 - Caracterização do modelo experimental. Peso fígado (g). CT-grupo controle, DOX- grupo tratado com doxorubicina $(15 \mathrm{mg} / \mathrm{kg}) . \mathrm{n}=4-5$.

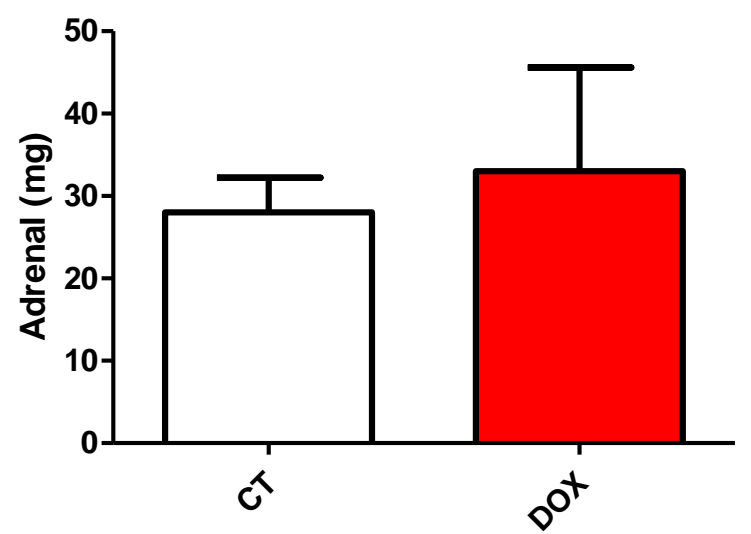

Figura 10 - Caracterização do modelo experimental. Peso da adrenal (g). CT-grupo controle, DOXgrupo tratado com doxorubicina $(15 \mathrm{mg} / \mathrm{kg}) . \mathrm{n}=4-5$. 
Corroborando com a diminuição do peso do músculo EDL, o tratamento com doxorubicina diminuiu a área de secção transversa da fibra muscular (figura 11 - CT $2065 \pm 869,2$ vs. DOX $1508 \pm 669,8 ; p=<0$, 001) e aumentou a expressão gênica de Atrogin1 (figura 12 - CT 1,02 $\pm 0,27$ vs. DOX 7,29 $\pm 3,59$; $p=<0,0055$ ).

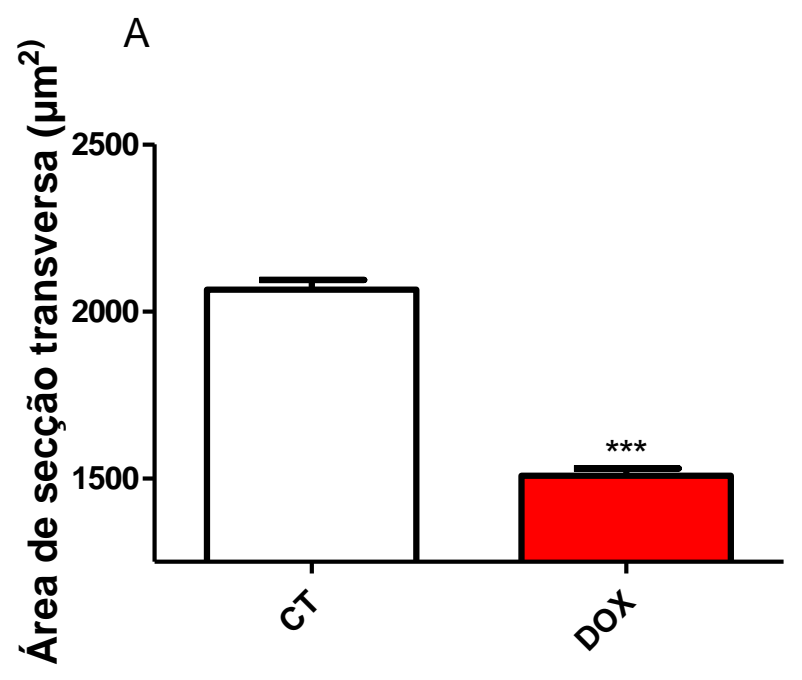

B
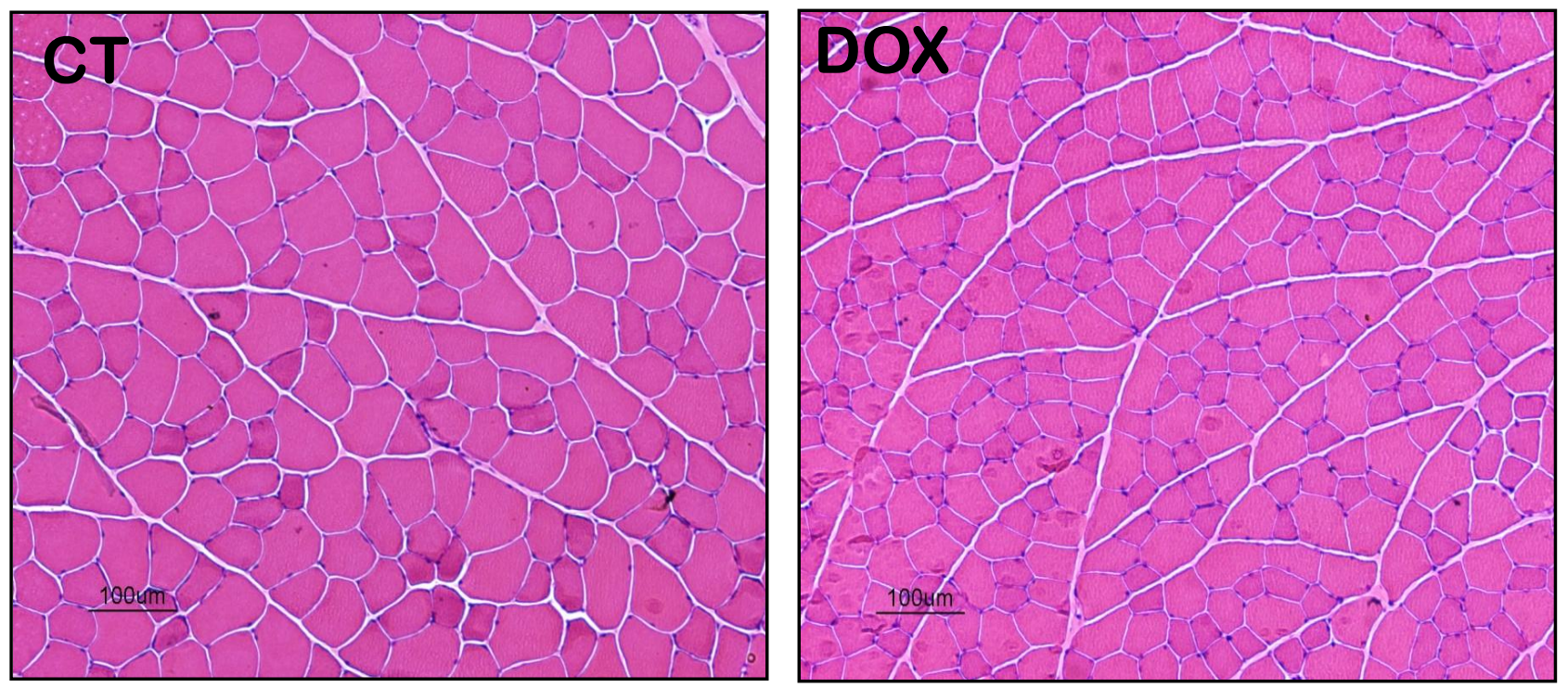

Figura 11 - Caracterização do modelo experimental. A. Quantificação da área de secção transversa da fibra muscular do EDL $\left(\mu \mathrm{m}^{2}\right)$; B. Cortes histológicos do músculo EDL corados com H\&E com aumento 10x. CT-grupo controle, DOX- grupo tratado com doxorubicina (15 mg/kg). $\mathrm{n}=4-5$. ${ }^{* * *} \mathrm{p}<0,001$. 


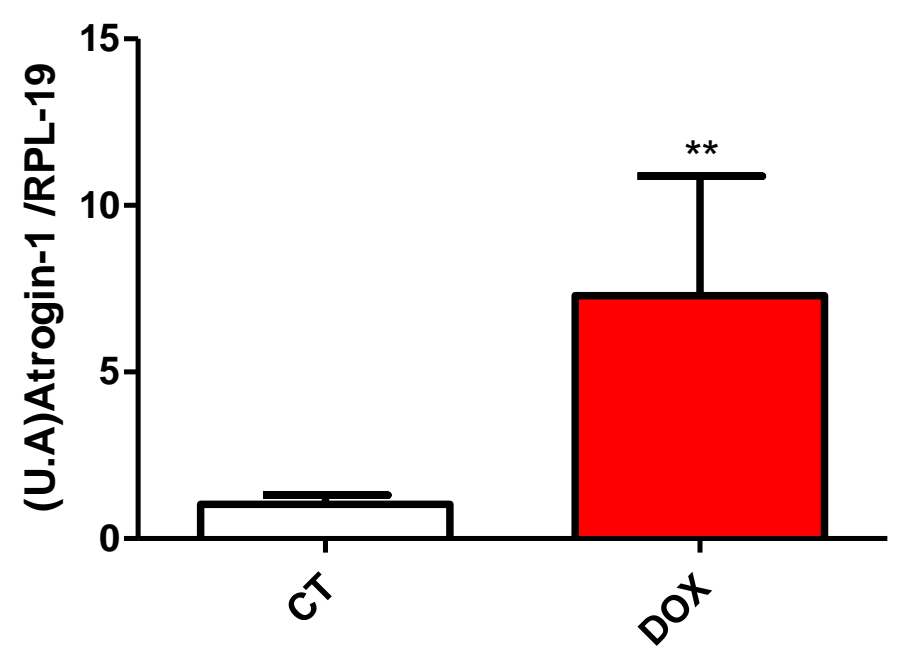

Figura 12 - Caracterização do modelo experimental. Expressão gênica de Atrogin-1 no músculo EDL. $n=5 .{ }^{* *} p<0,005$.

Para confirmar o alto estado catabólico de nosso modelo experimental avaliamos a concentração circulante de testosterona e corticosterona. Essa razão se mostrou significantemente maior no grupo DOX (figura 13 - CT 0,039 $\pm 0,028(\mathrm{ng} / \mathrm{ml}$ ) vs. DOX 0,93 $\pm 0,25(\mathrm{ng} / \mathrm{ml}) ; \mathrm{p}=0,0002)$.

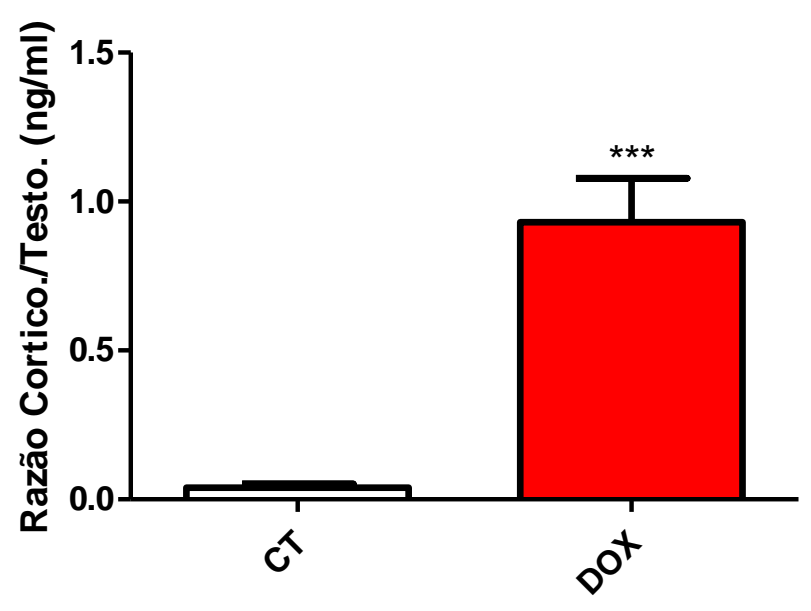

Figura 13 - Caracterização do modelo experimental. Razão da concentração de corticosterona/ testosterona. CT-grupo controle, DOX- grupo tratado com doxorubicina (15 mg/kg). n=3-5. ${ }^{* * *} \mathrm{p}<0,001$. 
O músculo EDL do grupo DOX também apresentou aumento da atividade do complexo mitocondrial 1 (Figura 14 - CT. $241,61 \pm 58,90$ vs. DOX 398,23 $\pm 124,74$; $\mathrm{p}<0,03$ ) e diminuição do complexo mitocondrial 3 (Figura 14 - CT. $0,85 \pm 0,18$ vs DOX 0,41 $\pm 0,27$; $\mathrm{p}<0,01)$.

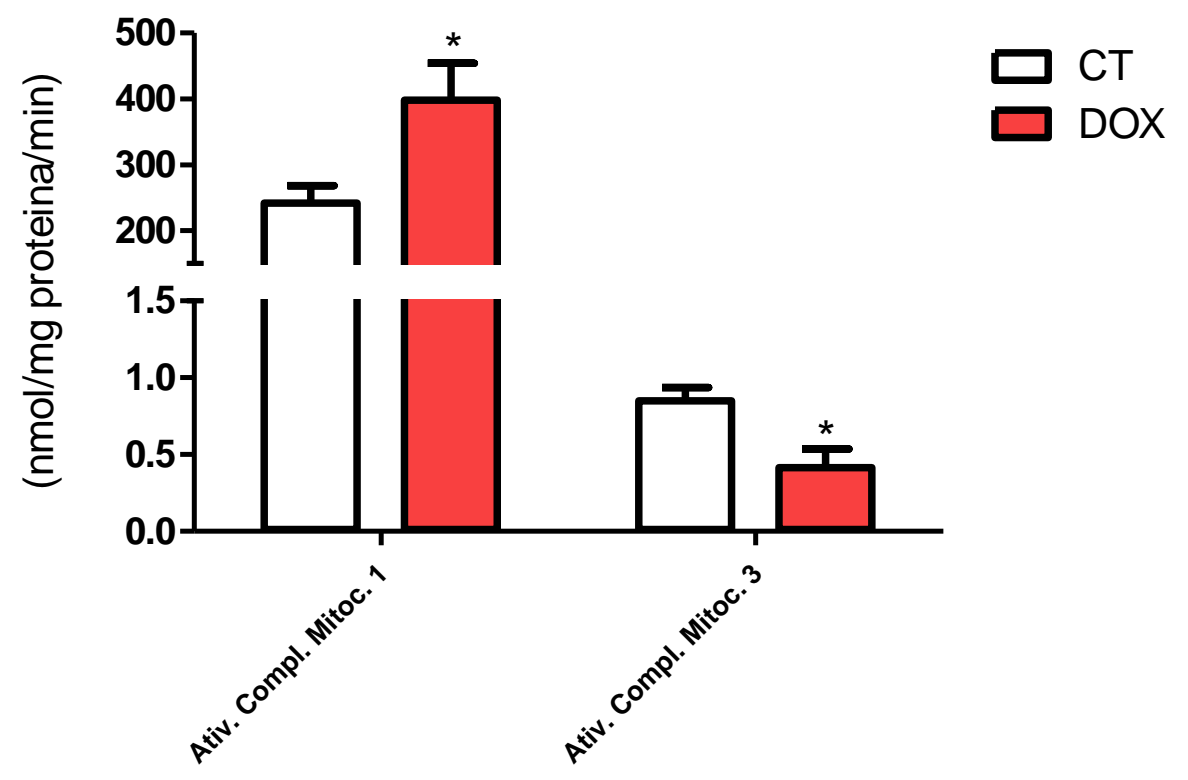

Figura 14 - Caracterização do modelo experimental. Atividade dos complexos mitocondriais 1 e 3. CTgrupo controle, DOX- grupo tratado com doxorubicina (15 mg/kg). $n=5$. ${ }^{*} p<0,05$.

Ainda como caracterização de nosso modelo, avaliamos a concentração circulante de AST (figura 15 - CT 70,47 $\pm 4,16$ (U/L) vs. DOX 109,3 $\pm 4,50$ (U/L); $p=<0,0001$ ), ácido úrico (figura $16-$ CT $3,43 \pm 0,12(\mathrm{U} / \mathrm{L})$ vs. DOX 4,68 $\pm 0,46(\mathrm{U} / \mathrm{L}) ; \mathrm{p}=0,0240$ ) e ácidos graxos livres (figura 17 - CT 0,64 $\pm 0,028$ ( $m E q / L)$ vs. DOX 0,72 $\pm 0,030$ ( $m E q / L) ; ~ p=0,0408)$. 


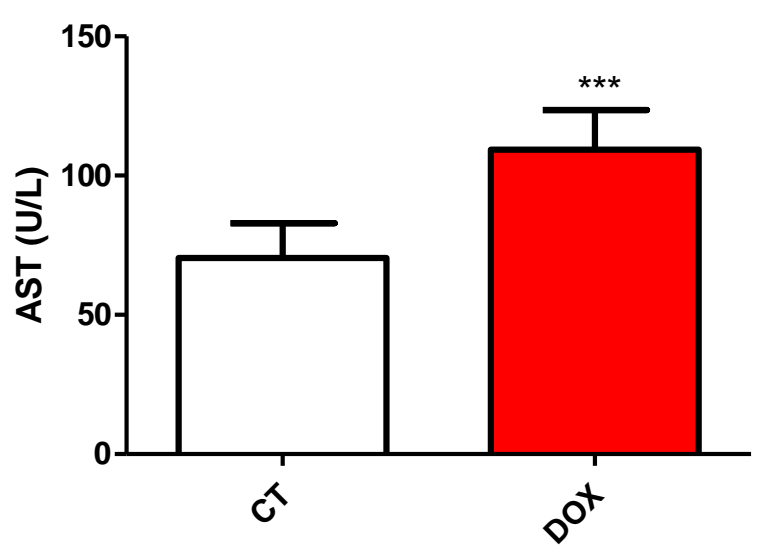

Figura 15 - Caracterização do modelo experimental. Marcador de dano hepático AST. CT-grupo controle, DOX- grupo tratado com doxorubicina (15 mg/kg). $n=9-10 .{ }^{* * *} p<0,001$.

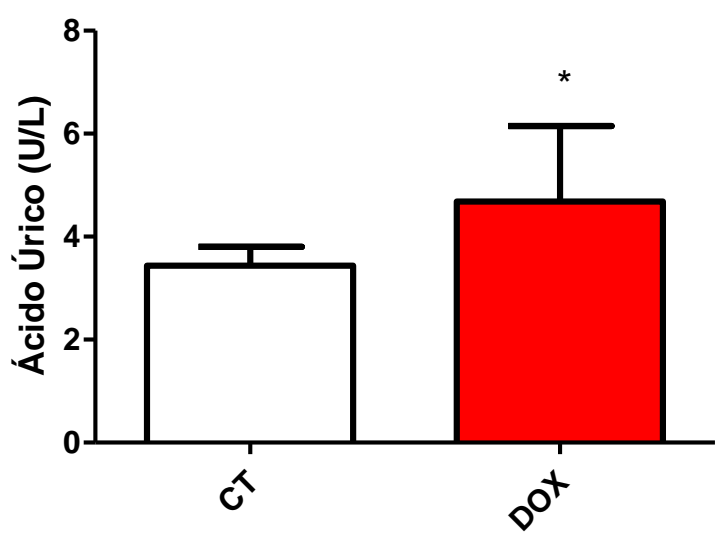

Figura 16 - Caracterização do modelo experimental. Concentração de ácido úrico no soro. CT-grupo controle, DOX- grupo tratado com doxorubicina $(15 \mathrm{mg} / \mathrm{kg}) . \mathrm{n}=9-10 .{ }^{*} \mathrm{p}<0,05$.

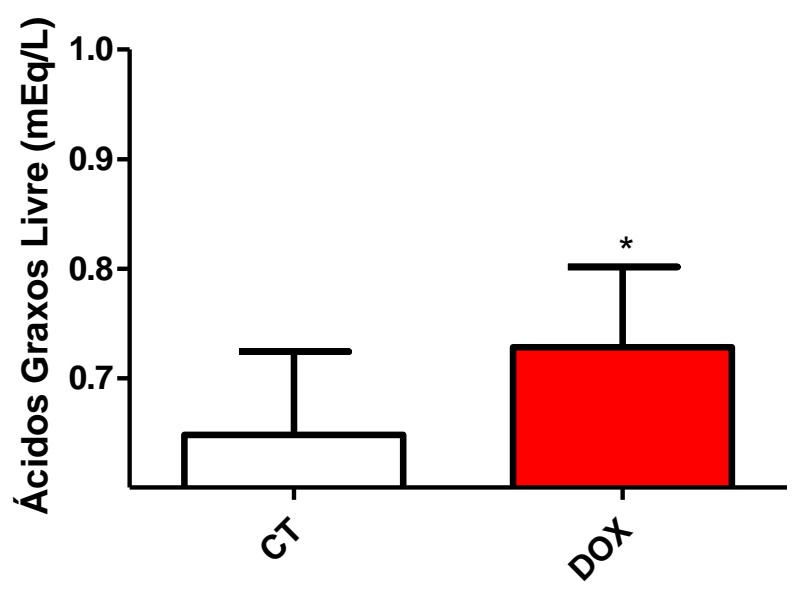


Figura 17 - Caracterização do modelo experimental. Concentração de ácidos graxos livres no soro. CT-grupo controle, DOX- grupo tratado com doxorubicina (15 mg/kg). $n=6-7$. ${ }^{*} p<0,05$.

\subsection{Doxorubicina e resistência à insulina sistêmica}

Inicialmente, para avaliação dos parâmetros indicativos de resistência à insulina mensuramos a glicemia e a insulinemia basal. Ambos os parâmetros se mostraram elevados no grupo DOX (Figura 18 - CT 143,2 $\pm 8,35(\mathrm{mg} / \mathrm{dl})$ vs. DOX 310,7 \pm $35,19(\mathrm{mg} / \mathrm{dl})$ ); $\mathrm{p}=<0,0001)$ (Figura $19-$ CT $1,68 \pm 0,36(\mathrm{ng} / \mathrm{ml}) \quad$ vs. DOX 2,44 $\pm 0,88(\mathrm{ng} / \mathrm{ml}) ;$ $\mathrm{p}=0,0406)$.

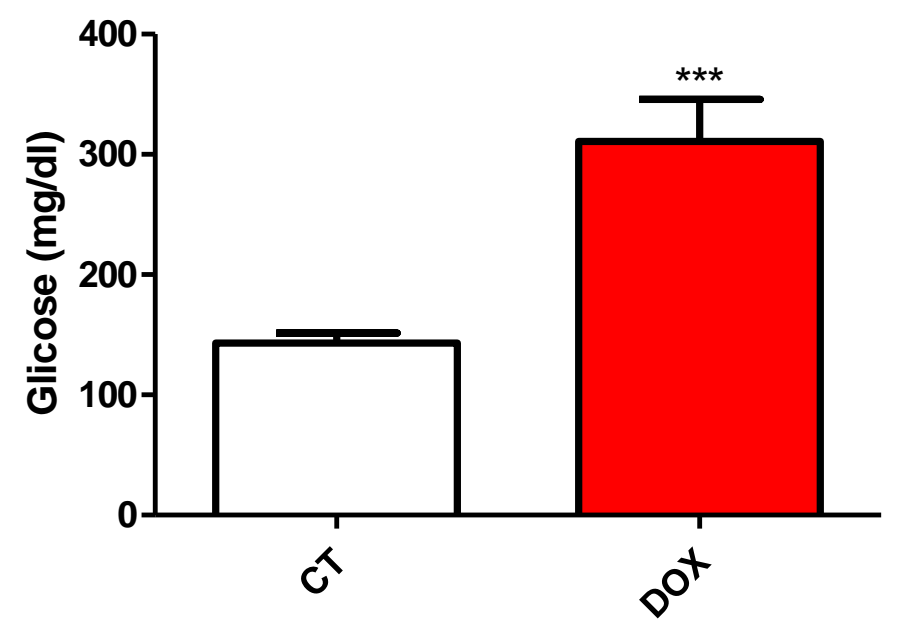

Figura 18 - Avaliação da glicemia (mg/dl). CT-grupo controle, DOX- grupo tratado com doxorubicina $(15 \mathrm{mg} / \mathrm{kg}) . \mathrm{n}=9-10 .{ }^{* * *} \mathrm{p}<0,001$.

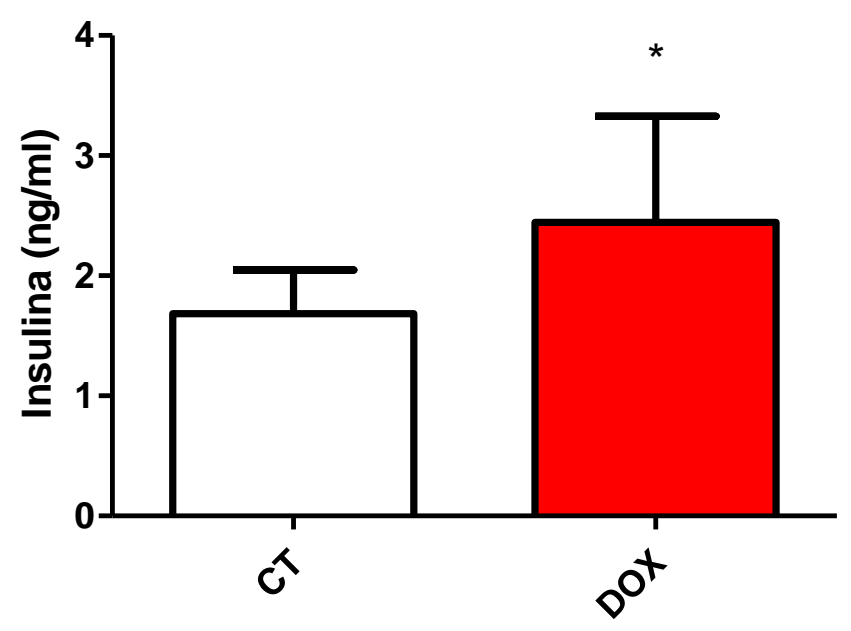


Figura 19 - Avaliação da insulinemia basal (ng/ml). CT-grupo controle, DOX- grupo tratado com doxorubicina $(15 \mathrm{mg} / \mathrm{kg}) . \mathrm{n}=8 .{ }^{*} \mathrm{p}<0,05$.

Nesse sentido, a quantificação da resistência à insulina por HOMA-IR foi menor no grupo DOX (figura 20 - CT 19,20 $\pm 4,30$ vs. DOX 12,92 $\pm 2,19$ ); $p=0,0070$ ).

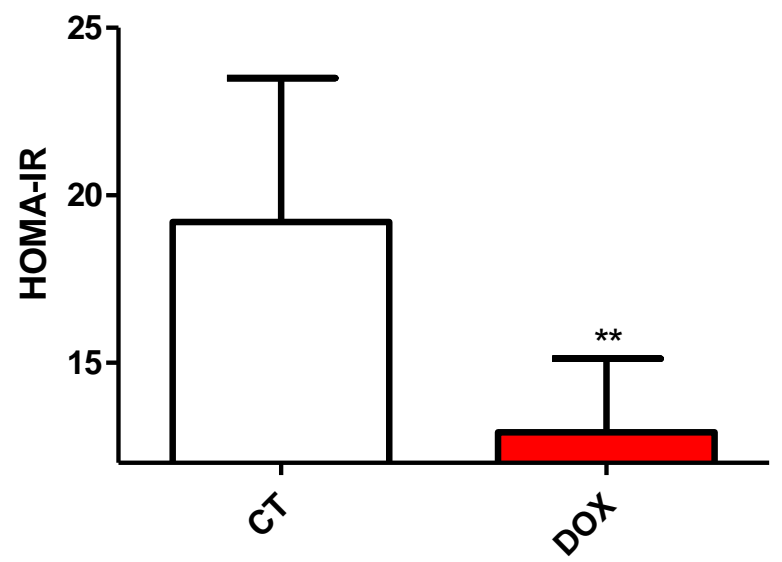

Figura 20 - Modelo de avaliação da homeostase de resistência à insulina (HOMA-IR). CT-grupo controle, DOX- grupo tratado com doxorubicina (15 mg/kg). $n=6-8 .{ }^{* *} \mathrm{p}<0,01$.

O teste de tolerância à insulina (iTT) confirmou a menor sensibilidade à insulina no grupo DOX em relação ao grupo CT. Animais tratados com doxorubicina mostraram maior glicemia durante todo o intervalo do experimento (figura 21A), no qual, a constante de decaimento da glicose (KiTT) apresentou-se profundamente diminuída no grupo DOX (Figura 21B - CT 1,95 $\pm 0,50$ (\% glicose/ min) vs. DOX 0,64 $\pm 0,42$ (\% glicose/ $\min )$ ); $p=0,0075)$.

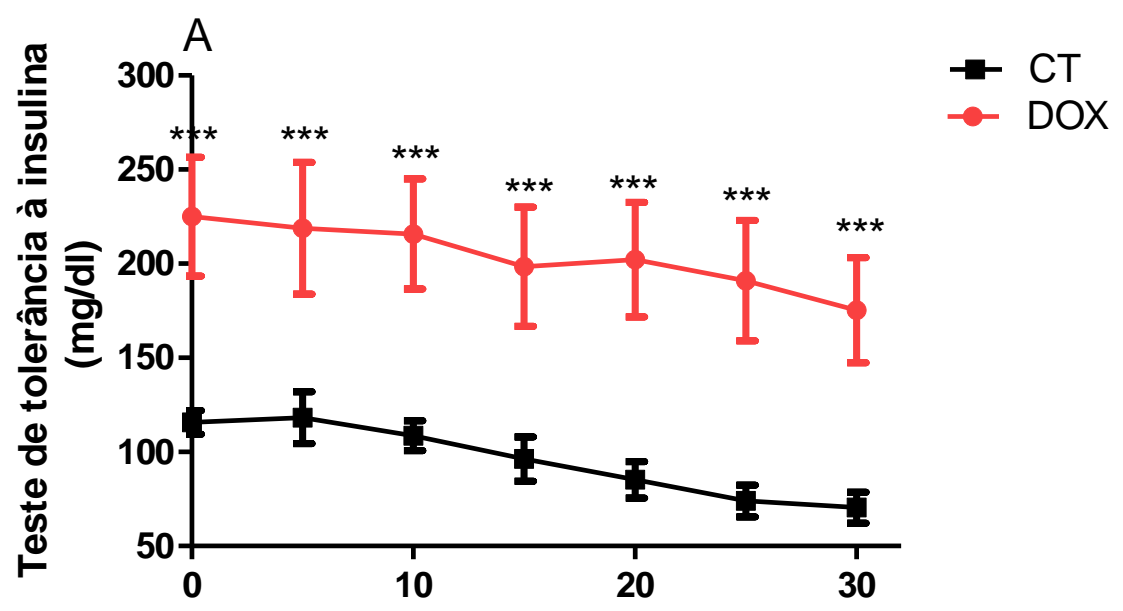




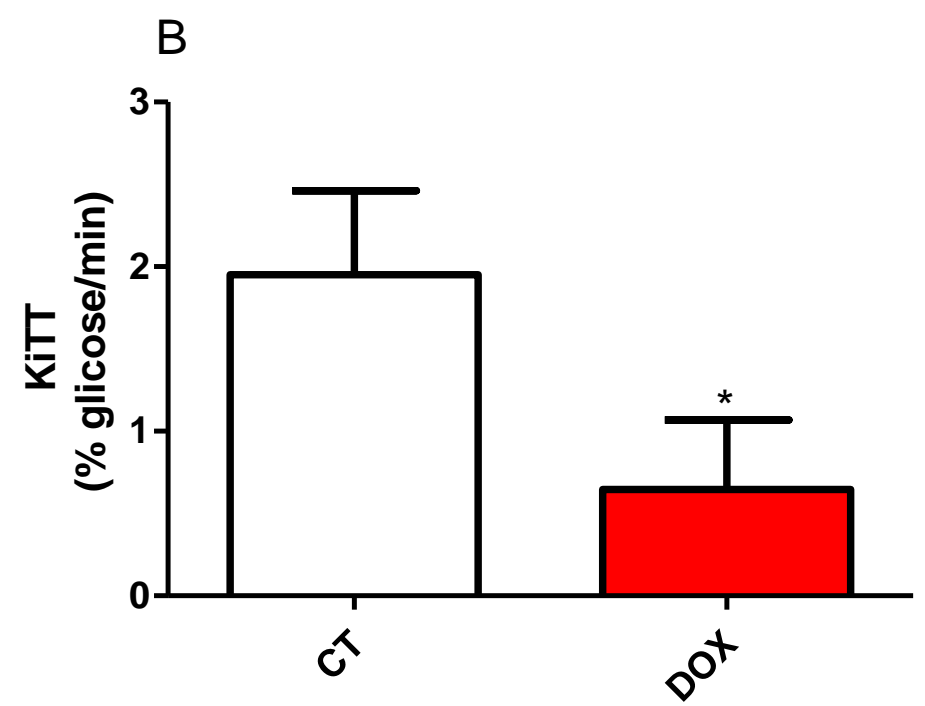

Figura 21 - Teste de tolerância à insulina (iTT). A. Curva da glicemia após injeção intraperitoneal de insulina (0,5 UI); B. Constante de decaimento da glicose (KiTT). CT-grupo controle, DOX- grupo tratado com doxorubicina (15 mg/kg). $n=4$. ${ }^{*} p<0,05,{ }^{* \star *} p<0,001$.

\subsection{Doxorubicina e cultura de miócitos L6}

Para os ensaios in vitro utilizamos o ensaio com MTT para determinar uma dose não letal que permitissem o tratamento por 48 horas com o quimioterápico doxorubicina na cultura de miócitos. Nas concentrações avaliadas, a dose de $1 \mu \mathrm{Me}$ $500 \mathrm{nM}$ de doxorubicina foram consideradas letais, enquanto doses menores que essas não (figura 22).

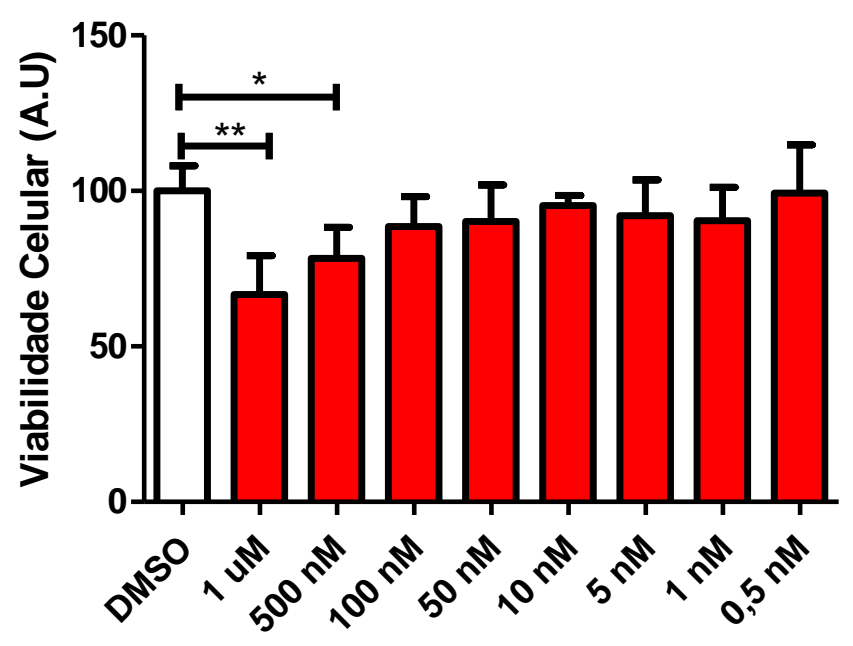


Figura 22 - Viabilidade celular. Células L6 diferenciadas foram tratadas durante 48 horas com diferentes concentrações de doxorrubicina. O ensaio de MTT foi realizado posteriormente para avaliar a viabilidade celular. $n=7$. ${ }^{*} p<0,05,{ }^{* * *} p<0,001$.

Uma vez que observamos uma diminuição da sensibilidade à insulina in vivo, investigamos se o músculo esquelético poderia estar envolvido nesse fenômeno. Desse modo, em cultura celular de miócitos L6 realizamos a captação de 2-deoxi[14C]-D-glicose na presença ou ausência de tratamento com doxorubicina (na concentração de $100 \mathrm{nMol}$ doxorubicina por 48 horas) . O grupo DOX apresentou significante redução da captação de 2-deoxi-[14C]-D-glicose, com e sem estímulo de insulina (figura 23 - CT (-) 1,00 $\pm 0,32$; CT (+) 1,77 $\pm 0,59$ vs. DOX (-) 0,48 $\pm 0,12$; DOX (+) 0,51 $\pm 0,21)$.

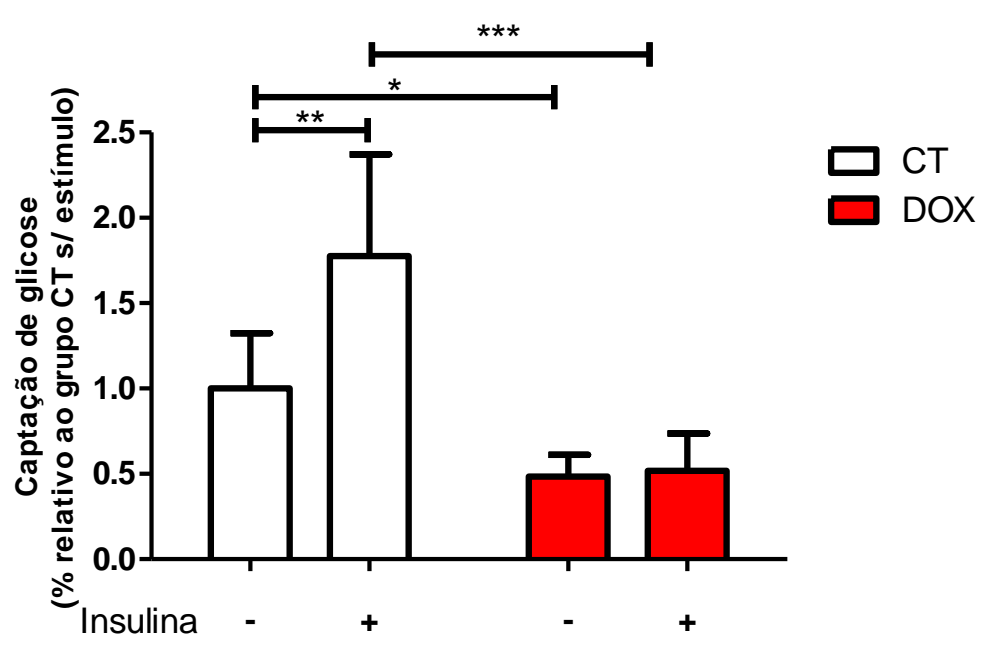

Figura 23 - Doxorubicina diminui a captação de glicose em miócitos L6. As células L6 foram submetidas ao ensaio de captação de 2-deoxi-[14C]-D-glicose após diferenciação, com (+) ou sem (-) estimulo de insulina (100 nM), após 48 horas de tratamento com doxorubicina (100 nM)CT- células L6 controle, DOX- Células tratadas com doxorubicina. $n=5-6 .{ }^{*} p<0,05,{ }^{* *} p<0,01,{ }^{* * *} p<0,001$.

\subsection{Expressão de proteínas envolvidas na captação de glicose no músculo EDL}

No músculo EDL, avaliamos a expressão gênica e proteica envolvida na captação de glicose. Observamos uma diminuição da expressão gênica de IRS-1 (CT $1,03 \pm 0,29$ (U.A) vs. DOX 0,392 $\pm 0,47$ (U.A); $p=0,0349$ ), GSK3- $\beta$ (CT 1,00 $\pm 0,09$ (U.A) vs. DOX $0,48 \pm 0,30$ (U.A); $p=0,0086$ ), GLUT-4 (CT 1,16 $\pm 0,71$ (U.A) vs. DOX 0,05 $\pm 0,05$ (U.A) ; $p=0,0179$ ) e AMPk (CT 1,08 $\pm 0,39$ (U.A) vs. DOX 0,30 $\pm 0,37$ (U.A) ; $p=0,0203$ ) após o tratamento com 
doxorubicina (figura 24). Não houve diferença estatística na expressão gênica da AKT (figura 24). CT 1,05 $\pm 0,40$ (U.A) vs. DOX 0,62 $\pm 0,82$ (U.A) ; $p=0,3353$ ).

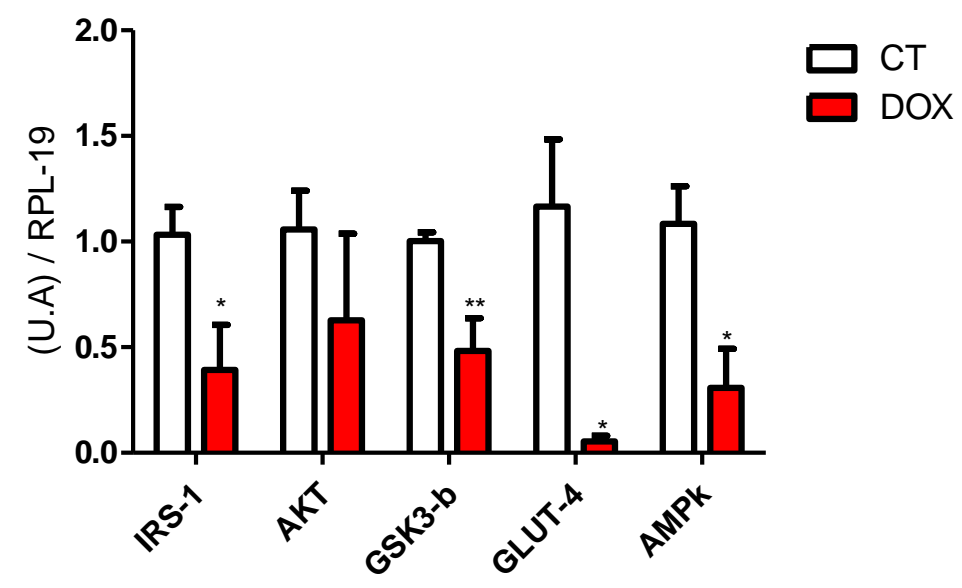

Figura 24 - Expressão de genes envolvidos no metabolismo de glicose do músculo EDL. CT-grupo controle, DOX- grupo tratado com doxorubicina (15 mg/kg). $n=4-5 .{ }^{*} p<0,05,{ }^{* *} p<0,01$.

Já a expressão proteica de GLUT-4 (figura 25 - CT 1,00 $\pm 0,44$ (U.A) vs. DOX 0,12 \pm 0,10 (U.A); $p=0,039$ ) e da razão AMPk a ${ }^{\text {pThr172 }}$ e AMPk a foram diminuídas (figura 25 - CT $1,00 \pm 0,18$ (U.A) vs. DOX $0,55 \pm 0,26$ (U.A); $p=0,0338$ ). Não foi verificado alteração na expressão do IR (figura 25 - CT 1,00 $\pm 0,27$ (U.A) vs. DOX 1,38 $\pm 0,54$ (U.A); $p=0,1226$ ) e da razão $A K T^{\text {pSer473 }}$ e AKT total (figura 25 - CT $1,00 \pm 0,17$ (U.A) vs. DOX 1,03 $\pm 0,28$ (U.A); $p=0,793)$.

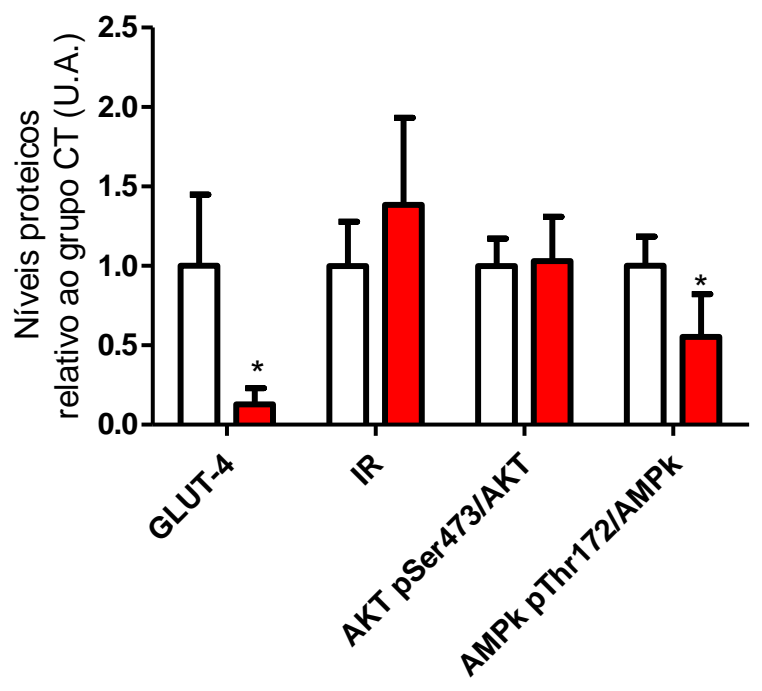

$\square$ CT
$\square$ DOX

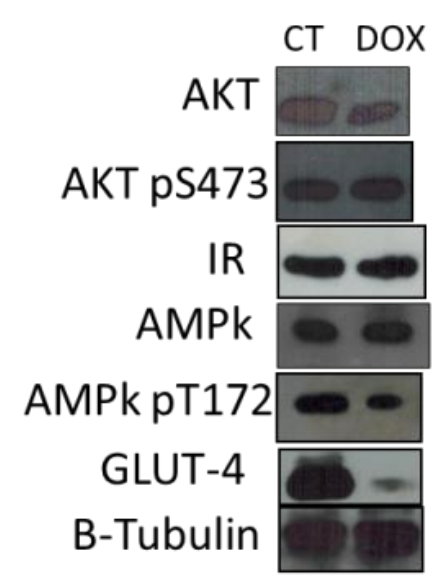


Figura 25 - Expressão de proteínas envolvidas no metabolismo de glicose no músculo EDL. CT-grupo controle, DOX- grupo tratado com doxorubicina (15 mg/kg). $n=4-5 .{ }^{*} p<0,05$.

\subsection{Concentração de adiponectina e de seus receptores no músculo EDL}

A concentração de adiponectina avaliada no soro (figura 26 - CT $4851 \pm 1412$ (ng/ml) vs. DOX $2670 \pm 524,3(\mathrm{ng} / \mathrm{ml}) ; \mathrm{p}=0,0005)$ e no tecido adiposo retroperitoneal (figura 27 - CT 463,0 \pm 172,3 (ng/mg proteína) vs. DOX 235,8 \pm 132,7 (ng/mg proteína); p=0,0060) do grupo tratado com doxorubicina foi estatisticamente menor em relação ao grupo CT. Não houve alteração da expressão gênica dos receptores de adiponectina 1 (figura 28 - CT $1 \pm 0,87$ (U.A) vs. DOX 1,50 $\pm 1,25$ (U.A); $p=0,8965$ ) e 2 (figura 27 - CT $1 \pm 1,10$ (U.A) vs. DOX 1,09 $\pm 1,17$ (U.A); $p=0,8927)$.

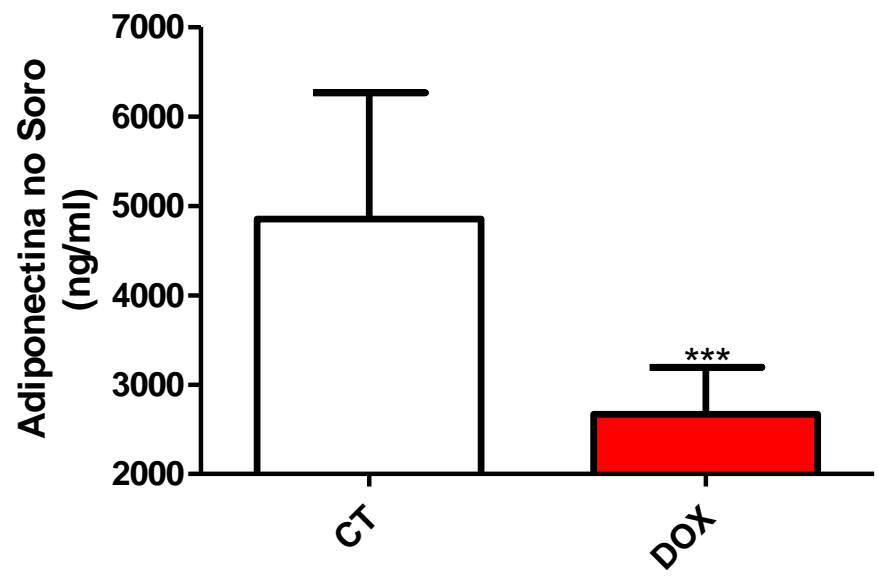

Figura 26 - Concentração de adiponectina no soro. CT-grupo controle, DOX- grupo tratado com doxorubicina $(15 \mathrm{mg} / \mathrm{kg}) . \mathrm{n}=4-5 .{ }^{* * *} \mathrm{p}<0,001$.

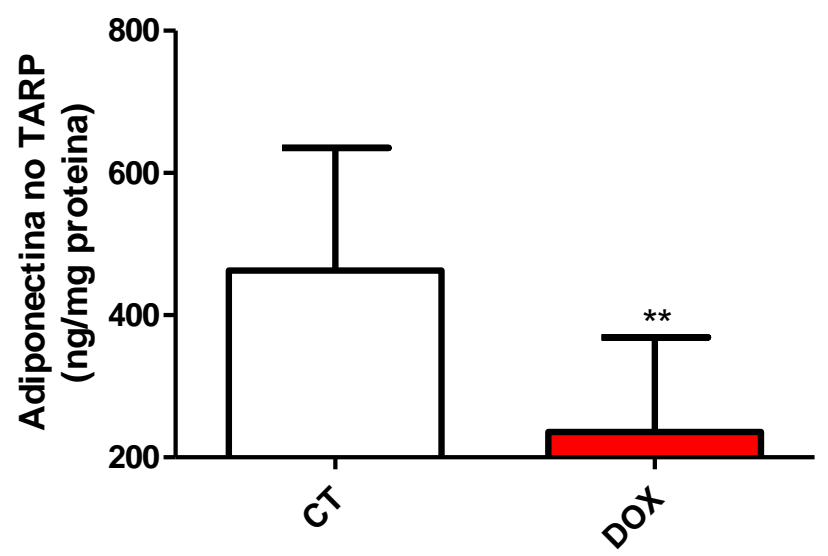


Figura 27 - Concentração de adiponectina no tecido adiposo retroperitoneal. CT-grupo controle, DOXgrupo tratado com doxorubicina $(15 \mathrm{mg} / \mathrm{kg}) . \mathrm{n}=4-5 .{ }^{* * *} \mathrm{p}<0,01$.

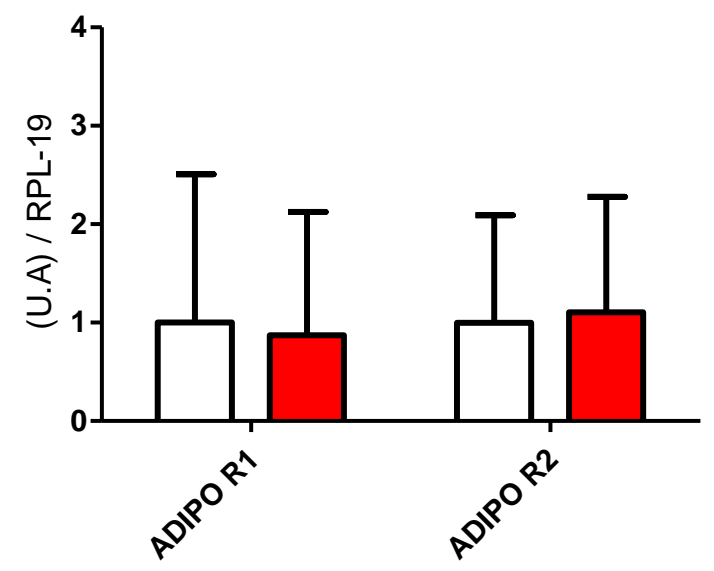

Figura 28 - Expressão gênica dos receptores de adiponectina 1 e 2 no músculo EDL. CT-grupo controle, DOX- grupo tratado com doxorubicina (15 mg/kg). $\mathrm{n}=4-5$.

\subsection{Doxorubicina e acúmulo de triacilglicerol}

Em nosso modelo, não houve alteração do conteúdo total de triacilglicerol no músculo esquelético (figura 29 - CT 0,84 $\pm 0,13$ ( $\mathrm{mg} / \mathrm{mg}$ tecido) vs. DOX 0,99 $\pm 0,25$ ( $\mathrm{mg} / \mathrm{mg}$ tecido); $p=0,1194)$, e sequer alteração na expressão de genes envolvidos na oxidação de lipídios (CPT-1. figura 30 - CT 1,04 $\pm 0,33$ (U.A) vs. DOX 0,80 $\pm 0,67$ (U.A); $p=0,500$ ), (ACC. figura 30 - CT 1,09 $\pm 0,49$ (U.A) vs. DOX 1,47 $\pm 0,91$ (U.A); $p=0,457$ ) e (PGC1 - a figura 30 - CT $1,01 \pm 0,33$ (U.A) vs. DOX $0,94 \pm 0,51$ (U.A); $p=0,115$ ). 


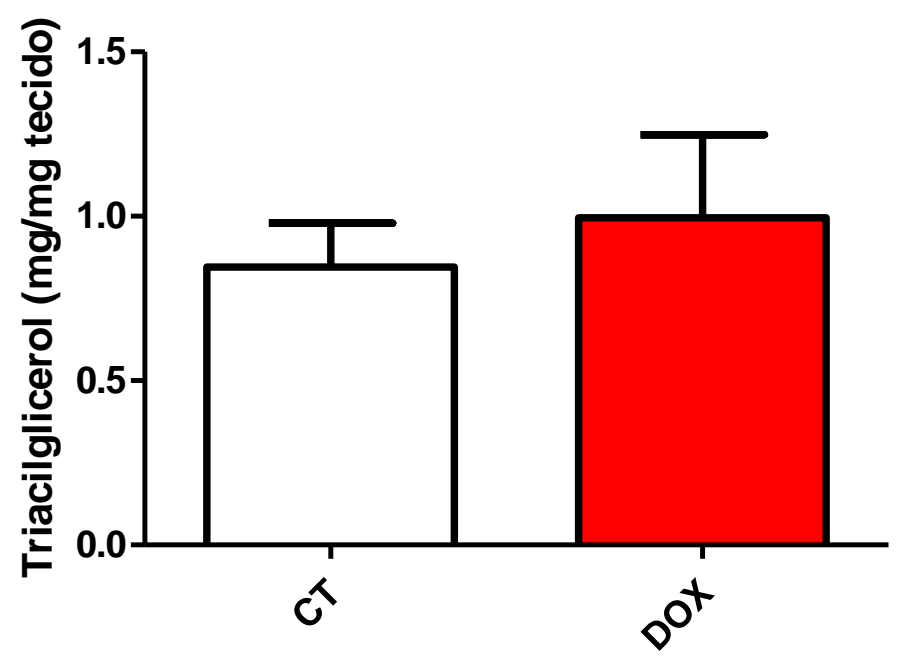

Figura 29 - Conteúdo de triacilglicerol no músculo gastrocnêmio. CT-grupo controle, DOX- grupo tratado com doxorubicina $(15 \mathrm{mg} / \mathrm{kg}) . \mathrm{n}=9-10$.

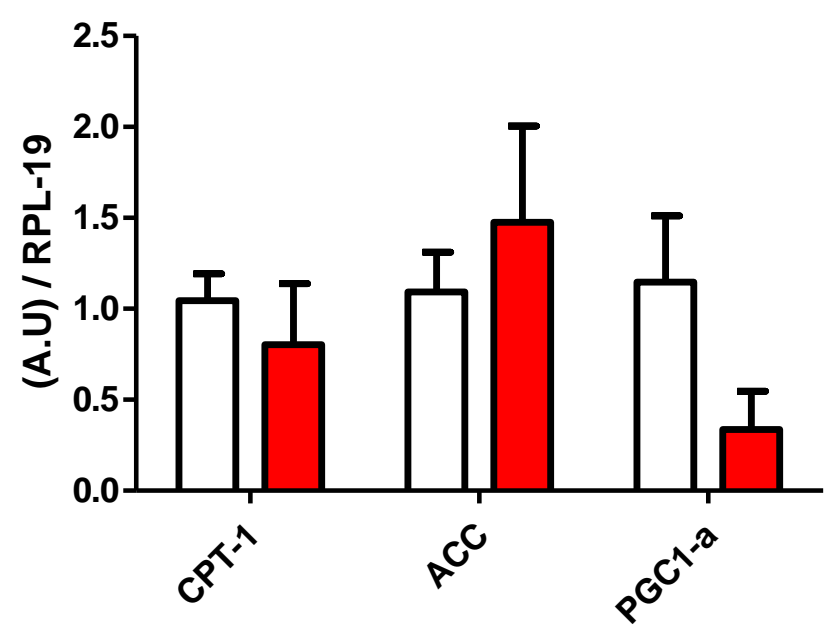

Figura 30 - Expressão gênica de proteínas envolvidas no metabolismo oxidativo no músculo EDL. CTgrupo controle, DOX- grupo tratado com doxorubicina (15 mg/kg). $\mathrm{n}=4-5$.

Também não houve diferença estatística para atividade das enzimas oxidativas, citrato sintase (figura 31 - CT 103,8 \pm 10,93 (IU/mg proteína) vs. DOX 104,8 $\pm 12,96$ (IU/ mg proteína); p=0,9147) e malato desidrogenase.(figura 32 - CT 78,56 $\pm 14,1 \quad$ (nmol/mg proteína/ min) vs. DOX 87,09 $\pm 11,39$ ( $\mathrm{mmol} / \mathrm{mg}$ proteína/ min); p=0,3235). 


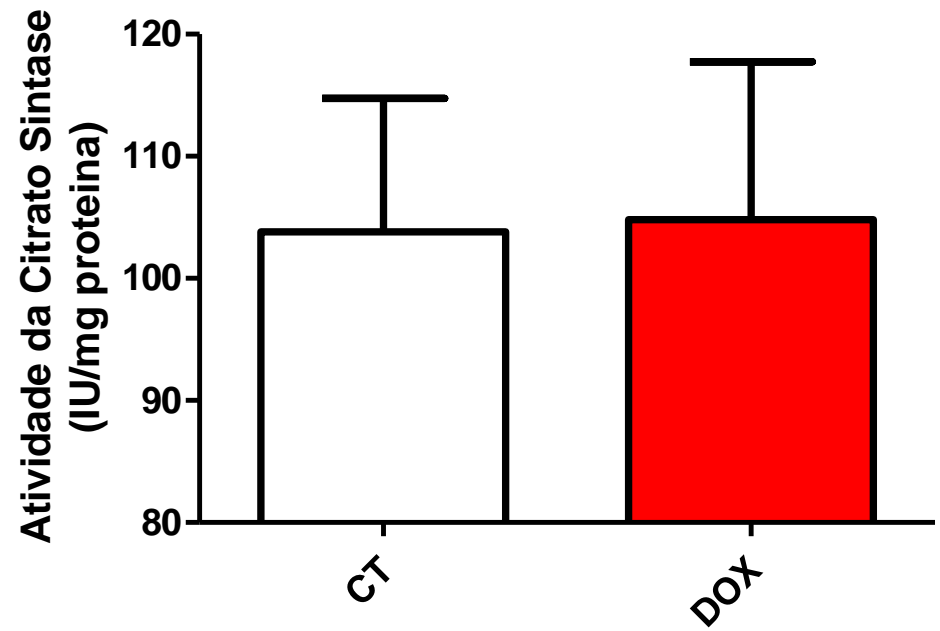

Figura 31 - Atividade da citrato sintase no músculo EDL. CT-grupo controle, DOX- grupo tratado com doxorubicina $(15 \mathrm{mg} / \mathrm{kg}) . \mathrm{n}=3-5$.

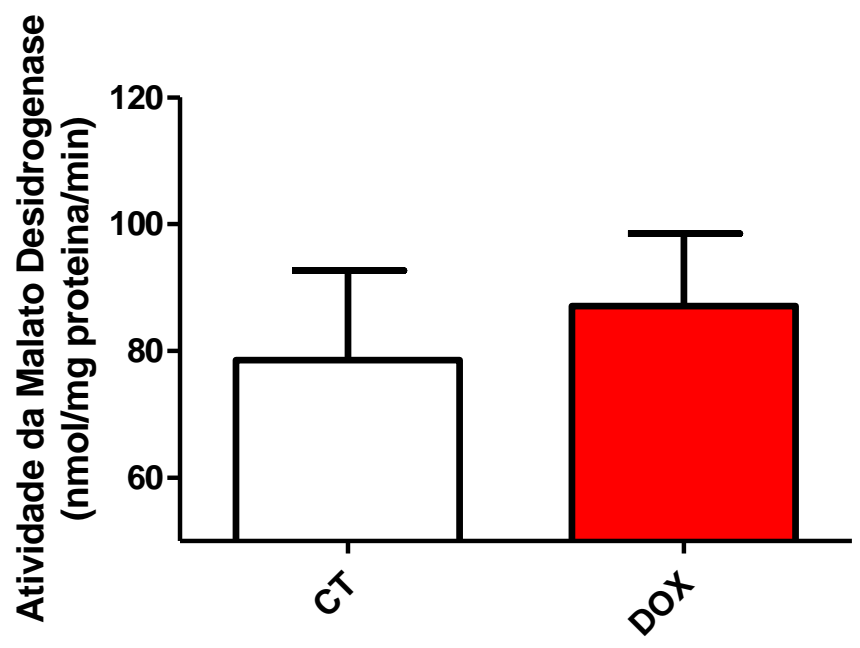

Figura 32 - Atividade da malato desidrogenase no músculo EDL. CT-grupo controle, DOX- grupo tratado com doxorubicina $(15 \mathrm{mg} / \mathrm{kg}) . \mathrm{n}=5$.

\subsection{Doxorubicina e inflamação}

O tratamento com a doxorubicina diminui a concentração da citocina próinflamatória TNF- $\alpha$ (figura 33 - CT 2,33 $\pm 0,75$ (pg/mg proteína) vs. DOX 0,1,64 $\pm 0,39$ (pg/mg proteína); $\mathrm{p}=0,0266)$ e da citocina anti-inflamatória IL-10 (figura 33 - CT 14,90 $\pm 5,02$ (pg/mg proteína) vs. DOX $8,87 \pm 1,44$ (pg/mg proteína); $\mathrm{p}=0,0101$ ) no músculo EDL. Não houve 
diferença estatística para a citocina IL-6 (figura 33 - CT 7,46 1,64 (pg/mg proteína) vs. DOX $6,00 \pm 1,32$ (pg/mg proteína); $p=0,0938)$.

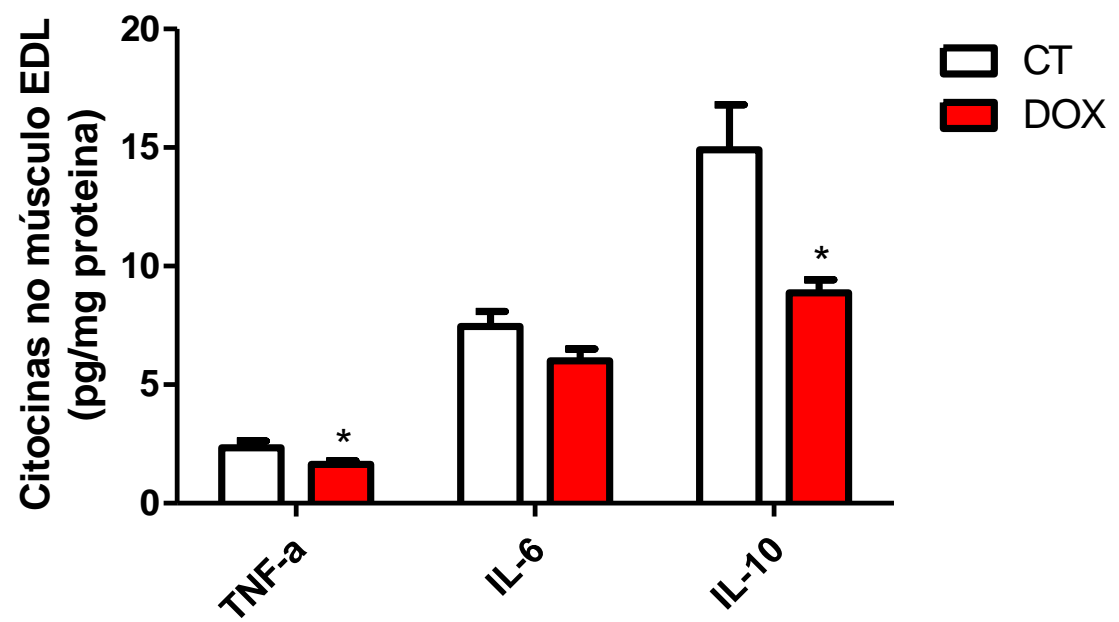

Figura 33 - Concentração das citocinas TNF-a, IL-6 e IL-10 no músculo EDL (pg/mg proteína). CTgrupo controle, DOX- grupo tratado com doxorubicina (15 mg/kg). $n=7 .{ }^{*} p<0,05$.

Não houve diferença estatística para a expressão gênica de IL-1 $\beta$ (figura 34 CT $1,004 \pm 0,12$ (U.A) vs. DOX 0,745 $\pm 0,44$ (U.A); $p=0,2461$ ) e para as proteínas envolvidas no complexo do inflamassoma, dentre essas enzimas mensuramos a caspase-1 (figura 34. CT 1,00 0,15 (U.A) vs. DOX 2,24 $\pm 3,28$ (U.A); p=0,4188), NLRP-1 (figura 34 - CT 1,14 \pm 0,61 (U.A) vs. DOX 5,82 $\pm 9,74$ (U.A); $p=0,3119$ ), NLRP-3 (figura 34 - CT 1,03 0,27 (U.A) vs. DOX 4,42 $\pm 2,95$ (U.A); p=0,057), NOD-1 (figura 34 - CT 2,04 $\pm 2,62$ (U.A) vs. DOX 1,00 $\pm 0,14$ (U.A); $p=0,4022$ ) e NOD-2 (figura 34 - CT 1,15 $\pm 0,57$ (U.A) vs. DOX 4,16 $\pm 3,00$ (U.A); $p=0,0620$ ) no músculo EDL. Já a expressão gênica de TLR-4 foi maior no grupo DOX (figura 34 CT $1,23 \pm 0,84$ (U.A) vs. DOX 15,66 $\pm 13,44$ (U.A); $p=0,0449$ ). 


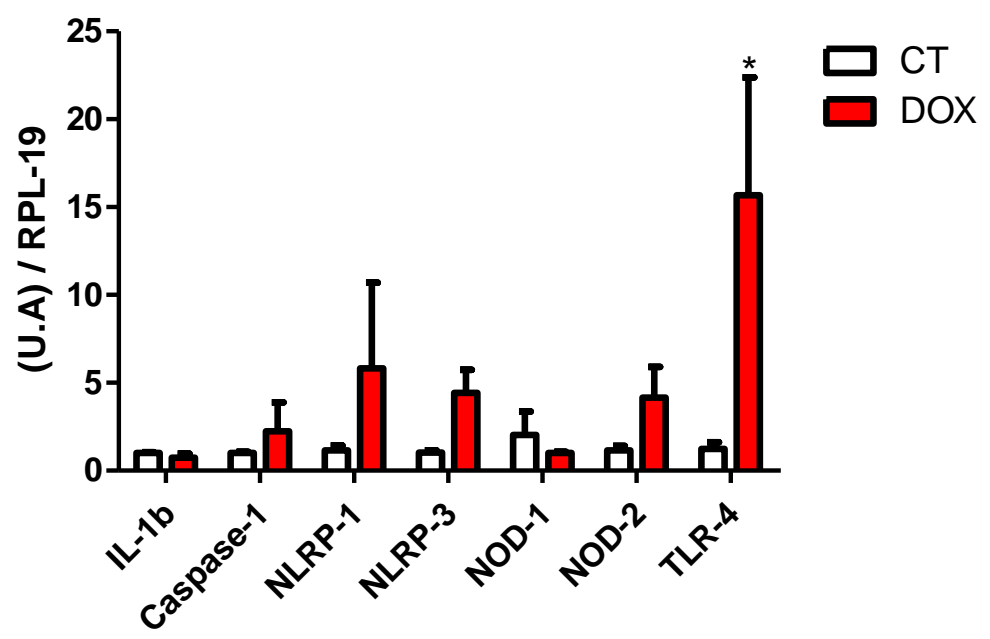

Figura 34 - Expressão gênica de proteínas envolvidas na inflamação realizadas no músculo EDL. CTgrupo controle, DOX- grupo tratado com doxorubicina (15 mg/kg). $n=4-5 .{ }^{*} p<0,05$.

\subsection{Expressão de GLUT-4 e AMPk em cultura de miócitos L6}

Uma vez que nossos resultados in vivo observamos uma diminuição da expressão protéica de GLUT-4 e AMPka e diminuição da captação de 2-deoxi[14C]-D-glicose nos ensaios in vitro avaliamos a expressão proteica de GLUT-4 e AMPk nos miócitos L6. O tratamento com doxorubicina diminuiu a expressão de GLUT-4 (figura 35 - CT 1,00 $\pm 0,053$ (U.A) vs. DOX 0,71 $\pm 0,12$ (U.A); $p=0,022$ ) e a fosforilação da AMPka ${ }^{\text {Thr172 }}$ (figura 35 - CT 1,00 $\pm 0,26$ (U.A) vs. DOX 0,37 $\pm 0,08$ (U.A); $p=0,017$ ). 

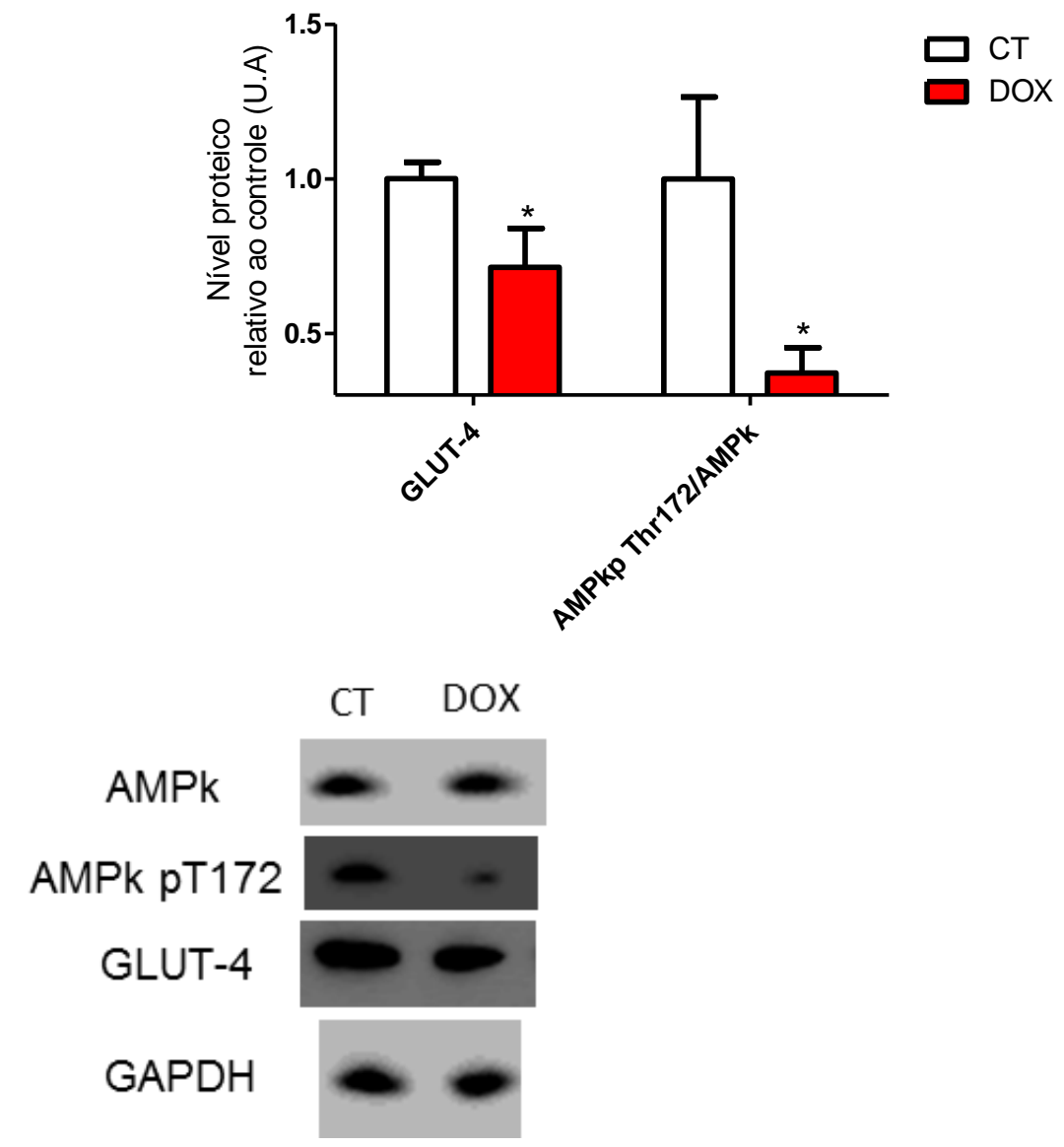

Figura 35 - Expressão proteica de GLUT-4 e AMPk em células L6. CT - cultura de miócitos controle, DOX- cultura de miócitos tratados com doxorubicina (100 nM por 48 horas) . $n=3 .{ }^{*} p<0,05$.

\subsection{Efeito do AICAR sobre a captação de 2-deoxi-[14C]-D-glicose}

Uma vez que observamos a diminuição da fosforilação da proteína AMPka em miócitos L6 com o tratamento com doxorubicina (figura 36) investigamos o efeito da utilização do agonista de AMPk (AICAR) sobre a captação de 2-deoxi-[14C]-Dglicose. O tratamento crônico com AICAR (por 48 horas na concentração de 2 mM) foi capaz de recuperar a queda na captação de 2-deoxi-[14C]-D-glicose causado pela doxorubicina, enquanto no tratamento agudo (por 1 horas na concentração de 2 $\mathrm{mM}$ ) esse efeito foi estatisticamente não significante (figura 36 - CT 1,69 $\pm 0,14$ (U.A) vs. DOX 1,049 0,51 (U.A) vs. DOX + Al1 h 1,48 0,19 (U.A) vs DOX + Al48 h 1,79 0,05 (U.A). 


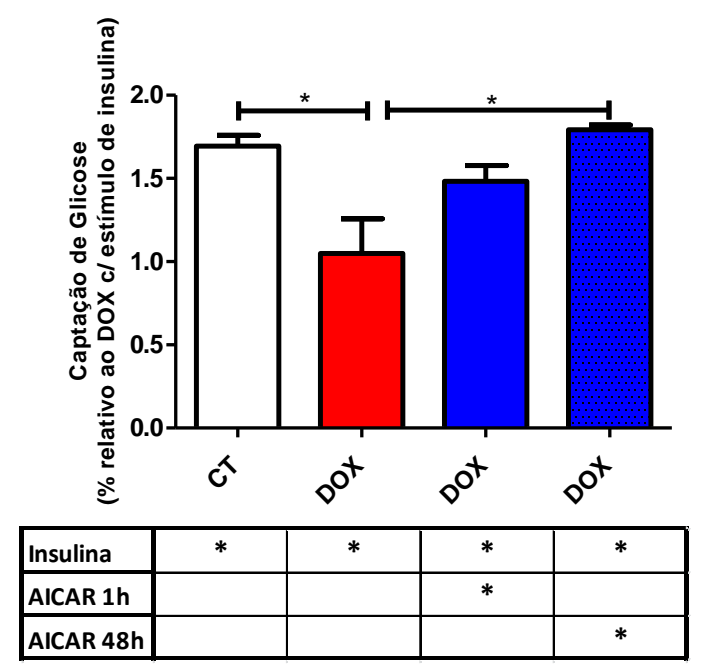

Figura 36 - Tratamento crônico com AICAR recupera a captação de 2-deoxi-[14C]-D-glicose em cultura de miócitos L6. As células L6 foram submetidas ao ensaio de captação de 2-deoxi-[14C]-Dglicose após diferenciação, na presença de estímulo de insulina (100 nM), após 48 horas de tratamento com doxorubicina (100 nM), com ou sem tratamento com AICAR ( 1 h-agudo/48 h crônico). CT- células L6 controle, DOX- Células tratadas com doxorubicina. $n=4-6$. ${ }^{*} p<0,05$.

Para confirmar o efeito do AICAR sobre a ativação da AMPk realizamos a expressão proteica dessa proteína. Não houve alteração no conteúdo da AMPka entre os grupos estudados (Figura 37B - CT 1,00 (U.A) vs. DOX 0,86 $\pm 0,07$ (U.A) vs. CTAl1 $1,76 \pm 1,05$ (U.A) vs DOXAl1 0,93 $\pm 0,07$ (U.A) vs CT Al48 0,55 $\pm 0,29$ (U.A) vs DOX Al48 0,51 \pm 0,25(U.A)). Quando avaliamos o efeito do agonista da AMPk (AICAR) no aumento da fosforilação do sítio ${ }^{\text {Thr172 }}$ observamos que o tratamento mostrou-se efetivo, uma vez que houve aumento da atividade dessa proteína na comparação dos grupos CT e CT Al1 (Figura 37A - CT 1,00 (U.A) vs CT Al1 1,24 $\pm 0,35$ (U.A)). Esse efeito foi observado somente nos grupos que receberam tratamento agudo (AICAR por 1 hora) (Figura 37A - DOX 0,46 $\pm 0,04$ (U.A) vs. CT Al1 1,24 $\pm 0,35$ (U.A) vs DOX Al1 1,00 $\pm 0,15$ (U.A)). Não houve diferença estatística para a fosforilação da AMPka ${ }^{\text {Thr172 }}$ para os grupos tratados com AICAR por 48 horas (Figura 37A. CT Al48 0,94 $\pm 0,17$ (U.A) vs DOX Al48 0,81 $\pm 0,18$ (U.A)).

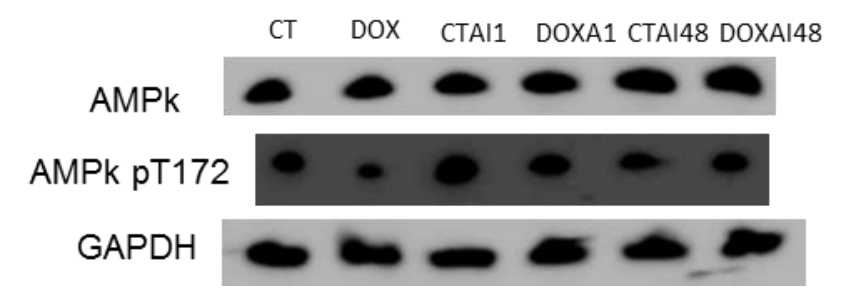



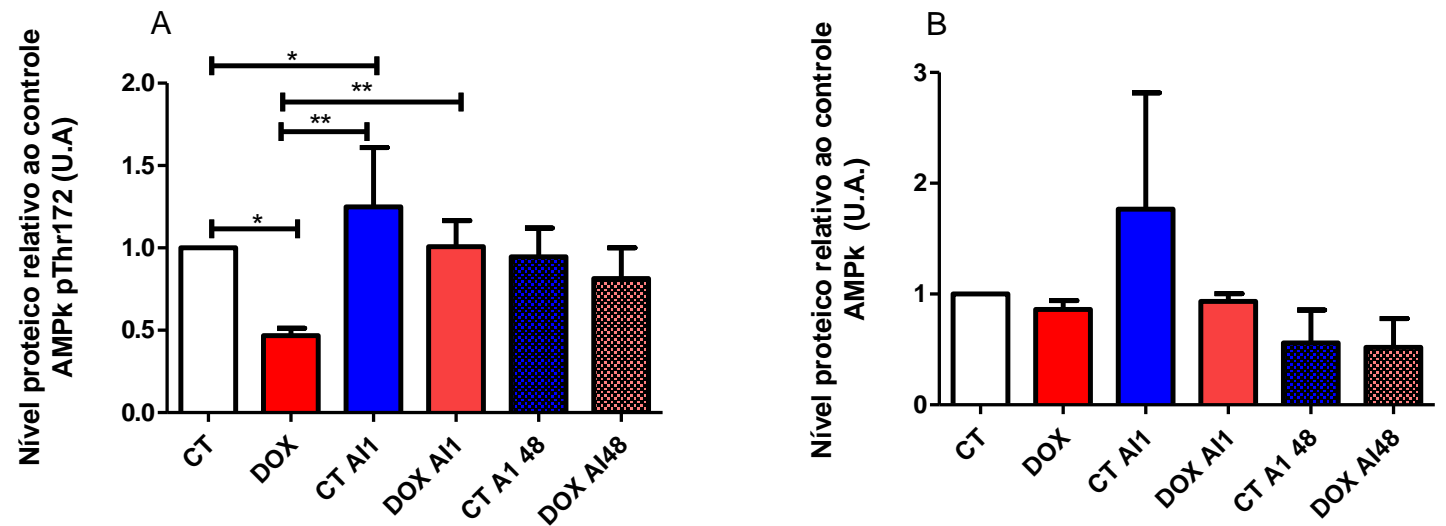

Figura 37 - Efeito do tratamento com AICAR sobre a atividade da AMPk. As células L6 foram submetidas ao tratamento com o quimioterápico doxorrubicina (100 nM por $48 \mathrm{~h}$ ) na presença ou ausência do agonista de AMPk (1 $\mathrm{h}$ - tratamento agudo/48 $\mathrm{h}$-tratamento crônico $-2 \mathrm{mM})$. A. Expressão proteica de AMPka pThr172; B. Expressão protéica da AMPka. CT- células L6 controle, DOX- Células tratadas com doxorubicina, Al1 - tratamento agudo com AICAR, Al48 - tratamento crônico com AICAR. $n=3 .{ }^{*} p<0,05,{ }^{* *} p<0,01$. 


\section{DISCUSSÃO}

Nossos principais resultados sugerem que o tratamento com doxorrubicina leva a intolerância à glicose severa que é observada tanto in vivo como in vitro. A diminuição da atividade da proteína AMPK foi modulada de forma negativa com o tratamento e mostrou ser um possível alvo terapêutico capaz de recuperar a tolerância à glicose.

O tratamento com doxorrubicina causou uma intensa diminuição do peso corporal e um relevante quadro anoréxico, 72 horas, após a aplicação inicial do quimioterápico. Além disso, o tratamento promoveu uma severa queda no peso do coxim adiposo epididimal e do músculo esquelético EDL. Associado a isso a doxorrubicina causou toxicidade hepática e renal como já observado por outros estudos (110-111), e que por nós pode ser inferida pelo aumento exponencial de AST e ácido úrico circulante.

Corroborando com a queda no peso do músculo EDL, a aplicação de doxorrubicina conduz a diminuição da área de secção transversa. Esses resultados vão ao encontro dos achados na literatura (112-115). Para pacientes em tratamento quimioterápico, a perda de massa muscular possui importante efeito negativo sobre a saúde do indivíduo, já que está associada a maior morbidade e piora na qualidade de vida (40-41).

A fim de melhor caracterizar as alterações sistêmicas da utilização de doxorrubicina sobre a regulação dos mecanismos de controle dos processos de síntese e degradação protéica avaliamos a concentração circulante dos dois principais hormônios esteróides que regulam esses processos. Uma razão corticosterona/testosterona significantemente mais alta foi observada no grupo DOX, confirmando assim o elevado estado catabólico de nosso modelo experimental. Devido aos efeitos tóxicos da quimioterapia, disfunções testiculares são comuns, levando a diminuição da produção de testosterona (116-117) e consequente efeito negativo sobre a homeostase do músculo esquelético. Além disso, recentemente foi demonstrado que o aumento de corticosterona provocado pelo tratamento induz um potencial efeito catabólico no músculo esquelético, efeito este dependente de receptores de glicocorticóides (118).

Ao nível molecular, nós encontramos aumento da E3 enzima ligase de ubiquitina, Atrogin-1, o qual se observa aumentada durante a atrofia muscular (119). Sendo 
assim, o tratamento com doxorrubicina é um importante fator de risco para o desenvolvimento da atrofia muscular. Pior ainda é o fato que a perda de massa muscular após o tratamento quimioterápico é um fator de risco independente para pior prognóstico (120). Não obstante, a sarcopenia tem sido recentemente associada a uma maior toxicidade do próprio tratamento quimioterápico, sendo sugerido que a dose utilizada pela área corporal do paciente deveria ser corrigida pela massa muscular com o fim de diminuir os efeitos citotóxicos (121). Além do papel desses dois hormônios esteroidais sobre o balanço da síntese e degradação proteica, a insulina é um hormônio peptídico que também apresenta grande efeito sobre as vias anabólicas em diferentes tipos celulares $(52,122)$.

O tratamento com este quimioterápico induz uma profunda resistência à insulina, após 48 horas da sua administração. Essa diminuição da sensibilidade à insulina sistêmica foi avaliada pelo iTT e HOMA-IR. Além disso, em restrição alimentar, animais tratados com o quimioterápico apresentaram hiperglicemia e hiperinsulinemia. Na prática clínica, já se observou, que a utilização de algumas drogas quimioterápicas pode alterar a sensibilidade à insulina (91-92). No entanto, o efeito da doxorubicina sobre este parâmetro é muito pouco descrito na literatura. Apenas em (123), Arunachalam e colaboradores hipotetizaram o efeito da doxorubicina na mimetização das características do diabetes tipo 2 e o papel do tecido adiposo nesse processo.

A partir dos resultados obtidos, e devido ao notável papel do músculo esquelético sobre a captação de glicose, investigamos se esse tecido poderia estar envolvido no processo de desenvolvimento da intolerância à glicose. A insulina, uma vez na circulação, favorece a atividade tirosina quinase intrísica de seu receptor, gerando uma cascata de sinalização intracelular, via interação proteína-proteína e fosforilação, que favorece a captação de glicose. Esse aumento na captação de glicose pode ocorrer por via dependente ou independente da cascata de PI3K (124).

Não observamos no músculo EDL alteração da expressão protéica do receptor de insulina, bem como da expressão protéica e gênica de Akt, proteína downstream de PI3-k. Apesar disso, outras proteínas envolvidas no metabolismo de glicose e sinalização da insulina tiveram diminuição da expressão gênica. A expressão, tanto em nível gênico quanto protéico, de GLUT-4 e AMPka ${ }^{\mathrm{pT} 172}$ foi reduzida. Esses dados sugerem que apesar da cascata de sinalização da insulina não ser completamente 
perturbada, importantes proteínas com participação efetiva na captação de glicose estão menos expressas ou ativadas.

O GLUT-4 é o principal transportador de glicose do músculo esquelético sob condições estimuladas $(48,67)$. É sintetizado e armazenado em vesículas intracelulares que são exocitadas para o sarcolema após estímulo (125-126). Os mecanismos que viabilizam a captação de glicose pelo músculo esquelético permitindo a translocação desses transportadores, ocorrem primordialmente em função da ativação da cascata de sinalização da insulina e das alterações intracelulares geradas decorrentes da contração muscular (125-126). Apesar de não observarmos modulação da proteína Akt, chave na cascata de sinalização da insulina, a supressão da expressão gênica e protéica de GLUT-4 e AMPk foi evidente, sendo essas proteínas extremamente relevantes na captação de glicose (127-129). Nossos resultados em miócitos L6 confirmaram a hipótese de que o caos metabólico gerado por essa droga no metabolismo de carboidratos deve-se em parte a uma prejudicada captação de glicose.

Uma vez que os resultados no músculo EDL demonstram diminuição da ativação da AMPk, e essa proteína possui um importante papel na captação de glicose independente da sinalização da insulina e na regulação da expressão de GLUT-4 (74-78, 130), fomos investigar esse fenômeno mais a fundo. Para isso, miócitos foram tratados com o agonista da AMPk de forma crônica e aguda. O AICAR, também conhecido como ZMP, mimetiza os efeitos do aumento intracelular de AMP através da interação com a subunidade gama regulatória da AMPk, causando alteração conformacional e fosforilação da subunidade catalítica dessa proteína (131-132), no qual, em nossos resultados, a intervenção com AICAR recuperou a captação de glicose estimulada por insulina em miócitos L6 com 48 horas. Consistente com os resultados anteriores, Sakoda e colaboradores (133) demonstraram que a ativação de AMPk é essencial para o aumento da captação de glicose induzida por AICAR. Várias evidências apontam a inibição da atividade da AMPk por doxorubicina, assim como efeito protetor na toxicidade celular por sua ativação (83-84).

Ainda ao encontro com resultados da diminuição da fosforilação de AMPk encontrada em nosso modelo animal, uma importante proteína produzida primordialmente no tecido adiposo $(127,134-135)$, e que tem a sua concentração 
circulante correlacionada positivamente com a sensibilidade à insulina (127) é a adiponectina. O músculo esquelético apresenta a expressão dos receptores de adiponectina 1 e 2 (136-137), os quais não foram modulados no grupo DOX. Essa adipocina melhora a sensibilidade à insulina no músculo esquelético pelo aumento da oxidação de lipídios e ativação do fator de transcrição PPAR-a (138). Já ativação da AMPk por essa adipocina é decorrente de aumento do influxo de $\mathrm{Ca}^{++}$mediado pela interação da adiponectina globular no receptor ADIPOR1, e consequente ativação da quinase ativada por proteína quinase dependente de cálcio/calmodulina (CaMKKß), upstream da AMPk (139). No grupo DOX, a concentração dessa proteína no tecido adiposo e no soro foi diminuída, e pode explicar, pelo menos em parte, a diminuição da atividade da AMPk observada no músculo esquelético (136).

Diversas hipóteses estão associadas ao desenvolvimento de intolerância à glicose. Está bem estabelecido que a doxorubicina aumenta o estresse oxidativo e a disfunção mitocondrial (140-141) que são mecanismos importantes que podem levar à resistência à insulina, inclusive no músculo esquelético $(42,115)$. Aumenta a produção de espécies reativas de oxigênio (EROS) por interação com Fe III, pela perturbação da regulação da via do oxido nítrico (NO) e pelo ciclo redox da droga, no qual a reoxidação do radical da DOX-semiquinona em doxorubicina novamente favorece a formação de EROS (21-23). Além do mais, a estrutura do anel $\mathrm{B}$ da doxorubicina interage diretamente com o complexo 1 da cadeia de transporte de elétrons e serve como doador de elétrons para a geração de radical superóxido (42, 142-143). Por sua vez, o aumento da capacidade antioxidante mediado pelo exercício físico e por fatores nutricionais contribui para menor miotoxicidade (42, 144-145). Nossos resultados mostram-se congruentes com esses estudos, já que observamos alteração da atividade dos complexos mitocondriais no grupo DOX, levando assim a um gradiente de prótons que é favorável para a formação de espécies reativas de oxigênio(146-147).

Outro mecanismo que está associado a baixa sensibilidade à insulina é o acúmulo ectópico de lipídios no músculo esquelético (148-149). As ceramidas são lipídios bioativos que possuem importantes funções sobre a sinalização intracelular, sendo freqüentemente associadas ao quadro de resistência à insulina (150-152). Em tecidos periféricos e no próprio tumor já foi demonstrado aumento da concentração de ceramidas em função do tratamento com doxorrubicina (153-155). Em nosso 
modelo, não houve alteração do conteúdo total de triacilglicerol no músculo esquelético, sequer na expressão de genes envolvidos na oxidação de lipídios ou da atividade de enzimas do metabolismo oxidativo.

Outro fator bem conhecido que pode levar ao desencadeamento da diminuição da sensibilidade à insulina é o desenvolvimento da inflamação de baixo grau (156).O aumento de moléculas inflamatórias como TNF- $\alpha$, IL-6, óxido nítrico sintase induzível, fibrinogênio, proteína $C$ reativa (PCR), entre outras, além da infiltração de células do sistema imunológico no músculo esquelético estão associadas a resistência à insulina e maior incidência de diabetes tipo 2 (157-158). Sobretudo na obesidade, os estudos são sugestivos para uma resposta inflamatória desencadeada em condições de alta disponibilidade de ácidos graxos livres. Ácidos graxos de origem saturada são considerados pró-inflamatórios por interagirem com 0 receptor do tipo Toll-like Receptor 4 e indiretamente aumentar a produção e secreção de citocinas pró inflamatórias (159-160). Também no tratamento quimioterápico com doxorubicina há aumento sistêmico de citocinas inflamatórias (161). Em nosso modelo observamos uma alta disponibilidade de ácidos graxos livres circulantes, aumentada expressão gênica de TLR-4 no grupo DOX, com uma surpreendente e concomitante diminuição da expressão protéica das citocinas TNFa e IL-10. A inflamação no músculo esquelético tem sido apontada como um dos mecanismos pelo qual a doxorubicina gera disfunção músculo-esquelética (33). Quimioterápicos podem aumentar a produção e ativação de IL-1 $\beta$, via ativação do complexo do multiprotéico do inflamassoma (161-162). Entretanto no músculo EDL expressão gênica dessa via não foi alterada nos grupos tratados, assim como DirksNaylor e colaboradores (163) também não observaram alteração da caspase-1 nesse tecido com o quimioterápico. 


\section{CONCLUSÃO}

Em conclusão nossos resultados sugerem que a intolerância à glicose gerada pelo tratamento com doxorubicina se deve em parte a uma diminuída captação de glicose pelo músculo esquelético. A atividadeda da AMPk foi modulada de forma negativa com o quimioterápico no qual a utilização do agonista para essa proteína mostrou ser um possível alvo terapêutico capaz de recuperar a tolerância à glicose. Outros tratamentos farmacológicos e não farmacológicos que possuam como alvo essa proteína, deverão ser futuramente investigados, em associação ao tratamento com doxorubicina. 


\section{REFERÊNCIAS ${ }^{1}$}

1. Siegel RL, Miller KD, Jemal A. Cancer statistics, 2015. CA Cancer J Clin. 2015 JanFeb;65(1):5-29.

2. Ferlay J, Soerjomataram I, Dikshit R, Eser S, Mathers C, Rebelo M, et al. Cancer incidence and mortality worldwide: sources, methods and major patterns in GLOBOCAN 2012. Int J Cancer. 2015 Mar 1;136(5):E359-86.

3. INCA INDC-. Estimativa 2014 - Incidência de Câncer no Brasil 2014. Rio de Janeiro2013 [cited 2015 22/06]; Available from: http://www.inca.gov.br/estimativa/2014/estimativa-24012014.pdf.

4. Richardson DS, Johnson SA. Anthracyclines in haematology: preclinical studies, toxicity and delivery systems. Blood Rev. 1997 Dec;11(4):201-23.

5. Lai HC, Yeh YC, Ting CT, Lee WL, Lee HW, Wang LC, et al. Doxycycline suppresses doxorubicin-induced oxidative stress and cellular apoptosis in mouse hearts. Eur $\mathbf{J}$ Pharmacol. 2010 Oct 10;644(1-3):176-87.

6. Greene RF, Collins JM, Jenkins JF, Speyer JL, Myers CE. Plasma pharmacokinetics of adriamycin and adriamycinol: implications for the design of in vitro experiments and treatment protocols. Cancer Res. 1983 Jul;43(7):3417-21.

7. Lal S, Wong ZW, Jada SR, Xiang X, Chen Shu X, Ang PC, et al. Novel SLC22A16 polymorphisms and influence on doxorubicin pharmacokinetics in Asian breast cancer patients. Pharmacogenomics. 2007 Jun;8(6):567-75.

8. Singhal SS, Singhal J, Sharma R, Singh SV, Zimniak P, Awasthi YC, et al. Role of RLIP76 in lung cancer doxorubicin resistance: I. The ATPase activity of RLIP76 correlates with doxorubicin and 4-hydroxynonenal resistance in lung cancer cells. Int J Oncol. 2003 Feb;22(2):365-75.

9. Nagata J, Kijima H, Hatanaka H, Asai S, Miyachi H, Abe Y, et al. Reversal of drug resistance using hammerhead ribozymes against multidrug resistance-associated protein and multidrug resistance 1 gene. Int J Oncol. 2002 Nov;21(5):1021-6.

10. Yague E, Higgins CF, Raguz S. Complete reversal of multidrug resistance by stable expression of small interfering RNAs targeting MDR1. Gene Ther. 2004 Jul;11(14):1170-4.

11. Bellamy WT, Dalton WS, Kailey JM, Gleason MC, McCloskey TM, Dorr RT, et al. Verapamil reversal of doxorubicin resistance in multidrug-resistant human myeloma cells and association with drug accumulation and DNA damage. Cancer Res. 1988 Nov 15;48(22):6365-70.

\footnotetext{
${ }^{1}$ De acordo com: International Commitee of Medical Journal Editors. [Internet]. Uniform requirements for manuscripts submitted to biomedical journals.[2011 Jul 15]. Available from:

http://www.nlm.nih.gov/bsd/uniform_requirements.html
} 
12. Folmer Y, Schneider M, Blum HE, Hafkemeyer P. Reversal of drug resistance of hepatocellular carcinoma cells by adenoviral delivery of anti-ABCC2 antisense constructs. Cancer Gene Ther. 2007 Nov;14(11):875-84.

13. Dantzig AH, Law KL, Cao J, Starling JJ. Reversal of multidrug resistance by the Pglycoprotein modulator, LY335979, from the bench to the clinic. Curr Med Chem. 2001 Jan;8(1):39-50.

14. Cole SP, Sparks KE, Fraser K, Loe DW, Grant CE, Wilson GM, et al. Pharmacological characterization of multidrug resistant MRP-transfected human tumor cells. Cancer Res. 1994 Nov 15;54(22):5902-10.

15. Young LC, Campling BG, Cole SP, Deeley RG, Gerlach JH. Multidrug resistance proteins MRP3, MRP1, and MRP2 in lung cancer: correlation of protein levels with drug response and messenger RNA levels. Clin Cancer Res. 2001 Jun;7(6):1798-804.

16. Takanashi S, Bachur NR. Adriamycin metabolism in man. Evidence from urinary metabolites. Drug Metab Dispos. 1976 Jan-Feb;4(1):79-87.

17. Tewey KM, Rowe TC, Yang L, Halligan BD, Liu LF. Adriamycin-induced DNA damage mediated by mammalian DNA topoisomerase II. Science. 1984 Oct 26;226(4673):466-8.

18. Perego P, Corna E, De Cesare M, Gatti L, Polizzi D, Pratesi G, et al. Role of apoptosis and apoptosis-related genes in cellular response and antitumor efficacy of anthracyclines. Curr Med Chem. 2001 Jan;8(1):31-7.

19. Lal S, Mahajan A, Chen WN, Chowbay B. Pharmacogenetics of target genes across doxorubicin disposition pathway: a review. Curr Drug Metab. 2010 Jan;11(1):115-28.

20. Gigli M, Rasoanaivo TW, Millot JM, Jeannesson P, Rizzo V, Jardillier JC, et al. Correlation between growth inhibition and intranuclear doxorubicin and 4'-deoxy-4'iododoxorubicin quantitated in living K562 cells by microspectrofluorometry. Cancer Res. 1989 Feb 1;49(3):560-4.

21. Davies KJ, Doroshow JH. Redox cycling of anthracyclines by cardiac mitochondria. I. Anthracycline radical formation by NADH dehydrogenase. J Biol Chem. 1986 Mar $5 ; 261(7): 3060-7$.

22. Weinstein DM, Mihm MJ, Bauer JA. Cardiac peroxynitrite formation and left ventricular dysfunction following doxorubicin treatment in mice. J Pharmacol Exp Ther. 2000 Jul;294(1):396-401.

23. Deavall DG, Martin EA, Horner JM, Roberts R. Drug-induced oxidative stress and toxicity. J Toxicol. 2012 Aug;2012:645460.

24. Minotti G, Menna P, Salvatorelli E, Cairo G, Gianni L. Anthracyclines: molecular advances and pharmacologic developments in antitumor activity and cardiotoxicity. Pharmacol Rev. 2004 Jun;56(2):185-229. 
25. Fang J, Nakamura H, Iyer AK. Tumor-targeted induction of oxystress for cancer therapy. J Drug Target. 2007 Aug-Sep;15(7-8):475-86.

26. Thorn CF, Oshiro C, Marsh S, Hernandez-Boussard T, McLeod H, Klein TE, et al. Doxorubicin pathways: pharmacodynamics and adverse effects. Pharmacogenet Genomics. $2011 \mathrm{Jul} ; 21(7): 440-6$.

27. Shi Y, Moon M, Dawood S, McManus B, Liu PP. Mechanisms and management of doxorubicin cardiotoxicity. Herz. 2011 Jun;36(4):296-305.

28. Lopes MA, Meisel A, Dirnagl U, Carvalho FD, Bastos Mde L. Doxorubicin induces biphasic neurotoxicity to rat cortical neurons. Neurotoxicology. 2008 Mar;29(2):286-93.

29. Fahim MA, Kataya H, El-Kharrag R, Amer DA, al-Ramadi B, Karam SM. Ghrelin attenuates gastrointestinal epithelial damage induced by doxorubicin. World J Gastroenterol. 2011 Sep 7;17(33):3836-41.

30. Benjamin RS, Wiernik PH, Bachur NR. Adriamycin chemotherapy--efficacy, safety, and pharmacologic basis of an intermittent single high-dosage schedule. Cancer. 1974 Jan;33(1):19-27.

31. Neidhart JA, Gochnour D, Roach R, Hoth D, Young D. A comparison of mitoxantrone and doxorubicin in breast cancer. J Clin Oncol. 1986 May;4(5):672-7.

32. Stone P, Hardy J, Broadley K, Tookman AJ, Kurowska A, A'Hern R. Fatigue in advanced cancer: a prospective controlled cross-sectional study. Br J Cancer. 1999 Mar;79(910):1479-86.

33. Gilliam LA, Ferreira LF, Bruton JD, Moylan JS, Westerblad H, St Clair DK, et al. Doxorubicin acts through tumor necrosis factor receptor subtype 1 to cause dysfunction of murine skeletal muscle. J Appl Physiol (1985). 2009 Dec;107(6):1935-42.

34. Gilliam LA, Moylan JS, Callahan LA, Sumandea MP, Reid MB. Doxorubicin causes diaphragm weakness in murine models of cancer chemotherapy. Muscle Nerve. 2011 Jan;43(1):94-102.

35. Gorselink M, Vaessen SF, van der Flier LG, Leenders I, Kegler D, Caldenhoven E, et al. Mass-dependent decline of skeletal muscle function in cancer cachexia. Muscle Nerve. 2006 May;33(5):691-3.

36. van Norren K, van Helvoort A, Argiles JM, van Tuijl S, Arts K, Gorselink M, et al. Direct effects of doxorubicin on skeletal muscle contribute to fatigue. Br J Cancer. 2009 Jan 27;100(2):311-4.

37. De Beer EL, Finkle H, Voest EE, Van Heijst BG, Schiereck P. Doxorubicin interacts directly with skinned single skeletal muscle fibres. Eur J Pharmacol. 1992 Apr 7;214(1):97100. 
38. Hydock DS, Lien CY, Jensen BT, Schneider CM, Hayward R. Characterization of the effect of in vivo doxorubicin treatment on skeletal muscle function in the rat. Anticancer Res. 2011 Jun;31(6):2023-8.

39. Ertunc M, Sara Y, Korkusuz P, Onur R. Differential contractile impairment of fastand slow-twitch skeletal muscles in a rat model of doxorubicin-induced congestive heart failure. Pharmacology. 2009;84(4):240-8.

40. Sakkas GK, Kent-Braun JA, Doyle JW, Shubert T, Gordon P, Johansen KL. Effect of diabetes mellitus on muscle size and strength in patients receiving dialysis therapy. Am $\mathbf{J}$ Kidney Dis. 2006 May;47(5):862-9.

41. Prado CM, Lieffers JR, McCargar LJ, Reiman T, Sawyer MB, Martin L, et al. Prevalence and clinical implications of sarcopenic obesity in patients with solid tumours of the respiratory and gastrointestinal tracts: a population-based study. Lancet Oncol. 2008 Jul;9(7):629-35.

42. Smuder AJ, Kavazis AN, Min K, Powers SK. Exercise protects against doxorubicininduced oxidative stress and proteolysis in skeletal muscle. J Appl Physiol (1985). 2011 Apr;110(4):935-42.

43. Gilliam LA, Moylan JS, Patterson EW, Smith JD, Wilson AS, Rabbani Z, et al. Doxorubicin acts via mitochondrial ROS to stimulate catabolism in $\mathrm{C} 2 \mathrm{C} 12$ myotubes. Am $\mathrm{J}$ Physiol Cell Physiol. 2012 Jan 1;302(1):C195-202.

44. Kavazis AN, Smuder AJ, Powers SK. Effects of short-term endurance exercise training on acute doxorubicin-induced FoxO transcription in cardiac and skeletal muscle. $\mathbf{J}$ Appl Physiol (1985). 2014 Aug 1;117(3):223-30.

45. Thorens B, Mueckler M. Glucose transporters in the 21st Century. Am J Physiol Endocrinol Metab. 2010 Feb;298(2):E141-5.

46. Joost HG, Thorens B. The extended GLUT-family of sugar/polyol transport facilitators: nomenclature, sequence characteristics, and potential function of its novel members (review). Mol Membr Biol. 2001 Oct-Dec;18(4):247-56.

47. Olson AL, Pessin JE. Structure, function, and regulation of the mammalian facilitative glucose transporter gene family. Annu Rev Nutr. 1996;16:235-56.

48. Huang S, Czech MP. The GLUT4 glucose transporter. Cell Metab. 2007 Apr;5(4):237-52.

49. DeFronzo RA, Gunnarsson R, Bjorkman O, Olsson M, Wahren J. Effects of insulin on peripheral and splanchnic glucose metabolism in noninsulin-dependent (type II) diabetes mellitus. J Clin Invest. 1985 Jul;76(1):149-55.

50. Abdul-Ghani MA, DeFronzo RA. Pathogenesis of insulin resistance in skeletal muscle. J Biomed Biotechnol. 2010;2010:476279. 
51. Fu Z, Gilbert ER, Liu D. Regulation of insulin synthesis and secretion and pancreatic Beta-cell dysfunction in diabetes. Curr Diabetes Rev. 2013 Jan 1;9(1):25-53.

52. Saltiel AR, Kahn CR. Insulin signalling and the regulation of glucose and lipid metabolism. Nature. 2001 Dec 13;414(6865):799-806.

53. Patti ME, Kahn CR. The insulin receptor--a critical link in glucose homeostasis and insulin action. J Basic Clin Physiol Pharmacol. 1998;9(2-4):89-109.

54. Long YC, Cheng Z, Copps KD, White MF. Insulin receptor substrates Irs1 and Irs2 coordinate skeletal muscle growth and metabolism via the Akt and AMPK pathways. Mol Cell Biol. 2011 Feb;31(3):430-41.

55. Araki E, Lipes MA, Patti ME, Bruning JC, Haag B, 3rd, Johnson RS, et al. Alternative pathway of insulin signalling in mice with targeted disruption of the IRS-1 gene. Nature. 1994 Nov 10;372(6502):186-90.

56. Withers DJ, Gutierrez JS, Towery H, Burks DJ, Ren JM, Previs S, et al. Disruption of IRS-2 causes type 2 diabetes in mice. Nature. 1998 Feb 26;391(6670):900-4.

57. Backer JM, Myers MG, Jr., Shoelson SE, Chin DJ, Sun XJ, Miralpeix M, et al. Phosphatidylinositol 3'-kinase is activated by association with IRS-1 during insulin stimulation. EMBO J. 1992 Sep;11(9):3469-79.

58. Lietzke SE, Bose S, Cronin T, Klarlund J, Chawla A, Czech MP, et al. Structural basis of 3-phosphoinositide recognition by pleckstrin homology domains. Mol Cell. 2000 Aug;6(2):385-94.

59. Standaert ML, Galloway L, Karnam P, Bandyopadhyay G, Moscat J, Farese RV. Protein kinase C-zeta as a downstream effector of phosphatidylinositol 3-kinase during insulin stimulation in rat adipocytes. Potential role in glucose transport. J Biol Chem. 1997 Nov 28;272(48):30075-82.

60. Imamura T, Huang J, Usui I, Satoh H, Bever J, Olefsky JM. Insulin-induced GLUT4 translocation involves protein kinase C-lambda-mediated functional coupling between Rab4 and the motor protein kinesin. Mol Cell Biol. 2003 Jul;23(14):4892-900.

61. Miinea CP, Sano H, Kane S, Sano E, Fukuda M, Peranen J, et al. AS160, the Akt substrate regulating GLUT4 translocation, has a functional Rab GTPase-activating protein domain. Biochem J. 2005 Oct 1;391(Pt 1):87-93.

62. Pessin JE, Saltiel AR. Signaling pathways in insulin action: molecular targets of insulin resistance. J Clin Invest. 2000 Jul;106(2):165-9.

63. Baumann CA, Ribon V, Kanzaki M, Thurmond DC, Mora S, Shigematsu S, et al. CAP defines a second signalling pathway required for insulin-stimulated glucose transport. Nature. 2000 Sep 14;407(6801):202-7. 
64. Chiang SH, Baumann CA, Kanzaki M, Thurmond DC, Watson RT, Neudauer CL, et al. Insulin-stimulated GLUT4 translocation requires the CAP-dependent activation of TC10. Nature. 2001 Apr 19;410(6831):944-8.

65. Chang L, Chiang SH, Saltiel AR. Insulin signaling and the regulation of glucose transport. Mol Med. 2004 Jul-Dec;10(7-12):65-71.

66. Jiang ZY, Zhou QL, Coleman KA, Chouinard M, Boese Q, Czech MP. Insulin signaling through Akt/protein kinase B analyzed by small interfering RNA-mediated gene silencing. Proc Natl Acad Sci U S A. 2003 Jun 24;100(13):7569-74.

67. Richter EA, Hargreaves M. Exercise, GLUT4, and skeletal muscle glucose uptake. Physiol Rev. 2013 Jul;93(3):993-1017.

68. Pessin JE, Thurmond DC, Elmendorf JS, Coker KJ, Okada S. Molecular basis of insulin-stimulated GLUT4 vesicle trafficking. Location! Location! Location! J Biol Chem. 1999 Jan 29;274(5):2593-6.

69. Steinberg GR, Kemp BE. AMPK in Health and Disease. Physiol Rev. 2009 Jul;89(3):1025-78.

70. Oakhill JS, Steel R, Chen ZP, Scott JW, Ling N, Tam S, et al. AMPK is a direct adenylate charge-regulated protein kinase. Science. 2011 Jun 17;332(6036):1433-5.

71. Jorgensen SB, Nielsen JN, Birk JB, Olsen GS, Viollet B, Andreelli F, et al. The alpha2-5'AMP-activated protein kinase is a site 2 glycogen synthase kinase in skeletal muscle and is responsive to glucose loading. Diabetes. 2004 Dec;53(12):3074-81.

72. Carling D, Hardie DG. The substrate and sequence specificity of the AMP-activated protein kinase. Phosphorylation of glycogen synthase and phosphorylase kinase. Biochim Biophys Acta. 1989 Jun 15;1012(1):81-6.

73. Sakamoto K, Holman GD. Emerging role for AS160/TBC1D4 and TBC1D1 in the regulation of GLUT4 traffic. Am J Physiol Endocrinol Metab. 2008 Jul;295(1):E29-37.

74. Chen S, Murphy J, Toth R, Campbell DG, Morrice NA, Mackintosh C. Complementary regulation of TBC1D1 and AS160 by growth factors, insulin and AMPK activators. Biochem J. 2008 Jan 15;409(2):449-59.

75. Treebak JT, Glund S, Deshmukh A, Klein DK, Long YC, Jensen TE, et al. AMPKmediated AS160 phosphorylation in skeletal muscle is dependent on AMPK catalytic and regulatory subunits. Diabetes. 2006 Jul;55(7):2051-8.

76. Pehmoller C, Treebak JT, Birk JB, Chen S, Mackintosh C, Hardie DG, et al. Genetic disruption of AMPK signaling abolishes both contraction- and insulin-stimulated TBC1D1 phosphorylation and 14-3-3 binding in mouse skeletal muscle. Am J Physiol Endocrinol Metab. 2009 Sep;297(3):E665-75. 
77. Holmes BF, Sparling DP, Olson AL, Winder WW, Dohm GL. Regulation of muscle GLUT4 enhancer factor and myocyte enhancer factor 2 by AMP-activated protein kinase. Am J Physiol Endocrinol Metab. 2005 Dec;289(6):E1071-6.

78. Zheng D, MacLean PS, Pohnert SC, Knight JB, Olson AL, Winder WW, et al. Regulation of muscle GLUT-4 transcription by AMP-activated protein kinase. J Appl Physiol (1985). 2001 Sep;91(3):1073-83.

79. Fujii N, Aschenbach WG, Musi N, Hirshman MF, Goodyear LJ. Regulation of glucose transport by the AMP-activated protein kinase. Proc Nutr Soc. 2004 May;63(2):205-10.

80. Ojuka EO. Role of calcium and AMP kinase in the regulation of mitochondrial biogenesis and GLUT4 levels in muscle. Proc Nutr Soc. 2004 May;63(2):275-8.

81. McGarry JD, Brown NF. The mitochondrial carnitine palmitoyltransferase system. From concept to molecular analysis. Eur J Biochem. 1997 Feb 15;244(1):1-14.

82. Merrill GF, Kurth EJ, Hardie DG, Winder WW. AICA riboside increases AMPactivated protein kinase, fatty acid oxidation, and glucose uptake in rat muscle. Am J Physiol. 1997 Dec;273(6 Pt 1):E1107-12.

83. Wang S, Song $\mathrm{P}$, Zou $\mathrm{MH}$. Inhibition of AMP-activated protein kinase alpha (AMPKalpha) by doxorubicin accentuates genotoxic stress and cell death in mouse embryonic fibroblasts and cardiomyocytes: role of p53 and SIRT1. J Biol Chem. 2012 Mar 9;287(11):8001-12.

84. Tokarska-Schlattner M, Zaugg M, da Silva R, Lucchinetti E, Schaub MC, Wallimann $\mathrm{T}$, et al. Acute toxicity of doxorubicin on isolated perfused heart: response of kinases regulating energy supply. Am J Physiol Heart Circ Physiol. 2005 Jul;289(1):H37-47.

85. Gratia S, Kay L, Potenza L, Seffouh A, Novel-Chate V, Schnebelen C, et al. Inhibition of AMPK signalling by doxorubicin: at the crossroads of the cardiac responses to energetic, oxidative, and genotoxic stress. Cardiovasc Res. 2012 Aug 1;95(3):290-9.

86. Konishi M, Haraguchi G, Ohigashi H, Ishihara T, Saito K, Nakano Y, et al. Adiponectin protects against doxorubicin-induced cardiomyopathy by anti-apoptotic effects through AMPK up-regulation. Cardiovasc Res. 2011 Feb 1;89(2):309-19.

87. Cai C, Lothstein L, Morrison RR, Hofmann PA. Protection from doxorubicin-induced cardiomyopathy using the modified anthracycline N-benzyladriamycin-14-valerate (AD 198). J Pharmacol Exp Ther. 2010 Oct;335(1):223-30.

88. Ji C, Yang B, Yang YL, He SH, Miao DS, He L, et al. Exogenous cell-permeable C6 ceramide sensitizes multiple cancer cell lines to Doxorubicin-induced apoptosis by promoting AMPK activation and mTORC1 inhibition. Oncogene. 2010 Dec 16;29(50):6557-68.

89. Tayek JA. A review of cancer cachexia and abnormal glucose metabolism in humans with cancer. J Am Coll Nutr. 1992 Aug;11(4):445-56. 
90. Lundholm K, Holm G, Schersten T. Insulin resistance in patients with cancer. Cancer Res. 1978 Dec;38(12):4665-70.

91. Feng JP, Yuan XL, Li M, Fang J, Xie T, Zhou Y, et al. Secondary diabetes associated with 5-fluorouracil-based chemotherapy regimens in non-diabetic patients with colorectal cancer: results from a single-centre cohort study. Colorectal Dis. 2013 Jan;15(1):27-33.

92. Chala E, Manes C, Iliades H, Skaragkas G, Mouratidou D, Kapantais E. Insulin resistance, growth factors and cytokine levels in overweight women with breast cancer before and after chemotherapy. Hormones (Athens). 2006 Apr-Jun;5(2):137-46.

93. Cairns RA, Harris IS, Mak TW. Regulation of cancer cell metabolism. Nat Rev Cancer. 2011 Feb;11(2):85-95.

94. McBrayer SK, Cheng JC, Singhal S, Krett NL, Rosen ST, Shanmugam M. Multiple myeloma exhibits novel dependence on GLUT4, GLUT8, and GLUT11: implications for glucose transporter-directed therapy. Blood. 2012 May 17;119(20):4686-97.

95. Zhao W, Chen R, Zhao M, Li L, Fan L, Che XM. High glucose promotes gastric cancer chemoresistance in vivo and in vitro. Mol Med Rep. 2015 Jul;12(1):843-50.

96. Feng YH, Velazquez-Torres G, Gully C, Chen J, Lee MH, Yeung SC. The impact of type 2 diabetes and antidiabetic drugs on cancer cell growth. J Cell Mol Med. 2011 Apr;15(4):825-36.

97. Pagano G, Cavallo-Perin P, Cassader M, Bruno A, Ozzello A, Masciola P, et al. An in vivo and in vitro study of the mechanism of prednisone-induced insulin resistance in healthy subjects. J Clin Invest. 1983 Nov;72(5):1814-20.

98. Hruz PW. HIV protease inhibitors and insulin resistance: lessons from in-vitro, rodent and healthy human volunteer models. Curr Opin HIV AIDS. 2008 Nov;3(6):660-5.

99. Jacob S, Rett K, Wicklmayr M, Agrawal B, Augustin HJ, Dietze GJ. Differential effect of chronic treatment with two beta-blocking agents on insulin sensitivity: the carvedilol-metoprolol study. J Hypertens. 1996 Apr;14(4):489-94.

100. Bonora E, Manicardi V, Zavaroni I, Coscelli C, Butturini U. Relationships between insulin secretion, insulin metabolism and insulin resistance in mild glucose intolerance. Diabete Metab. 1987 Apr;13(2):116-21.

101. Bradford MM. A rapid and sensitive method for the quantitation of microgram quantities of protein utilizing the principle of protein-dye binding. Anal Biochem. 1976 May 7;72:248-54.

102. Towbin H, Staehelin T, Gordon J. Electrophoretic transfer of proteins from polyacrylamide gels to nitrocellulose sheets: procedure and some applications. Proc Natl Acad Sci U S A. 1979 Sep;76(9):4350-4.

103. Laemmli UK. Cleavage of structural proteins during the assembly of the head of bacteriophage T4. Nature. 1970 Aug 15;227(5259):680-5. 
104. Shapiro AL, Vinuela E, Maizel JV, Jr. Molecular weight estimation of polypeptide chains by electrophoresis in SDS-polyacrylamide gels. Biochem Biophys Res Commun. 1967 Sep 7;28(5):815-20.

105. Chomczynski P, Sacchi N. Single-step method of RNA isolation by acid guanidinium thiocyanate-phenol-chloroform extraction. Anal Biochem. 1987 Apr;162(1):156-9.

106. Higuchi R, Dollinger G, Walsh PS, Griffith R. Simultaneous amplification and detection of specific DNA sequences. Biotechnology (N Y). 1992 Apr;10(4):413-7.

107. Livak KJ, Schmittgen TD. Analysis of relative gene expression data using real-time quantitative PCR and the 2(-Delta Delta C(T)) Method. Methods. 2001 Dec;25(4):402-8.

108. Souza CO, Teixeira AA, Lima EA, Batatinha HA, Gomes LM, Carvalho-Silva M, et al. Palmitoleic acid (n-7) attenuates the immunometabolic disturbances caused by a high-fat diet independently of PPARalpha. Mediators Inflamm. 2014 Aug;2014:582197.

109. Folch J, Lees M, Sloane Stanley GH. A simple method for the isolation and purification of total lipides from animal tissues. J Biol Chem. 1957 May;226(1):497-509.

110. Swamy AV, Gulliaya S, Thippeswamy A, Koti BC, Manjula DV. Cardioprotective effect of curcumin against doxorubicin-induced myocardial toxicity in albino rats. Indian $\mathbf{J}$ Pharmacol. 2012 Jan;44(1):73-7.

111. Roomi MW, Kalinovsky T, Roomi NW, Rath M, Niedzwiecki A. Prevention of Adriamycin-induced hepatic and renal toxicity in male BALB/c mice by a nutrient mixture. Exp Ther Med. 2014 Apr;7(4):1040-4.

112. Hajjaji N, Couet C, Besson P, Bougnoux P. DHA effect on chemotherapy-induced body weight loss: an exploratory study in a rodent model of mammary tumors. Nutr Cancer. 2012;64(7):1000-7.

113. Mostafa MG, Mima T, Ohnishi ST, Mori K. S-allylcysteine ameliorates doxorubicin toxicity in the heart and liver in mice. Planta Med. 2000 Mar;66(2):148-51.

114. Hesketh PJ. Chemotherapy-induced nausea and vomiting. N Engl J Med. 2008 Jun $5 ; 358(23): 2482-94$.

115. Gilliam LA, St Clair DK. Chemotherapy-induced weakness and fatigue in skeletal muscle: the role of oxidative stress. Antioxid Redox Signal. 2011 Nov 1;15(9):2543-63.

116. Turedi S, Yulug E, Alver A, Kutlu O, Kahraman C. Effects of resveratrol on doxorubicin induced testicular damage in rats. Exp Toxicol Pathol. 2015 Mar;67(3):229-35.

117. Prahalathan C, Selvakumar E, Varalakshmi P. Lipoic acid ameliorates adriamycininduced testicular mitochondriopathy. Reprod Toxicol. 2005 May-Jun;20(1):111-6. 
118. Braun TP, Szumowski M, Levasseur PR, Grossberg AJ, Zhu X, Agarwal A, et al. Muscle atrophy in response to cytotoxic chemotherapy is dependent on intact glucocorticoid signaling in skeletal muscle. PLoS One. 2014;9(9):e106489.

119. Gomes MD, Lecker SH, Jagoe RT, Navon A, Goldberg AL. Atrogin-1, a musclespecific F-box protein highly expressed during muscle atrophy. Proc Natl Acad Sci U S A. 2001 Dec 4;98(25):14440-5.

120. Miyamoto Y, Baba Y, Sakamoto Y, Ohuchi M, Tokunaga R, Kurashige J, et al. Negative Impact of Skeletal Muscle Loss after Systemic Chemotherapy in Patients with Unresectable Colorectal Cancer. PLoS One. 2015;10(6):e0129742.

121. Barret M, Antoun S, Dalban C, Malka D, Mansourbakht T, Zaanan A, et al. Sarcopenia is linked to treatment toxicity in patients with metastatic colorectal cancer. Nutr Cancer. 2014;66(4):583-9.

122. Dimitriadis G, Mitrou P, Lambadiari V, Maratou E, Raptis SA. Insulin effects in muscle and adipose tissue. Diabetes Res Clin Pract. 2011 Aug;93 Suppl 1:S52-9.

123. Arunachalam S, Tirupathi Pichiah PB, Achiraman S. Doxorubicin treatment inhibits PPARgamma and may induce lipotoxicity by mimicking a type 2 diabetes-like condition in rodent models. FEBS Lett. 2013 Jan 16;587(2):105-10.

124. Wang Q, Somwar R, Bilan PJ, Liu Z, Jin J, Woodgett JR, et al. Protein kinase B/Akt participates in GLUT4 translocation by insulin in L6 myoblasts. Mol Cell Biol. 1999 Jun;19(6):4008-18.

125. Cushman SW, Wardzala LJ. Potential mechanism of insulin action on glucose transport in the isolated rat adipose cell. Apparent translocation of intracellular transport systems to the plasma membrane. J Biol Chem. 1980 May 25;255(10):4758-62.

126. Wardzala LJ, Jeanrenaud B. Potential mechanism of insulin action on glucose transport in the isolated rat diaphragm. Apparent translocation of intracellular transport units to the plasma membrane. J Biol Chem. 1981 Jul 25;256(14):7090-3.

127. Yamauchi T, Kamon J, Waki H, Terauchi Y, Kubota N, Hara K, et al. The fat-derived hormone adiponectin reverses insulin resistance associated with both lipoatrophy and obesity. Nat Med. 2001 Aug;7(8):941-6.

128. Zisman A, Peroni OD, Abel ED, Michael MD, Mauvais-Jarvis F, Lowell BB, et al. Targeted disruption of the glucose transporter 4 selectively in muscle causes insulin resistance and glucose intolerance. Nat Med. 2000 Aug;6(8):924-8.

129. Mu J, Brozinick JT, Jr., Valladares O, Bucan M, Birnbaum MJ. A role for AMPactivated protein kinase in contraction- and hypoxia-regulated glucose transport in skeletal muscle. Mol Cell. 2001 May;7(5):1085-94.

130. Bruss MD, Arias EB, Lienhard GE, Cartee GD. Increased phosphorylation of Akt substrate of $160 \mathrm{kDa}$ (AS160) in rat skeletal muscle in response to insulin or contractile activity. Diabetes. 2005 Jan;54(1):41-50. 
131. Daignan-Fornier B, Pinson B. 5-Aminoimidazole-4-carboxamide-1-beta-Dribofuranosyl 5'-Monophosphate (AICAR), a Highly Conserved Purine Intermediate with Multiple Effects. Metabolites. 2012;2(2):292-302.

132. Sabina RL, Patterson D, Holmes EW. 5-Amino-4-imidazolecarboxamide riboside (Zriboside) metabolism in eukaryotic cells. J Biol Chem. 1985 May 25;260(10):6107-14.

133. Sakoda H, Ogihara T, Anai M, Fujishiro M, Ono H, Onishi Y, et al. Activation of AMPK is essential for AICAR-induced glucose uptake by skeletal muscle but not adipocytes. Am J Physiol Endocrinol Metab. 2002 Jun;282(6):E1239-44.

134. Scherer PE, Williams S, Fogliano M, Baldini G, Lodish HF. A novel serum protein similar to C1q, produced exclusively in adipocytes. J Biol Chem. 1995 Nov 10;270(45):26746-9.

135. Maeda K, Okubo K, Shimomura I, Funahashi T, Matsuzawa Y, Matsubara K. cDNA cloning and expression of a novel adipose specific collagen-like factor, apM1 (AdiPose Most abundant Gene transcript 1). Biochem Biophys Res Commun. 1996 Apr 16;221(2):286-9.

136. Yamauchi T, Kamon J, Ito Y, Tsuchida A, Yokomizo T, Kita S, et al. Cloning of adiponectin receptors that mediate antidiabetic metabolic effects. Nature. 2003 Jun $12 ; 423(6941): 762-9$.

137. Civitarese AE, Jenkinson CP, Richardson D, Bajaj M, Cusi K, Kashyap S, et al. Adiponectin receptors gene expression and insulin sensitivity in non-diabetic Mexican Americans with or without a family history of Type 2 diabetes. Diabetologia. 2004 May;47(5):816-20.

138. Yoon MJ, Lee GY, Chung JJ, Ahn YH, Hong SH, Kim JB. Adiponectin increases fatty acid oxidation in skeletal muscle cells by sequential activation of AMP-activated protein kinase, p38 mitogen-activated protein kinase, and peroxisome proliferator-activated receptor alpha. Diabetes. 2006 Sep;55(9):2562-70.

139. Iwabu M, Yamauchi T, Okada-Iwabu M, Sato K, Nakagawa T, Funata M, et al. Adiponectin and AdipoR1 regulate PGC-1alpha and mitochondria by $\mathrm{Ca}(2+)$ and AMPK/SIRT1. Nature. 2010 Apr 29;464(7293):1313-9.

140. Zhou S, Palmeira CM, Wallace KB. Doxorubicin-induced persistent oxidative stress to cardiac myocytes. Toxicol Lett. 2001 May 19;121(3):151-7.

141. Childs AC, Phaneuf SL, Dirks AJ, Phillips T, Leeuwenburgh C. Doxorubicin treatment in vivo causes cytochrome $\mathrm{C}$ release and cardiomyocyte apoptosis, as well as increased mitochondrial efficiency, superoxide dismutase activity, and Bcl-2:Bax ratio. Cancer Res. 2002 Aug 15;62(16):4592-8.

142. Cadenas E, Davies KJ. Mitochondrial free radical generation, oxidative stress, and aging. Free Radic Biol Med. 2000 Aug;29(3-4):222-30. 
143. Mukhopadhyay P, Rajesh M, Yoshihiro K, Hasko G, Pacher P. Simple quantitative detection of mitochondrial superoxide production in live cells. Biochem Biophys Res Commun. 2007 Jun 22;358(1):203-8.

144. Quiles JL, Huertas JR, Battino M, Mataix J, Ramirez-Tortosa MC. Antioxidant nutrients and adriamycin toxicity. Toxicology. 2002 Oct 30;180(1):79-95.

145. Danz ED, Skramsted J, Henry N, Bennett JA, Keller RS. Resveratrol prevents doxorubicin cardiotoxicity through mitochondrial stabilization and the Sirt1 pathway. Free Radic Biol Med. 2009 Jun 15;46(12):1589-97.

146. $\mathrm{Xu} \mathrm{X,} \mathrm{Persson} \mathrm{HL,} \mathrm{Richardson} \mathrm{DR.} \mathrm{Molecular} \mathrm{pharmacology} \mathrm{of} \mathrm{the} \mathrm{interaction} \mathrm{of}$ anthracyclines with iron. Mol Pharmacol. 2005 Aug;68(2):261-71.

147. Chen Q, Vazquez EJ, Moghaddas S, Hoppel CL, Lesnefsky EJ. Production of reactive oxygen species by mitochondria: central role of complex III. J Biol Chem. 2003 Sep 19;278(38):36027-31.

148. Pan DA, Lillioja S, Kriketos AD, Milner MR, Baur LA, Bogardus C, et al. Skeletal muscle triglyceride levels are inversely related to insulin action. Diabetes. 1997 Jun;46(6):983-8.

149. Jacob S, Machann J, Rett K, Brechtel K, Volk A, Renn W, et al. Association of increased intramyocellular lipid content with insulin resistance in lean nondiabetic offspring of type 2 diabetic subjects. Diabetes. 1999 May;48(5):1113-9.

150. Chavez JA, Knotts TA, Wang LP, Li G, Dobrowsky RT, Florant GL, et al. A role for ceramide, but not diacylglycerol, in the antagonism of insulin signal transduction by saturated fatty acids. J Biol Chem. 2003 Mar 21;278(12):10297-303.

151. Hajduch E, Balendran A, Batty IH, Litherland GJ, Blair AS, Downes CP, et al. Ceramide impairs the insulin-dependent membrane recruitment of protein kinase $\mathrm{B}$ leading to a loss in downstream signalling in L6 skeletal muscle cells. Diabetologia. 2001 Feb;44(2):173-83.

152. Summers SA, Garza LA, Zhou H, Birnbaum MJ. Regulation of insulin-stimulated glucose transporter GLUT4 translocation and Akt kinase activity by ceramide. Mol Cell Biol. 1998 Sep;18(9):5457-64.

153. Martinez R, Navarro R, Lacort M, Ruiz-Sanz JI, Ruiz-Larrea MB. Doxorubicin induces ceramide and diacylglycerol accumulation in rat hepatocytes through independent routes. Toxicol Lett. 2009 Oct 8;190(1):86-90.

154. Delpy E, Hatem SN, Andrieu N, de Vaumas C, Henaff M, Rucker-Martin C, et al. Doxorubicin induces slow ceramide accumulation and late apoptosis in cultured adult rat ventricular myocytes. Cardiovasc Res. 1999 Aug 1;43(2):398-407.

155. Lucci A, Han TY, Liu YY, Giuliano AE, Cabot MC. Modification of ceramide metabolism increases cancer cell sensitivity to cytotoxics. Int J Oncol. 1999 Sep;15(3):541-6. 
156. Wei Y, Chen K, Whaley-Connell AT, Stump CS, Ibdah JA, Sowers JR. Skeletal muscle insulin resistance: role of inflammatory cytokines and reactive oxygen species. Am $\mathbf{J}$ Physiol Regul Integr Comp Physiol. 2008 Mar;294(3):R673-80.

157. Perreault M, Marette A. Targeted disruption of inducible nitric oxide synthase protects against obesity-linked insulin resistance in muscle. Nat Med. 2001 Oct;7(10):1138-43.

158. Wellen KE, Hotamisligil GS. Inflammation, stress, and diabetes. J Clin Invest. 2005 May;115(5):1111-9.

159. Huang S, Rutkowsky JM, Snodgrass RG, Ono-Moore KD, Schneider DA, Newman JW, et al. Saturated fatty acids activate TLR-mediated proinflammatory signaling pathways. J Lipid Res. 2012 Sep;53(9):2002-13.

160. Pal D, Dasgupta S, Kundu R, Maitra S, Das G, Mukhopadhyay S, et al. Fetuin-A acts as an endogenous ligand of TLR4 to promote lipid-induced insulin resistance. Nat Med. 2012 Aug;18(8):1279-85.

161. Sauter KA, Wood LJ, Wong J, Iordanov M, Magun BE. Doxorubicin and daunorubicin induce processing and release of interleukin-1beta through activation of the NLRP3 inflammasome. Cancer Biol Ther. 2011 Jun 15;11(12):1008-16.

162. Bruchard M, Mignot G, Derangere V, Chalmin F, Chevriaux A, Vegran F, et al. Chemotherapy-triggered cathepsin B release in myeloid-derived suppressor cells activates the Nlrp3 inflammasome and promotes tumor growth. Nat Med. 2013 Jan;19(1):57-64.

163. Dirks-Naylor AJ, Tran NT, Yang S, Mabolo R, Kouzi SA. The effects of acute doxorubicin treatment on proteome lysine acetylation status and apical caspases in skeletal muscle of fasted animals. J Cachexia Sarcopenia Muscle. 2013 Sep;4(3):239-43. 